U.S. Department

of Energy

Office of Civilian

Radioactive Waste

Management

and

Electric Power

Research Institute
Topics:

Spent-fuel storage

Radioactive waste management

Heat transfer

Radiation shielding
EPRI NP-6941

Project 2566-1

PNL-7327

UC-812

Final Report

September 1990

\title{
NUHOMS Modular Spent-Fuel Storage System: Performance Testing
}

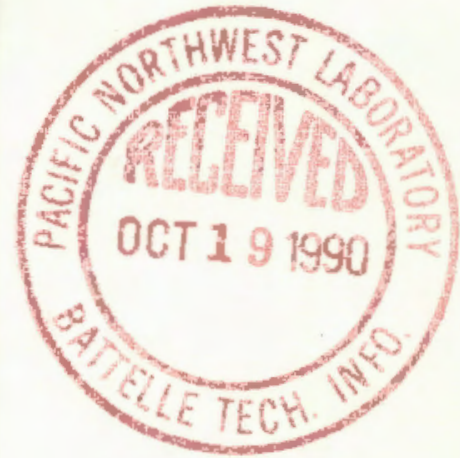

Prepared by

Pacific Northwest Laboratory

Richland, Washington

and

Carolina Power and Light Company

Raleigh, North Carolina 



R E P O R T S U M M A R Y

SUBJECTS Light water reactor fuel / Radioactive waste management

TOPICS Spent-fuel storage Heat transfer

Radioactive waste management Radiation shielding

AUDIENCE Fuels engineers / R\&D scientists

\title{
NUHOMS Modular Spent-Fuel Storage System: Performance Testing
}

\begin{abstract}
A concrete horizontal modular system for spent-fuel storage was constructed and demonstrated at Carolina Power and Light's (CP\&L) Robinson station. This report documents the success of both cold and hot performance testing of the modules.
\end{abstract}

BACKGROUND The Nuclear Waste Policy Act (NWPA) of 1982 reaffirms that U.S. utilities are responsible for the interim storage of their spent nuclear fuel until DOE begins accepting it for disposal. The act also directs DOE to work with the private sector in demonstrating viable new storage technologies that expand interim storage options. CP\&L subsequently entered into a cooperative agreement with DOE and EPRI in 1983 to demonstrate dry storage of spent fuel in the NUTECH horizontal modular storage system (NUHOMS) at the H. B. Robinson plant near Hartsville, South Carolina. This report evaluates the system's thermal performance during cold heater tests, as well as its thermal and shielding performance when loaded with spent fuel.

OBJECTIVES To demonstrate and document the thermal performance of the NUHOMS system under normal and simulated off-normal conditions while validating the heat transfer and shielding design analyses.

APPROACH Before loading the modules with spent fuel, researchers conducted a series of cold electric heater tests to simulate the decay heat of spent-fuel assemblies. To model off-normal conditions, they blocked the air inlets and outlets. Researchers then repeated the tests after loading spent fuel into the storage modules and determined shielding performance by measuring radioactive dose rates around the modules.

RESULTS The results of this project demonstrated the conservative design of the NUHOMS systems used at the H. B. Robinson site. Measurement of fuel temperatures, for example, indicated that fuel was maintained well below peak NRC limits. With the spent fuel in place, the peak measured concrete temperatures were below the maximum design temperatures recommended by the American Concrete Institute. Evaluation of data indicated that thermal performance of the system was only mildly sensitive to blockage of the module's air inlets or outlets. Similarly, evaluation of radiologic data around 
the loaded horizontal module showed very low gamma and neutron readings, which were well within design limits.

EPRI PERSPECTIVE This report complements report NP-6940, which documents the design, licensing, and construction of the test NUHOMS modules. With the completion of this project, utilities now have an additional spent-fuel storage option available to them to meet their growing needs in this area. On the basis of the demonstration program-which documents technical performance, NRC licensability, and system economicsutilities can now more confidently plan their spent-fuel storage strategies.

\section{PROJECT RP2566-1}

EPRI Project Manager: Ray W. Lambert

Nuclear Power Division

Contractor: Carolina Power and Light Company

For further information on EPRI research programs, call EPRI Technical Information Specialists (415) 855-2411. 


\title{
NUHOMS Modular Spent-Fuel Storage System: \\ Performance Testing
}

\author{
NP-6941 \\ Research Project 2566-1 \\ PNL-7327 \\ UC-812
}

Final Report, September 1990

Prepared by

PACIFIC NORTHWEST LABORATORY

Battelle Boulevard

Richland, Washington 99352

Prinçipal Investigators

L. A. Strope

M. A. McKinnon

CAROLINA POWER AND LIGHT COMPANY

411 Fayetteville Street

Raleigh, North Carolina 27602

Principal Investigators

D. J. Dyksterhouse

J. C. McLean

Prepared for

Carolina Power and Light Company

U.S. Department of Energy

and

Electric Power Research Institute

3412 Hillview Avenue

Palo Alto, California 94304

EPRI Project Manager

R. W. Lambert

High Level Waste Program

Nuclear Power Division 


\section{ORDERING INFORMATION}

Requests for copies of this report should be directed to Research Reports Center (FRC), Box 50490, Palo Alto, CA 94303, (415) 965-4081. There is no charge for reports requested by EPRI member utilities and affiliates, U.S. utility associations, U.S. government agencies (federal, state, and local), media, and foreign organizations with which EPRI has an information exchange agreement. On request, ARC will send a catalog of EPRI reports.

\section{DISCLAIMER}

This report was prepared as an account of work sponsored by the United States Government. Neither the United States nor the United States Department of Energy, nor any of their employees, makes any warranty, express or implied, or assumes ary legal liability or responsibility for the accuracy, completeness, or usefulness of any information, apparatus, product, or process disclosed, or represents that its use would not infringe privately owned rights. Reference herein to any specific commercial product, process, or service by trade name, mark, manufacturer, or otherwise, does not necessarily constitute or imply its endorsement, recommendation, or favoring by the United States Government or any agency thereof. The views and opinions of authors expressed herein do not necessarily state or reflect those of the United States Government or any agency thereof.

\section{NOTICE}

This report was prepared by Pacific Northwest Laboratory as an account of work sponsored by Carolina Power and Light (CP\&L), the U.S. Department of Energy (DOE), and the Electric Power Research Institute, Inc. (EPAI). Neither CP\&L, DOE, EPRI, their employees or members of EPRI, nor any person acting on their behalf: (a) makes any warranty, express or implied, with respect to the use of any information, apparatus, method, or process disclosed in this report or that such use may not infringe privately owned rights; or (b) assumes any liabilities with respect to the use of, or for damages resulting from the use of, any information, apparatus, method, or process disclosed in this report. 


\section{ABSTRACT}

This report documents the results of a heat transfer and shielding performance

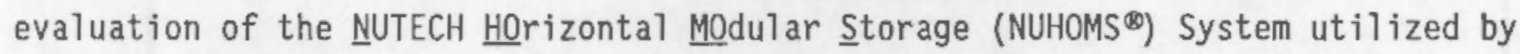
the Carolina Power and Light Co. (CP\&L) in an Independent Spent Fuel Storage Installation (ISFSI) licensed by the U. S. Nuclear Regulatory Commission (NRC). The ISFSI is located at CP\&L's H. B. Robinson Nuclear Plant (HBR) near Hartsville, South Carolina.

The demonstration included testing of three modules, first with electric heaters and then with spent fuel. The results indicated that the system was conservatively designed, with a11 heat transfer and shielding design criteria easily met.

NUHOMS is a registered trademark of NUTECH, Inc., San Jose, California. 



\section{ACKNOWLEDGMENTS}

The success of a complex cooperative program is heavily dependent on the contribution of many organizations and individuals. Appreciation is expressed to the following organizations and individuals for their support, contributions, and cooperation.

\section{Orqanizations}

Carolina Power \& Light Co.

Electric Power Research Institute NUTECH Engineers, Inc. Pacific Northwest Laboratory

U.S. Department of Energy

CP\&L

D. Alleman

D. M. Koss

J. Kozyra

L. H. Martin

J. C. McLean

D. J. Dyksterhouse

\section{DOE Headquarters}

C. R. Head

D. E. Shelor

\section{Technical Management Committee}

M. F. Thompson, Jr. (CP\&L)

R. K. Kunita (CP\&L)

C. E. Collantes (DOE-RL)

R. W. Lambert (EPRI)
PNL

G. H. Beeman

J. M. Creer

NUTECH/PNFS

J. R. Bondre

R. A. Lehnert

J. M. Rosa

B. D. Thomas

DOE-Richland Operations office

EPRI

G. J. Bracken

R. F. Williams

J. P. Collins

J. L. Daily

D. E. Trader 


\section{CONTENTS}

Section

$\underline{\text { Page }}$

1 INTRODUCTION 1-1

2 CONCLUSIONS AND RECDMMENDATIONS 2-1

Conclusions $2-1$

DSC/Cask Handling and Loading 2-1

Heat Transfer Performance 2-1

Shielding Performance 2-2

Recommendations 2-3

DSC/Cask Handling and Loading 2-3

Heat Transfer Performance 2-3

Shielding Performance 2-3

3 NUHDMS PERFDRMANCE TESTING/DEMONSTRATION 3-1

Horizontal Storage Module and Associated Instrumentation 3-4

Dry Shielded Canister and Associated Instrumentation 3-9

On-site Transfer Cask 3-11

H. B. Robinson Spent Fuel 3-14

Data Acquisition System $\quad 3-17$

Data Uncertainty Estimates $\quad 3-20$

Electric Heaters and Power Controller $3-20$

DSC and HSM Thermocouples $3-20$

Air Flow Transducers $3-21$

Data Acquisition System $\quad 3-22$

Radiological Instruments 3-22

Test Plan $3-22$

Operational Experience with the NUHOMS System 3-23

Facilities and Equipment $3-23$

Documentation Development $\quad 3-27$

Operational Training 3-28

Dry Shielded Canister Receipt and Preparation 3-29

Cask Receipts and Preparation 3-30 
Operational Dry Runs

Load Tests

3-32

Air Evacuation Test

$3-32$

Cask/DSC Performance Test

3-33

Annulus Seal Test

3-34

Dry Runs

3-35

Weld Mockups and Weld Improvement Program

3-35

Dry Shielded Canister Coatings

3-37

Spent Fuel Selection and Inspection

3-37

Dry Shielded Canister Seal Welding

3-37

Vacuum Drying

3-38

Helium Inerting and Leak Testing

3-39

Trailer Loading

$3-39$

Transport to Modules

3-41

Trailer/Skid Alignment

3-42

Loading with Hydraulic Ram and HSM Closure

3-43

Contamination Control

3-49

HSM Contact Doses

3-49

Environmental Monitoring and Results

3-49

Long-Term Surveillance/Five-Year Inspection

3-49

4 HEAT TRANSFER AND SHIELDING PERFORMANCE

Heat Transfer

4-1

Electrically Heated Test Runs

4-1

DSC in Transfer Cask

4-3

DSC in Horizontal Storage Module

4-7

Spent Fuel Storage Demonstration

4-17

Shielding

4-25

5 REFERENCES

APPENDIX A SPENT FUEL DATA

A-1

APPENDIX B MEASUREMENT UNCERTAINTIES

B-1

APPENDIX C HEAT TRANSFER DATA

C-1

APPENDIX D DOSE RATE DATA

D-1 


\section{ILLUSTRATIONS}

Figure

$\underline{\text { Page }}$

S-1 H. B. Robinson NUHOMS Demonstration System

S-2 Typical Center Canister and Module Temperatures on July 3, 1989, Prior to Loading Fuel in the Second Side Module

S-3 Effect of Blocking the Inlet Air Vents

S-4 Radiation Dose Rates at the Surface and at $3 \mathrm{ft}$ from the Surface of the HSM

3-1 H. B. Robinson NUHOMS Dry Storage System Profile

3-2 Cutaway of the H. B. Robinson NUHOMS Dry Shielded Canister

3-3 H. B. Robinson NUHOMS Dry Storage System

3-4 Basic Operations for the NUHOMS Dry Storage System

3-5 The NUHOMS Horizontal Storage Module 3-6

3-6 Air Flow Through the NUHOMS Dry Storage Module 3-8

3-7 Three-Module H. B. Robinson NUHOMS System 3-8

3-8 Thermocouple Locations in the Horizontal Storage Module 3-10

3-9 Thermocouple Locations in the Dry Shielded Canister 3-12

3-10 GE IF-300 Spent Fuel Transportation Cask 3-13

3-11 Cask Extension and Lid for the IF-300 Transportation Cask 3-15

3-12 Fuel Loading Pattern 3-16

3-13 H. B. Robinson $15 \times 15$ PWR Fuel Assembly Side View 3-17

3-14 H. B. Robinson $15 \times 15$ PWR Fuel Assembly Cross Section 3-18

3-15 Schematic of Data Acquisition System for H. B. Robinson ISFSI 3-18

3-16 Heater Controller Performance Curve 3-21

3-17 Dry Shielded Canister During Receipt at H. B. Robinson 3-30 
3-18 IF-300 Transportation Cask Being Loaded Into the Support

Cradle of the Transport Trailer

3-19 IF-300 Transportation Cask Being Lowered to the Horizontal

Position in the Trailer-Mounted Support Cradle.

3-20 IF-300 Transportation Cask Loaded and Secured in the Support

Cradle of the Transport Trailer

3-21 Loaded IF-300 Transportation Cask Being Transported to the ISFSI

3-22 IF-300 Transportation Cask Positioned at the Concrete Storage Modulus

3-23 Operation of the Trailer-Mounted Hydraulic Positioning System

3-24 Hydraulic Ram at the Rear of the Module

3-25 Shield Door Lowered to Cover the Front Access Port

4-1 Dry Storage Canister and Heater Locations Associated with the First Four Heater Test Runs

4-2 Location of DSC Thermocouples Used in the Electrically Heated Test Runs in the Transfer Cask

4-3 Dry Storage Canister Temperatures During Simulated Fuel Loading

4-4 Temperature Performance of the NUHOMS System During the Electrically Heated Tests

4-5 Effect of Blocking the Inlet Air Vents

4-6 Representative Temperatures from Heater No. 5 for a Vertical

Cross Section Through the Center of the Side Module

4-7 Representative Temperatures from Heater Test No. 6 for a Vertical Cross Section Through the Center of the Side Module

4-8 Representative Temperatures from Heater Test No. 7 for a Vertical Cross Section Through the Center of the Side Module

4-9 Representative Temperatures from Heater Test No. 8 for an Axial Vertical Cross Section Through the Center of the Side Module

4-10 Temperature History from the Center DSC/HSM Loaded with Spent Fuel

4-11 Representative Temperature from the Center DSC/HSM Loaded with Spent Fuel on July 3, 1989, Prior to Loading the Side Module

4-12 Temperature in the NUHOMS System on July 3, 1989, Prior to Loading Spent Fuel in the Last Module 
4-13 Temperature in the NUHOMS System on September 21, 1989, With A11 Modules Loaded with Spent Fuel. A vertical section along the axis of the center module (HSM-2) can be seen.

4-14 Temperatures in the NUHOMS System on September 21, 1989, with A11 Modules Loaded with Spent Fuel. A vertical section along the axis of the side module (HSM-3) can be seen.

4-15 Temperatures in the NUHOMS System on September 21, 1989, with A11 Modules Loaded with Spent Fuel. A vertical cross section through the midpoint of the canisters can be seen.

4-16 Radiation Dose Rates at the Surface of the Modules and at $3 \mathrm{ft}$ from the Surface 


\section{TABLES}

$\underline{\text { Table }}$

Page

S-1 Test Matrix and Peak Temperatures for the H. B. Robinson NUHOMS Demonstration

S-5

3-1 Handling Test Matrix 3-24

3-2 Heat Transfer Test Matrix 3-25

3-3 Radiation Shielding Text Matrix 3-26

3-4 Summary of New Plant and Special Procedures 3-28

3-5 Total Radiological Experience from the Loading of Eight Canisters 3-47

3-6 Dose Experience by Task $3-48$

3-7 TLD Results $\quad 3-50$

4-1 Test Matrix and Peak Temperatures for the H. B. Robinson NUHOMS 4-2 


\title{
NOMENCLATURE
}

\author{
Abbreviations and Acronyms \\ ACI American Concrete Institute \\ ADC analog-to-digital converter \\ ALARA as low as reasonably achievable \\ BWR boiling water reactor \\ CP\&L Carolina Power and Light Company \\ DAS data acquisition system \\ DOE U.S. Department of Energy \\ DOT U.S. Department of Transportation \\ DSC dry shielded canister \\ HBR H. B. Robinson \\ HSM horizontal storage module \\ ISFSI independent spent fuel storage installation \\ NRC U.S. Nuclear Regulatory Commission \\ NUHOMS NUTECH Horizontal Modular Storage \\ NWPA Nuclear Waste Policy Act \\ PWR pressurized water reactor \\ TLD thermoluminescent dosimeter \\ UT uttrasonic techniques
}





\section{EXECUTIVE SUMMARY}

This report documents the results of a heat transfer and shielding performance evaluation of the NUTECH HOrizontal MOdular storage (NUHOMS) ${ }^{\bullet}$ System utilized by the Carolina Power and Light Co. (CP\&L) in an Independent Spent Fuel Storage Installation (ISFSI) licensed by the U.S. Nuclear Regulatory Commission (NRC). The ISFSI is located at CP\&L's H. B. Robinson Nuclear Plant (HBR) near Hartsville, South Carolina.

In March 1984, the U.S. Department of Energy (DOE) entered into a cooperative agreement with CP\&L to demonstrate a licensed ISFSI based on the NUHOMS system. The Electric Power Research Institute (EPRI) participated in the demonstration program through a separate agreement with CP\&L.

The NUHOMS spent fuel dry storage system is designed and marketed by Pacific Nuclear Fuel Services (PNFS), formerly NUTECH Engineers, located in San Jose, California. The NUHOMS system used in the CP\&L/DOE/EPRI demonstration program consisted of three concrete modules housing 21 spent fuel assemblies. Five additional modules were added during the course of the demonstration program for the storage of a total of 56 assemblies. The major components of the system are a . horizontal storage module (HSM) made of reinforced concrete, a stainless steel dry shielded canister (DSC), an on-site transfer cask, and a special purpose trailer (Figure S-1). Each storage module houses a single canister containing seven unconsolidated pressurized-water reactor (PWR) assemblies from H. B. Robinson Unit 2. The HSM provides convective cooling air flow, missile protection, and biological shielding for the DSC. The DSC provides containment for the fuel assemblies, and the helium cover gas, and includes an internal basket to maintain the assemblies in a critically safe configuration. The transfer cask provides shielding and protection for the DSC when it is moved from the reactor spent fuel pool to the ISFSI. The special-purpose trailer is used to carry the transfer cask

'NUHOMS is a registered trademark of NUTECH, Inc., San Jose, California. 


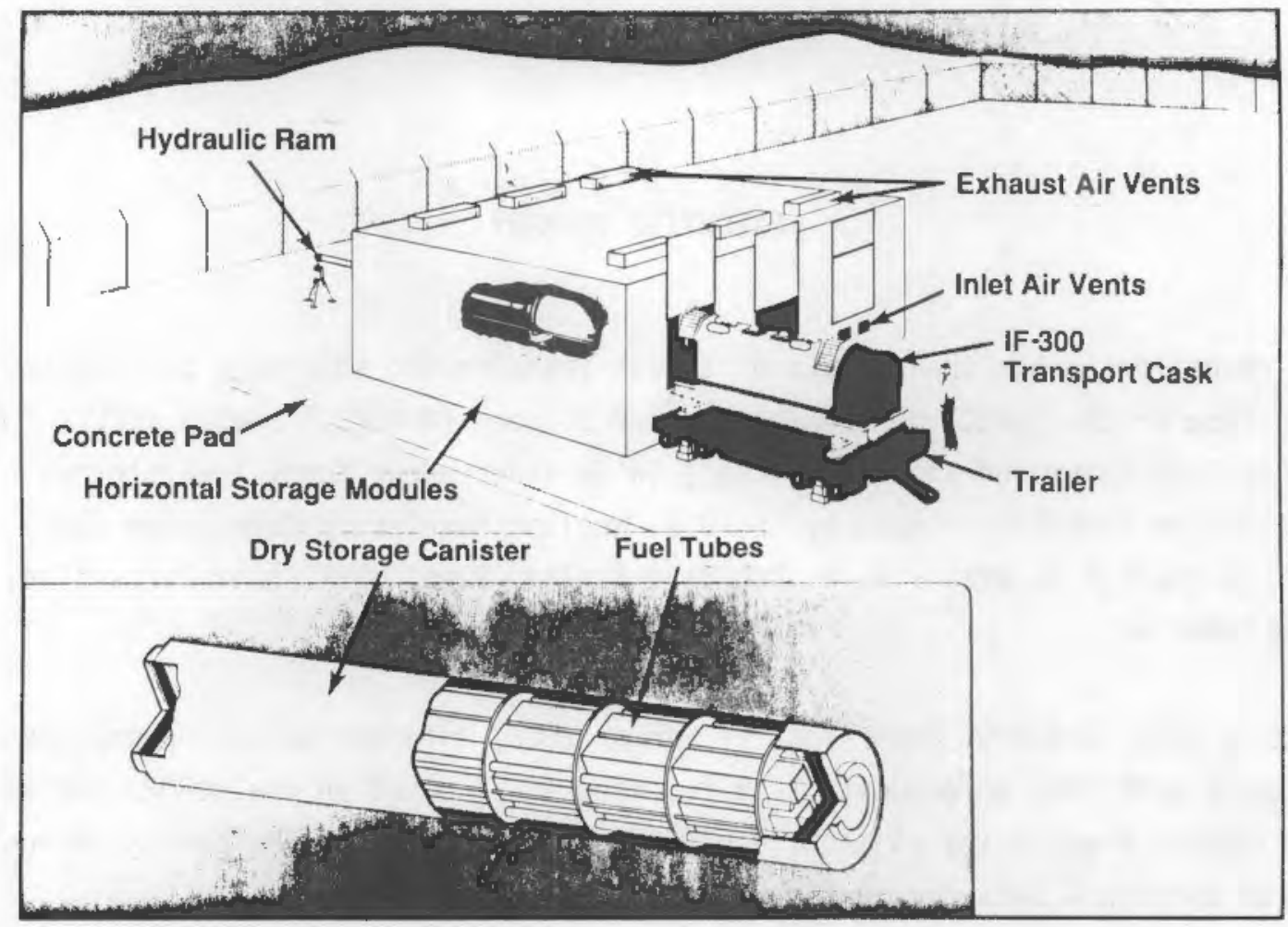

Figure S-1. H.B. Robinson NUHOMS Demonstration System

containing the loaded DSC to the ISFSI and, using the on-board positioning system, provides the alignment required to mate the cask with the NUHOMS storage module.

The design, construction, and licensing of the H. B. Robinson ISFSI were completed in 1987. Operational testing including a comprehensive handling test and a series of electrically heated tests were conducted in 1988 and 1989 . The first canister of spent fuel was loaded in March 1989 and the remaining two were loaded in May and June 1989. Temperature and weather information from the NUHOMS system presented in this report were obtained throughout July, August, and September 1989.

The NUHOMS system heat transfer test consisted of eight electrically heated test runs followed by two test runs with spent PWR fuel in the storage system. The first three electrically heated test runs were conducted with the DSC in the IF-300 transfer cask to evaluate the performance of the $\mathrm{DSC} /$ cask combination from the time it was loaded in the pool through vacuum drying of the DSC and during backfilling with helium in preparation for transfer to the HSM. Next, five electrically heated 
test runs were conducted with the DSC in the HSM to evaluate the performance of the dry storage system. These test runs simulated both the normal performance of the NUHOMS system and off-normal performance for air inlet/outlet blockages and higher decay heat levels.

Seventy-six thermocouples were used to assess the thermal performance of the DSC in the HSM during the heater and fuel tests. Three TCs recorded the ambient temperature, 12 recorded the outlet air temperature, 25 were used to monitor DSC temperatures, and 36 monitored the HSM heat shield and concrete temperatures.

The first heater test run in the HSM was designed to simulate the normal operation of the NUHOMS system. It was run with an electrical output simulating $1 \mathrm{~kW}$ per assembly, or a total of $7 \mathrm{~kW}$ per DSC. This was followed by a run with the air inlets to the HSM blocked. Then the outlets to the HSM were also blocked. The final heater test runs were performed at high and low power levels, $13 \mathrm{~kW}$ and $2 \mathrm{~kW}$, respectively. Following the heater test runs, three DSCs were loaded with spent PWR fuel and placed in the HSM storage modules. Temperatures typical of loaded modules are shown in Figure $\mathrm{S}-2$.

Table S-1 summarizes the peak concrete, heat shield, basket, and fuel temperatures measured for each of the test runs. Ambient temperatures are also indicated. The electrically heated test runs conducted in the IF-300 cask simulated loading, vacuum drying, and backfilling the cask with helium. The temperature of the center fuel sleeve of the DSC basket increased from $50^{\circ} \mathrm{C}$ with the canister filled with water to $255^{\circ} \mathrm{C}$ during vacuum drying. At the conclusion of the vacuum drying process, the canister was backfilled with helium and the peak temperature dropped to $138^{\circ} \mathrm{C}$.

Following the electrically heated test runs conducted in the IF-300 cask, the dry storage canister was placed in the HSM and another series of electrically heated test runs were conducted. The first run simulated normal operation of the cask. During normal operation (test run HT-5), peak basket, heat shield, and concrete temperatures reached $201^{\circ} \mathrm{C}, 79^{\circ} \mathrm{C}$, and $58^{\circ} \mathrm{C}$, respectively. Blockage of the air inlet vents (test run HT-6) increased basket, heat shield, and concrete temperatures about $15^{\circ} \mathrm{C}$. However, the temperature difference between the canister and the heat shield did not change appreciably indicating that the heat shield was still being cooled by convection. It should also be observed that the difference between the peak concrete temperature and the ambient temperature increased when the air 


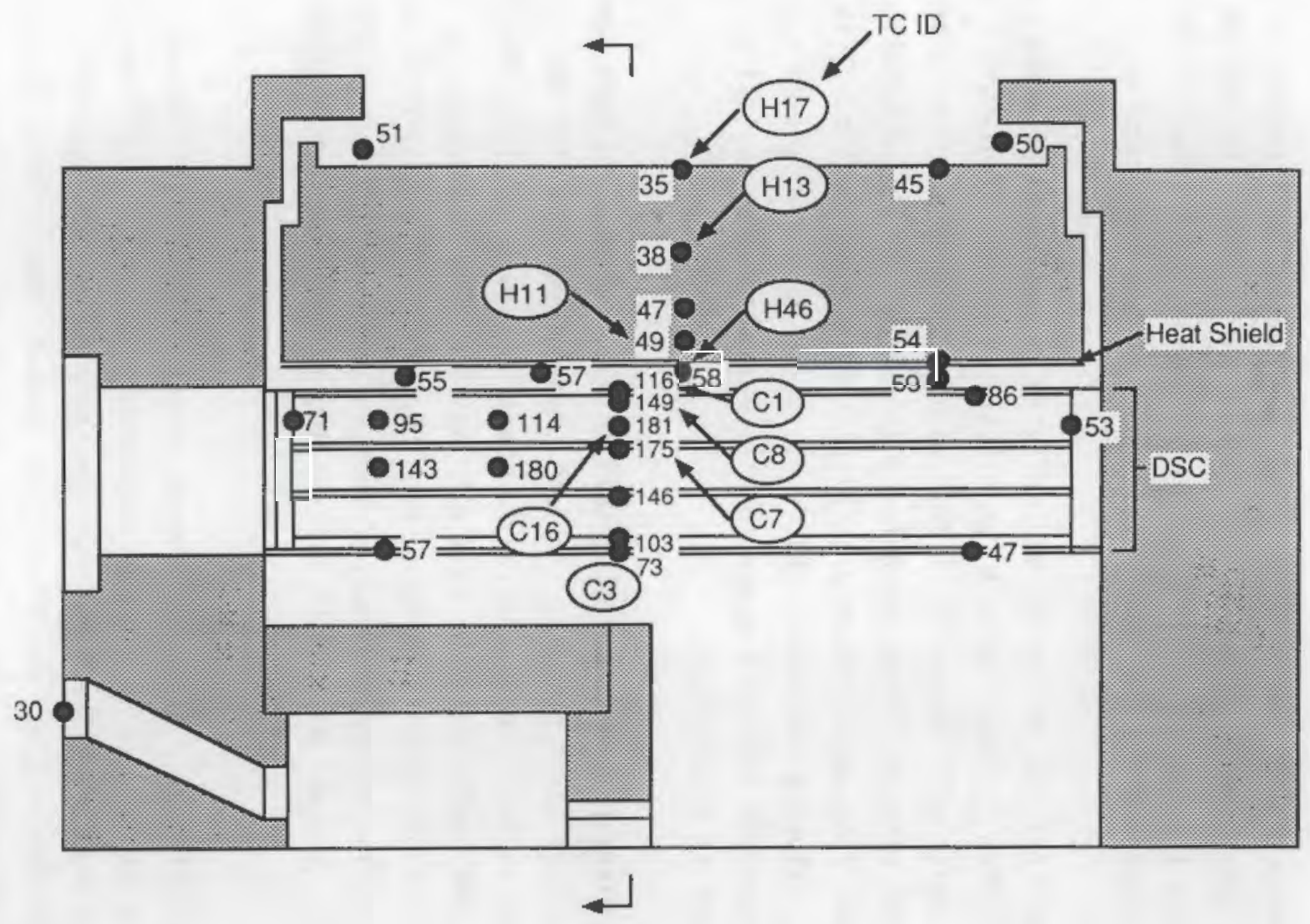

Figure S-2. Typical Center Canister and Module Temperatures $\left({ }^{\circ} \mathrm{C}\right)$ on July 3,1989 , Prior to Loading Fuel in the Second Side Module (Vertical Sections Along the Axial Centerline of the Module) 
Table S-1

TEST MATRIX AND PEAK TEMPERATURES FOR THE H.B. ROBINSON NUHOMS DEMONSTRATION

\begin{tabular}{|c|c|c|c|c|c|c|c|c|c|c|}
\hline \multirow[b]{2}{*}{ Run } & \multirow[b]{2}{*}{ Run Description } & \multirow[b]{2}{*}{$\begin{array}{c}\text { DSC } \\
\text { Location }\end{array}$} & \multirow[b]{2}{*}{$\begin{array}{c}\text { DSC } \\
\text { Atmosphere }\end{array}$} & \multirow[b]{2}{*}{$\begin{array}{c}\text { Heat } \\
\text { Source } \\
\end{array}$} & \multirow{2}{*}{$\begin{array}{c}\begin{array}{c}\text { Canister } \\
\text { Power Level } \\
\text { (kW) } \\
\end{array}\end{array}$} & \multicolumn{4}{|c|}{ Peak Temperature $\left({ }^{\circ} \mathrm{C}\right)$} & \multirow{2}{*}{$\begin{array}{c}\text { Inlet/Ambient } \\
\text { Air } \\
\text { Iemperature }\left({ }^{\circ} \mathrm{C}\right)\end{array}$} \\
\hline & & & & & & Fuel & $\begin{array}{c}\begin{array}{c}\text { Basket } \\
\text { Fuel Sleeve }\end{array} \\
\end{array}$ & $\begin{array}{c}\text { Heat } \\
\text { Shield }\end{array}$ & Concrete & \\
\hline HT-1 & $\begin{array}{l}\text { Ambient atmosphere (DSC } \\
\text { full of water) }\end{array}$ & Cask & Water & Electric & 7 & -- & 50 & -- & - & 25 \\
\hline HT-3 & Air or vacuum atmosphere & Cask & Air & Electric & 7 & $\cdots$ & 255 & -- & $\because$ & 26 \\
\hline HT -4 & Hel ium atmosphere & Cask & Helium & Electric & 7 & $\cdots$ & 138 & -- & $\cdots$ & 28 \\
\hline HT -5 & Normal operation & HSM & Helium & Electric & 7 & $\cdots$ & 201 & 79 & 58 & 23 \\
\hline HT- 6 & Air inlets blocked & HSM & Helium & Electric & 7 & $\cdots$ & 215 & 95 & 71 & 28 \\
\hline нт-7 & Inlets and outlets blocked & HSM & Helium & Electric & 7 & -- & 225 & 111 & 82 & 24 \\
\hline HT -8 & Variable power level & HSM & Helium & Electric & 13 & $-\cdot$ & 291 & 106 & 75 & 19 \\
\hline & & & & & 2.2 & $\cdots$ & 116 & 53 & 47 & 15 \\
\hline HT-11 & Two HSMs loaded & HSM & Helium & Spent Fuel & 5 & 181 & 146 & 59 & 49 & 29 \\
\hline & Three HSHS loaded & HSM & Helium & Spent Fuel & 5 & 180 & 155 & 66 & 51 & 25 \\
\hline
\end{tabular}


inlets were blocked showing a small decrease in cooling. It appears that blocking the inlet vent did not significantly effect the heat dissipation capability of the module.

When both inlet and outlet air vents were blocked (test run HT-7), Table S-1 showed that the heat shield temperature increased more than the concrete and DSC temperatures. The canister and DSC temperatures increased by about the same amount and the difference between the concrete and ambient temperatures increased. The reason the heat shield temperatures increased more than the concrete and DSC temperatures is because heat loss from the heat shield through convection was decreased due to the air flow blockage.

The variable power level test runs show expected performance. Table S-1 shows a substantial increase in basket temperatures for an increase of heater power from 7 to $13 \mathrm{~kW}$ (test run HT-8). This was accompanied by an increase in heat shield and concrete temperatures. However, the concrete temperatures were not much different from those for partial blockage. When the power was reduced to $2.2 \mathrm{~kW}$, basket, heat shield, and concrete temperatures decreased as would be expected.

An interesting phenomena was observed while the inlet air vent was blocked during an electric heater test run (test run HT-6). One of the outlets became an inlet and the other outlet remained an outlet shown in from Figure S-3. On September 22, the inlet vent was plugged. At this time the front outlet vent's temperature dropped to ambient temperature and the rear outlet vent's temperature increased by about $5^{\circ} \mathrm{C}$. This would be consistent with the front outlet vent becoming an inlet. At midday September 23, the temperatures of the two outlet vents reversed themselves which would be consistent with a change of air flow through the HSM; i.e., the back outlet became the inlet and the front air flow became the only outlet. At the conclusion of test run HT-6, both the outlets and inlets were blocked for test run HT-7. The blockage occurred about midday September 26 and resulted in both outlet temperatures converging to a single temperature.

Dose rates were measured at selected locations on the surface of the module and $3 \mathrm{ft}$ from the module. The results of these measurements are shown in Figure S-4. As can be seen from the figure, the majority of the surface dose rates are a result of gamma radiation. At a distance of $3 \mathrm{ft}$, the dose rates due to gamma and neutron sources are very low. The only location having a gamma dose rate greater than 


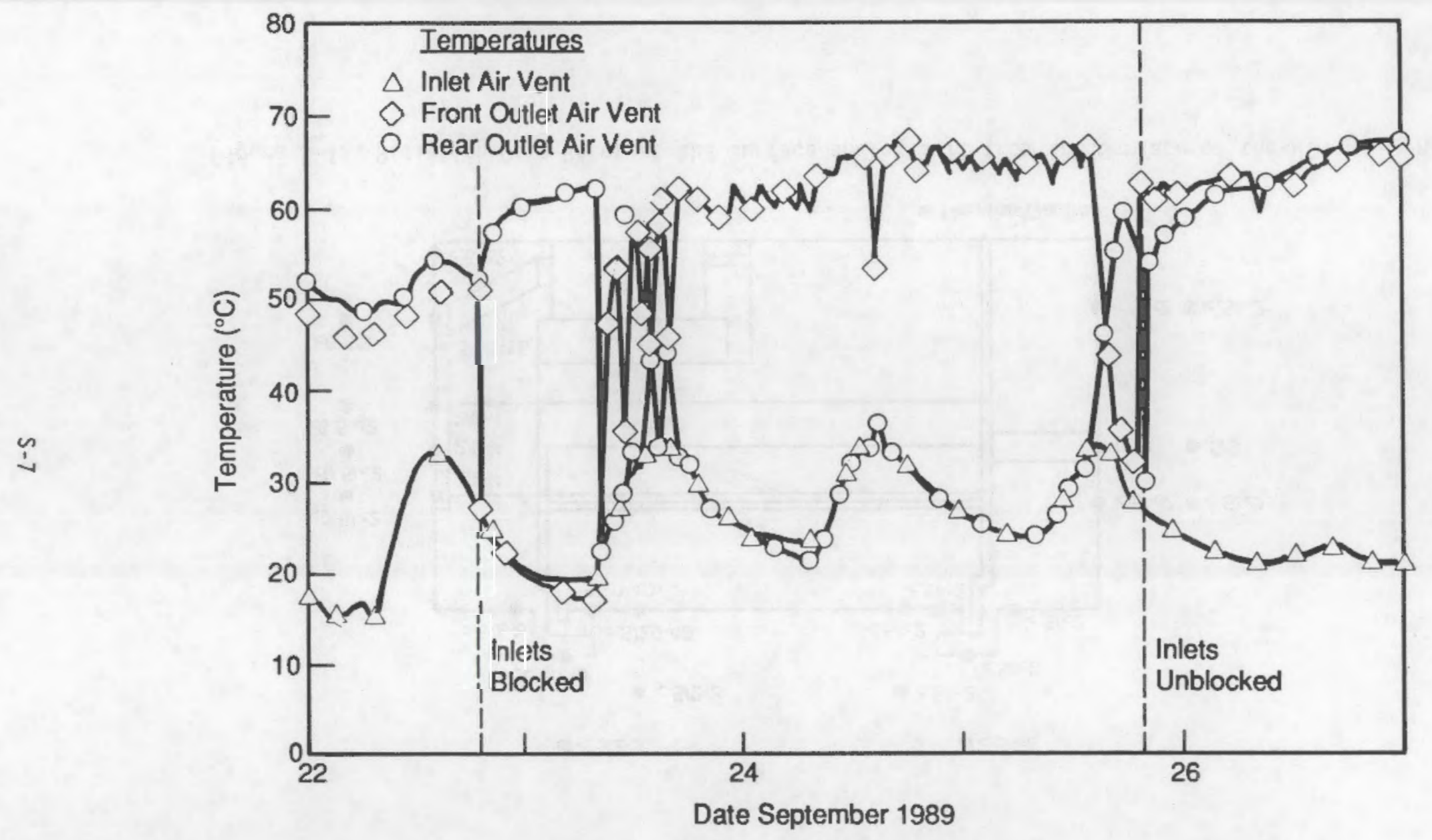

Figure S-3. Effect of Blocking the Inlet Air Vents 


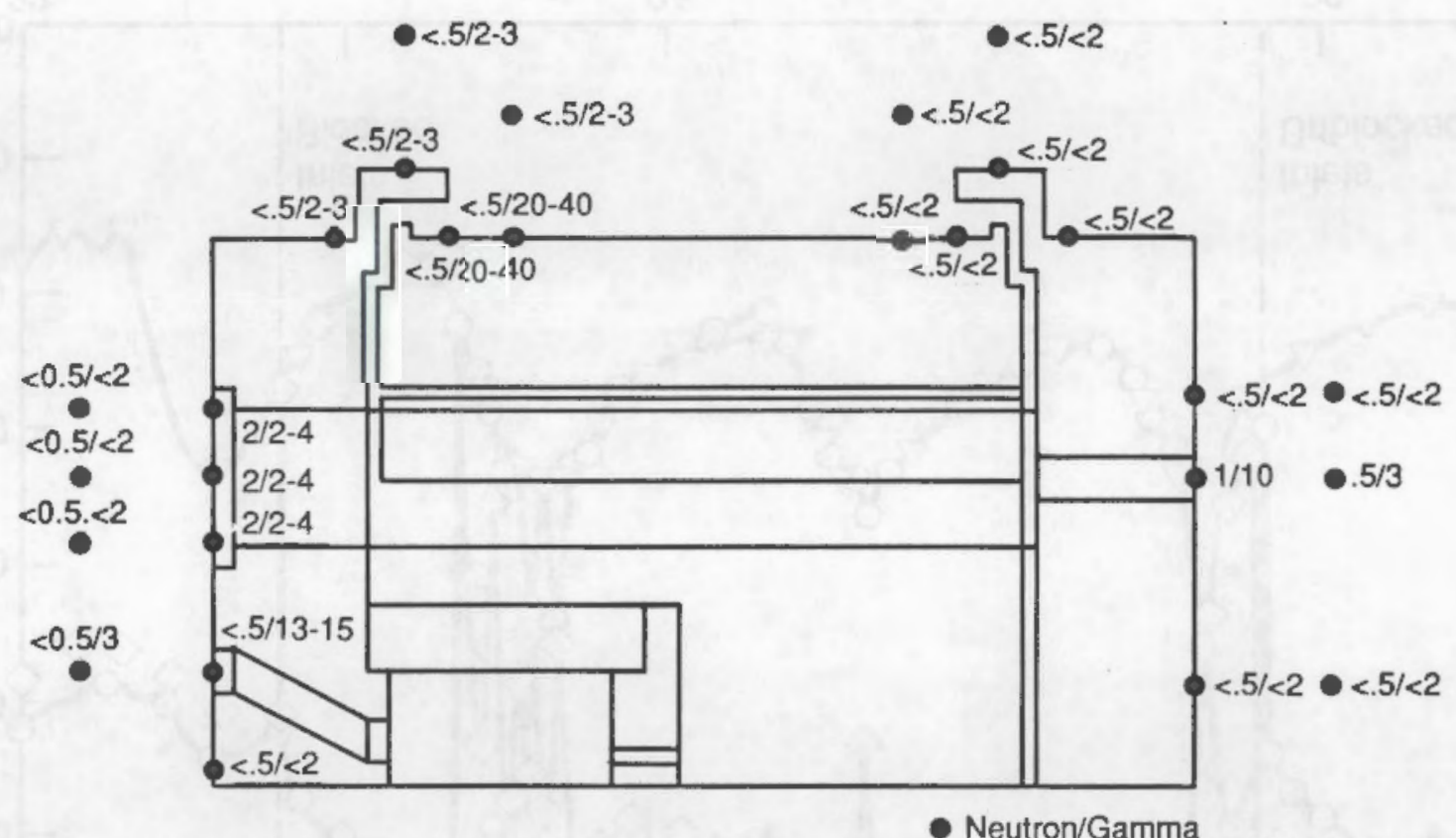

Figure S-4. Radiation Dose Rates at the Surface and at $3 \mathrm{ft}$ from the Surface of the HSM (mrem/hr) 
$3 \mathrm{mr} / \mathrm{h}$ at $3 \mathrm{ft}$ from the HSM occurred at the front air outlet; this was caused by the position of the lower end fitting of the stored assemblies in relation to the outlet.

At the conclusion of the heater tests, the HSMs were loaded with fuel and the last two test runs were conducted. The peak fuel temperature measured in the center guide tube was $181^{\circ} \mathrm{C}$ (see Table S-1 and Figure S-3). This temperature corresponded to peak basket, heat shield, concrete, and ambient temperatures of $146,59,47$, and $29^{\circ} \mathrm{C}$, respectively. It is interesting to note that the peak fuel temperature did not change much with the loading of two or three modules in the three module HSM system. The fully loaded modules (three HSMs loaded) showed slightly higher heat shield and concrete temperatures.

The results of this evaluation demonstrate the conservative design of the NUHOMS system used in the H. B. Robinson ISFSI. The temperatures measured in the center guide tube of the center fuel assembly in the DSC stored in the center HSM indicate that fuel temperatures are being maintained well below the peak fuel temperature allowed by the technical specifications in the 10CFR72 1icense. In addition, the peak concrete temperatures measured above the heat shield, for the spent fuel currently stored, are below the maximum design temperatures recommended by the American Concrete Institute (ACI). 



\section{Section 1}

INTRODUCTION

When the majority of the commercial nuclear power plants in the United States were designed and built, it was anticipated that spent fuel would be held in the onsite spent-fuel pool for initial cooling, then transferred to a reprocessing facility to recover unused uranium and other commercially valuable materials. The result of this design assumption was that most nuclear plants were built with relatively small spent fuel storage pools. In the late 1970s, U.S. policy changed and reprocessing was eliminated as an option for spent-fuel disposal, leaving nuclear power plants with inadequate storage capacities to attain the end of their design lives.

Recent U.S. Department of Energy (DOE) studies (DOE 1989) indicate that some nuclear power plants now need, and will continue to require, additional spent fuel storage capacities. To address this growing problem, the U.S. Congress passed the Nuclear Waste Policy Act (NWPA) in 1982. The Act directs DOE to begin accepting commercial spent fuel for disposal in a permanent repository in 1998 . At the same time, Section 111 of the NWPA confirmed that "... the generators and owners of ... spent nuclear fuel have the primary responsibility to provide for, and the responsibility to pay the cost of the interim storage of such ... spent fuel until such ... spent fuel is accepted by the Secretary of Energy in accordance with the provisions of this Act." To help nuclear utilities with that responsibility, Section 218 of the NWPA provided that, "The Secretary shall establish a demonstration program, in cooperation with the private sector, for the dry storage of spent nuclear fuel at civilian nuclear power reactor sites, with the objective of establishing one or more technologies that the Commission [NRC] may, by rule, approve for use at sites of civilian nuclear power reactors without, to the maximum extent practicable, the need for additional site-specific approvals by the Commission." To implement this directive, on May 9, 1983, DOE issued a Solicitation for Cooperative Agreement Proposal (DOE 1983) for a Licensed At-Reactor Dry Storage Demonstration Program. 
In response to the DOE solicitation, the Carolina Power and Light Company (CP\&L) submitted a proposal for a licensed dry storage demonstration program in August 1983. The CP\&L proposed the demonstration of an independent spent fuel storage installation (ISFSI) using the NUTECH horizontal modular storage (NUHOMS) ${ }^{\bullet}$ system at their H. B. Robinson nuclear plant located near Hartsville, South Carolina. The NUHOMS system was developed by NUTECH Engineers of San Jose, California, and stores spent fuel in large multi-element canisters inside horizontal concrete modules. The Cooperative Agreement for the CP\&L/DOE Dry Storage Demonstration was signed in March 1984.

The CP\&L submitted a 10CFR72 (Part 72 of Title 10, Code of Federal Regulations) license application to NRC in March 1985 for an ISFSI utilizing the NUHOMS dry storage system. The NRC's review of the license application continued through the remainder of 1985 and early 1986. The NRC issued a 10CFR72 license for the H. B. Robinson ISFSI on August 13,1986; and construction of the NUHOMS modules was completed in February 1987. Fabrication and delivery of the remaining components for the NUHOMS system were completed in July 1987.

Operational testing of procedures and equipment was conducted in FY88. A recurring problem throughout the testing was the contamination of the dry storage canister by residual contamination from previous unrelated fuel transhipments using an open basket in the IF-300 transfer cask. Extensive decontamination of the transfer cask and the replacement of drain valves was conducted in November 1987 and again in May 1988 but did not eliminate the possibility that the canister would be contaminated beyond the allowable limits when it was inserted into the transfer cask. In August 1988, CP\&L requested an amendment to the technical specifications for the ISFSI to address the potential contamination levels. The amendment was approved by the NRC in March 1989. Several other issues required action by NRC during this period. A11 were the result of a comprehensive operational readiness review conducted by CP\&L in preparing to load spent fuel. CP\&L worked closely with NRC and was able to reach favorable rulings on all outstanding issues in the spring of 1989.

As part of the operational testing, a series of heater test runs were conducted using electric heaters to simulate the decay heat of the nuclear fuel assemblies. The test runs were designed to model operational and off-normal conditions at

"NUHOMS is a registered trademark of NUTECH, Inc., San Jose, California. 
several power levels. The early results of these test runs were encouraging and verified the conservatism of the NUHOMS design.

The first canister of spent fuel was loaded into its module on March 1989, and the remaining two canisters were loaded in July 1989. Temperature and weather information presented in this report were obtained throughout July, August, and September 1989.

This report documents the performance of the NUHOMS system used in the CP\&L/DOE Cooperative Dry Storage Demonstration. Conclusions and recommendations are presented in Section 2. Section 3 describes the H. B. Robinson ISFSI, including the modules, canisters, instrumentation, and data acquisition system. Section 3 also contains a description of the spent fuel used in the demonstration, the test plan, and CP\&L'S operational experience with the NUHOMS system. Heat transfer and shielding data are presented and discussed in Section 4. 

Section 2

CONCLUSIONS AND RECOMMENDATIONS

Performance testing of the NUHOMS-07P PWR spent fuel storage system was successfully completed at H. B. Robinson. The tests demonstrated that the system could be satisfactorily handled and loaded, and demonstrated the heat transfer and shielding performance of the system when loaded with seven PWR spent fuel assemblies per module generating approximately $5 \mathrm{~kW}$. Electric heater tests demonstrated the performance of the system for heat loads up to $13 \mathrm{~kW} /$ module. The heat transfer performance with fuel in the module (at $5 \mathrm{~kW} / \mathrm{DSC}$ ) was exceptionally good, as indicated by measured peak fuel and concrete temperatures of $181^{\circ} \mathrm{C}$ and $51^{\circ} \mathrm{C}$, respectively. Shielding performance was excellent with peak surface dose rates less than $40 \mathrm{mrem} / \mathrm{hr}$. From both heat transfer and shielding perspectives, the NUHOMS spent fuel storage system can be used effectively to safely store spent fuel at reactor sites.

The following sections present specific conclusions and recommendations noted during the testing and analyses effort.

\section{CONCLUSIONS}

The results of the performance test permit the following conclusions.

\section{DSC/Cask Handling and Loading}

- The DSC/IF-300 combination can be satisfactorily handled and loaded in many reactor facilities with minor modifications to existing equipment and procedures.

- Operational testing (dry runs and mock-ups) of all system operational steps and associated procedures was invaluable in exposing problems with equipment and procedures which could then be satisfactorily resolved.

- Vacuum drying the dry shielded canisters required more time than anticipated. Strict adherence to a stepwise drying procedure is essential to minimize drying times and ice formation. 
- Canister closure welding can be readily accomplished with prequalified procedures, welding personnel, and automatic welding equipment.

- Alignment of the cask, module opening, and ram was not a serious problem. During the initial testing, optical alignment technicians with precision equipment were hired to perform the alignment. During later testing, the H. B. Robinson plant surveying group was able to align the system to within 1/16 in. using conventional surveying equipment.

- The hydraulic ram loads required to pull the DSC from the cask into the HSM were a fraction of the $20,000 \mathrm{lb}$ capacity of the ram.

\section{Heat Transfer Performance}

- The heat transfer performance of the system was exceptionally good. Peak fuel temperatures were $10 \mathrm{w}\left(180^{\circ} \mathrm{C}\right)$ for fuel assembly decay heat outputs of about 750 watts. Corresponding measured peak concrete temperatures were $50^{\circ} \mathrm{C}$.

- Blockage of the inlet air vents had little effect $\left(<15^{\circ} \mathrm{C}\right)$ on the performance of the module. When the inlet vents were blocked, one of the outlet vents began functioning as an inlet and natural convection continued to cool the fuel, canister, and concrete. When both inlets and outlets were blocked, the fuel, canister, and module temperatures increased less than $30^{\circ} \mathrm{C}$ during the two-day test. When the test was terminated the temperature was still rising at approximately $4^{\circ} \mathrm{C}$ per day.

- The heat shield installed between the top of the DSC and the roof of the HSM was very effective in limiting heat transfer by radiation between the DSC and the interior concrete surfaces of the HSM.

\section{Shielding Performance}

- Total radiation exposure to personnel involved in the operation of the NUHOMS system was relatively low. The total dose attributed to operations to complete the last loading sequence was less than 1 man-rem.

- A significant benefit was realized by using dedicated crews to perform repeated loading operations. The loading sequence for the first canister took 9 days and incurred a total radiation dose of approximately 3 man-rem. The final loading sequence took 5 days and incurred a total dose of less than 1 man-rem.

- Measured dose rates at $3 \mathrm{ft}$ from the transfer cask were all less than $4 \mathrm{mrem} / \mathrm{hr}$.

- Measured dose rates on the surface of the HSM were generally less than $3 \mathrm{mrem} / \mathrm{hr}$ except at locations of module penetrations. 
- The peak measured surface dose rate was about $40 \mathrm{mrem} / \mathrm{hr}$ at the air outlet closest to the front of the module. This reading was probably due to the radiological spectrum of the lower end fittings and their proximity to the front module vent.

- There has been no measurable increase in environmental exposure in the vicinity of the site resulting from the storage of spent fuel in the ISFSI. This conclusion was based on before and after TLD readings taken at several locations around the $\mathrm{H}$. B. Robinson plant.

\section{RECOMMENDATIONS}

The results and conclusions of the performance tests prompt the following recommendations.

\section{DSC/Cask Handling and Loading}

- Dry runs and operational tests should be performed for all operational phases of a NUHOMS system. The tests will help streamline procedures, identify problems with hardware, and provide valuable training for personnel.

- To simplify logistical support for an ISFSI, plant staff should be used to implement operations where possible.

- Verification parameters to be included in the technical specifications such as pressures to be achieved during vacuum drying and maximum permissable leak rates should be based on actual experience if possible.

\section{Heat Transfer Performance}

- Given the relatively low spent fuel and concrete temperatures, it is likely that the NUHOMS system could store much hotter fuel (i.e., fuel with higher burnups or shorter postirradiation cooling times).

\section{Shielding Performance}

- Dedicated crews should be used for all system operations. It is clear that as experience increases, time to perform system functions decreases and minimizes personnel exposure.

- Minor adjustments in the axial positions of DSCs may reduce the dose rates at front air outlets of the module. 



\section{Section 3}

\section{NUHOMS PERFORMANCE TESTING/DEMONSTRATION}

The CP\&L's generating facilities are located in northeastern South Carolina in Darlington County. The site is 54 miles east-northeast of Columbia, South Carolina, and 3 miles west-northwest of Hartsville, South Carolina. The plant is in an area of rolling sand hills and lies on the southwest shore of Lake Robinson, a 2280 -acre cooling impoundment owned by CP\&L. The site contains 2500 acres of 1and surrounding Lake Robinson with a 2800 -foot-diameter exclusion zone on the southwest shore. The exclusion zone contains two power plants: a 185 MWe fossilfueled generating plant (HBR Unit 1) and a 665 MWe nuclear plant (HBR Unit 2). The ISFSI is located within the protected area of the nuclear unit.

The ISFSI utilizes the NUHOMS dry storage system designed and marketed by PNSI, formerly NUTECH Engineers, of San Jose, California. The major components of the system are a horizontal storage module (HSM) made of reinforced concrete, a stainless steel dry shiẹlded canister (DSC), an onsite transfer cask, and a special-purpose trailer (see Figure 3-1). Each storage module houses a single canister containing seven intact pressurized-water reactor (PWR) assemblies from H. B. Robinson Unit 2. The OSC provides containment for the fuel assemblies and the cover gas and includes an internal basket to maintain the assemblies in a critically safe configuration (see Figure 3-2). The transfer cask provides shielding and protection for the DSC when it is moved from the reactor spent fuel pool to the HSM. The special-purpose trailer is used to move the transfer cask containing the loaded DSC to the HSM and provides the alignment required to mate the cask with the module. The HSM provides shielding and missile protection for the canister during long-term storage (see Figure 3-3). 


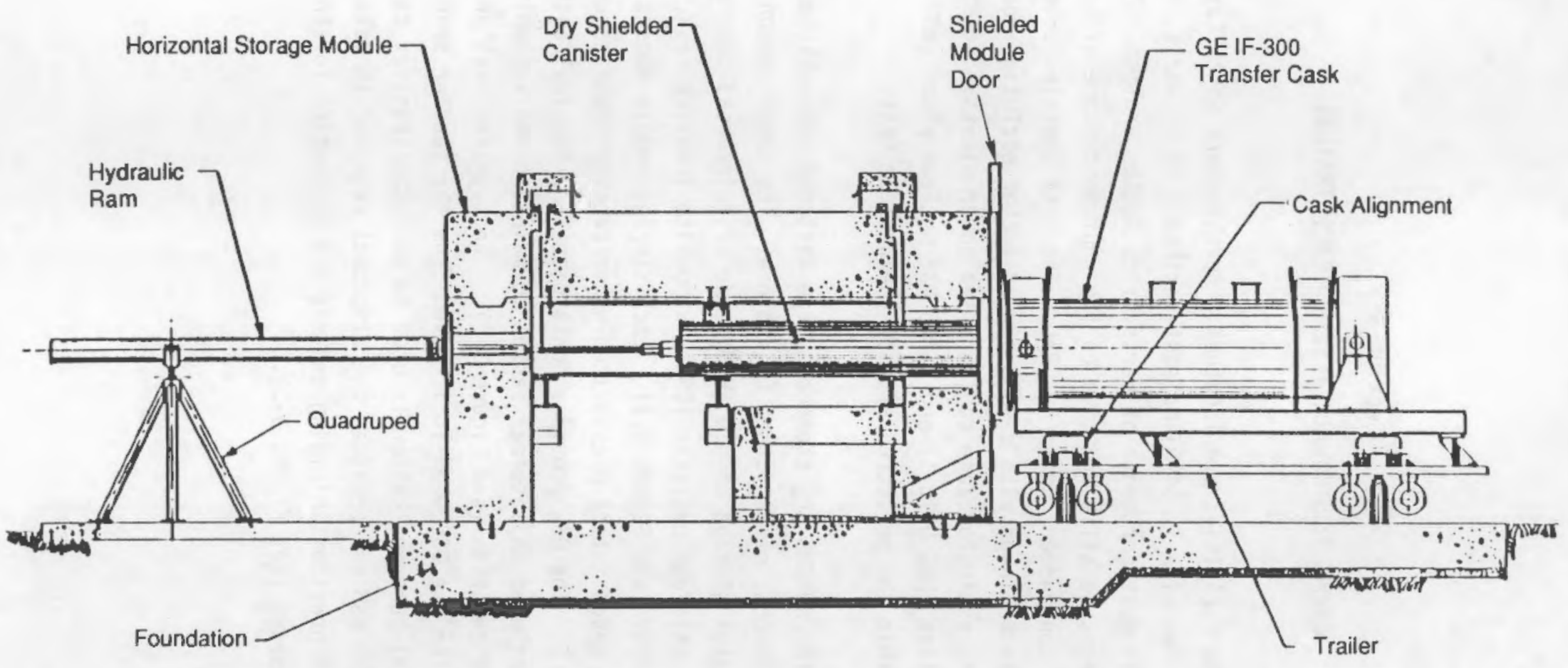

Figure 3-1. H. B. Robinson NUHOMS Dry Storage System Profile 


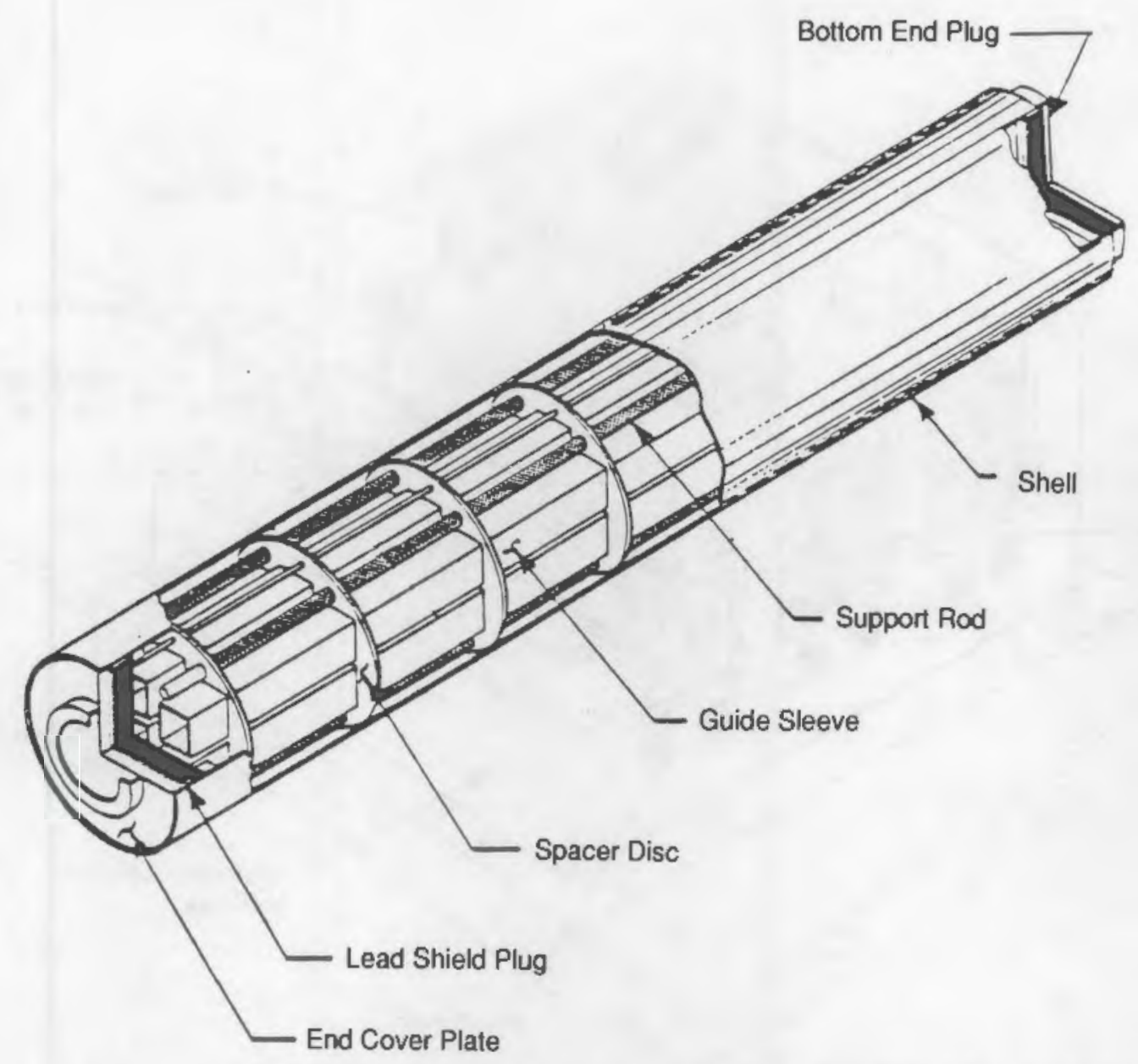

Figure 3-2. Cutaway of the H. B. Robinson NUHOMS Dry Shielded Canister

In operation, the DSC is inserted into the transfer cask and lowered into the reactor spent-fuel pool (see Figure $3-4$ ). The spent-fuel assemblies are placed in the canister basket and a lead shield plug is placed on the open end of the canister. The cask is then removed from the pool and transferred to the cask decontamination area where the water is removed from the cask and canister, the top shield plug is seal welded to the canister, and the canister is vacuum dried and backfilled with helium. The cask lid is then bolted on and the cask is decontaminated, placed on the trailer, and transported to the HSM. At the HSM, the cask lid is removed, the transfer cask is aligned with a docking port on the module, and the DSC is pulled from the cask into the module by a hydraulic ram extended through a port on the back of the module. To complete the installation, a 2-in. thick shielded door is lowered and welded in place to cover the docking port. 


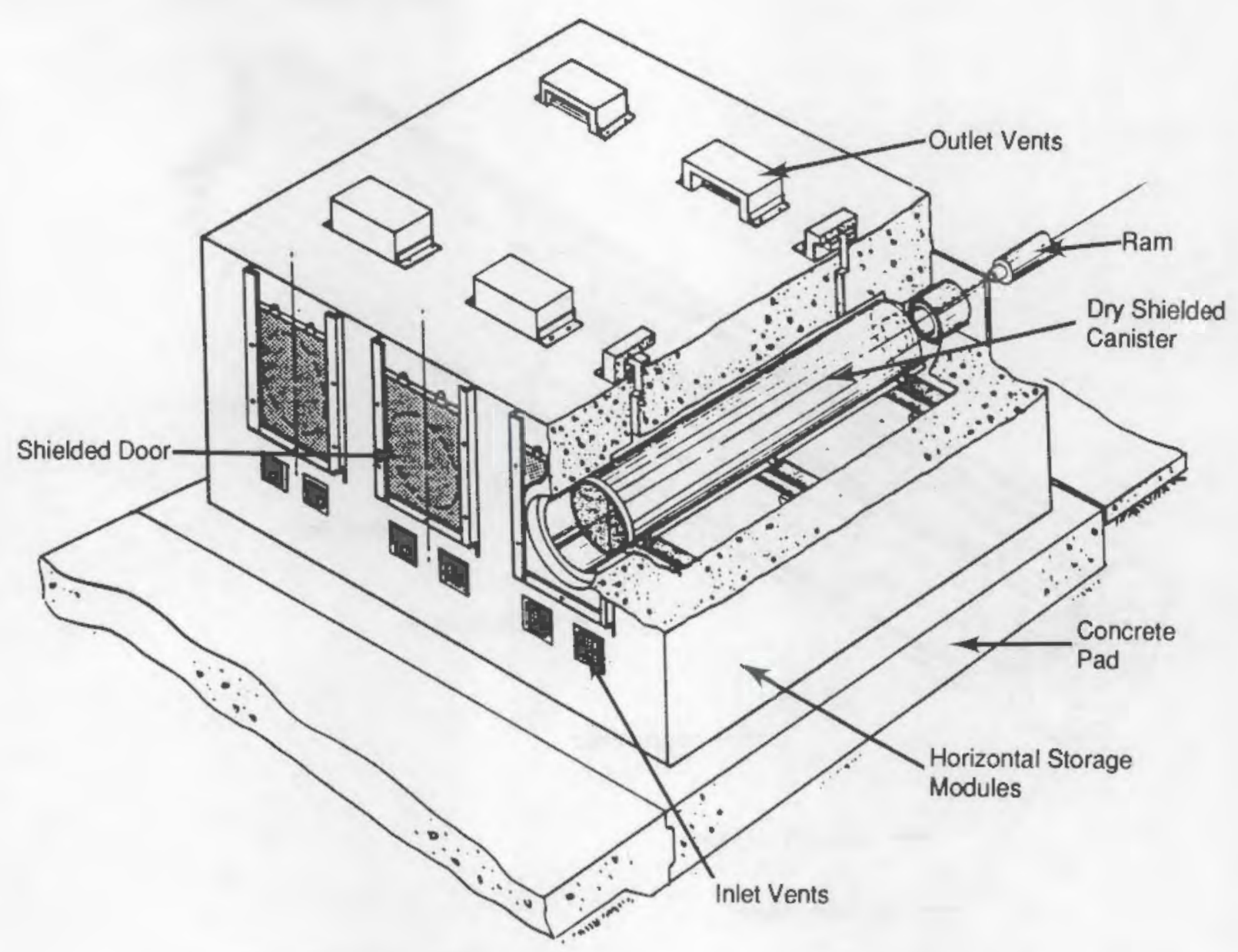

Figure 3-3. H. B. Robinson NUHOMS Dry Storage System

The 10CFR72 1icense granted CP\&L allows eight modules to be constructed on the site to store a total of 56 assemblies. However, the initial construction, and the subject of this report is the three-module installation that made up the scope of the CP\&L/DOE Cooperative Dry Storage Demonstration.

HORIZONTAL STORAGE MODULE AND ASSOCIATED INSTRUMENTATION

The horizontal storage modules constructed for the CP\&L/DOE project were built as a monolithic concrete structure with three modules (see Figure 3-5). The reinforced concrete structure is roughly $22 \mathrm{ft}$ long, $25 \mathrm{ft}$ wide, and $12 \mathrm{ft}$ high. The walls and roof of the module are approximately $3.5 \mathrm{ft}$ thick, providing the primary 


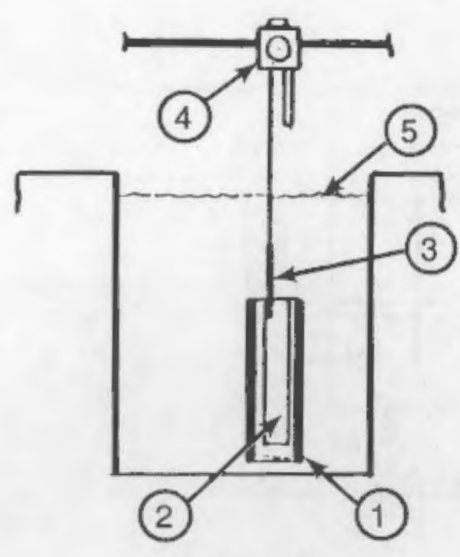

Cask Loading

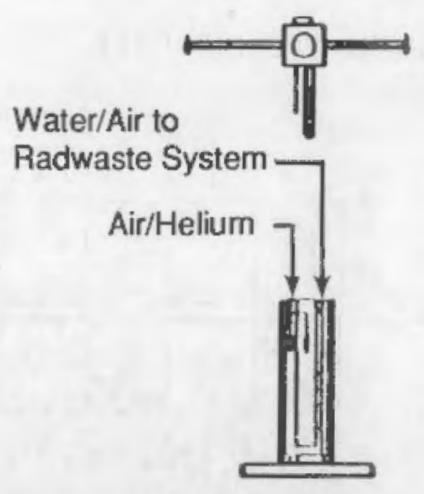

Cask/Canister Drying and Sealing
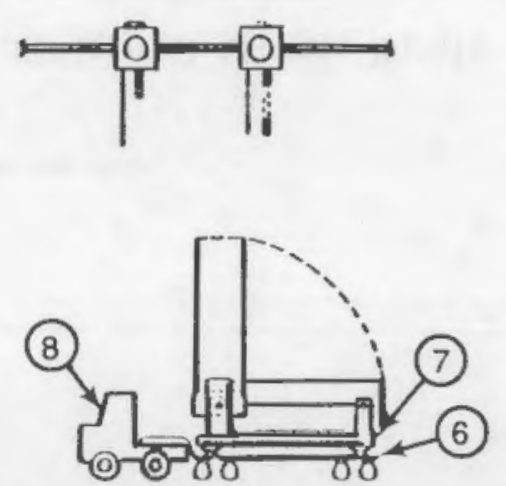

1. Transport Cask

2. Dry Shielded Canister

3. Irradiated Fuel Assembly

4. Overhead Crane

5. Irradiated Fuel Storage Pool

6. Transfer Trailer

7. Skid

8. Tow Vehicle

9. Hydraulic Positioners

10. Hydraulic Ram

11. Horizontal Storage Module

12. Horizontal Rollers

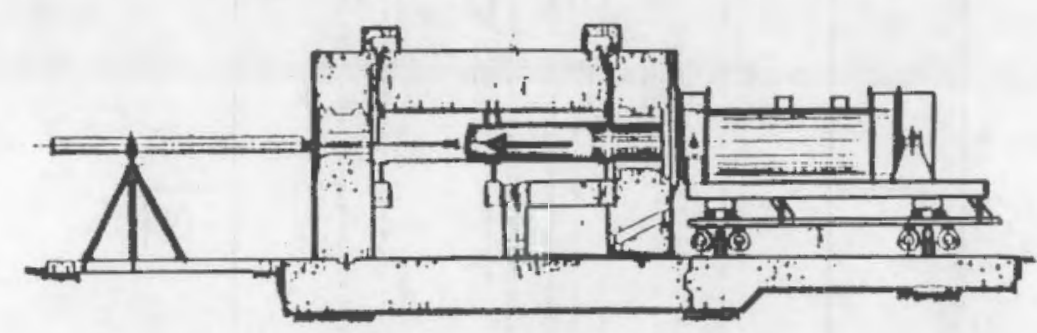

Module Loading $\underline{\text { Skid Loading }}$

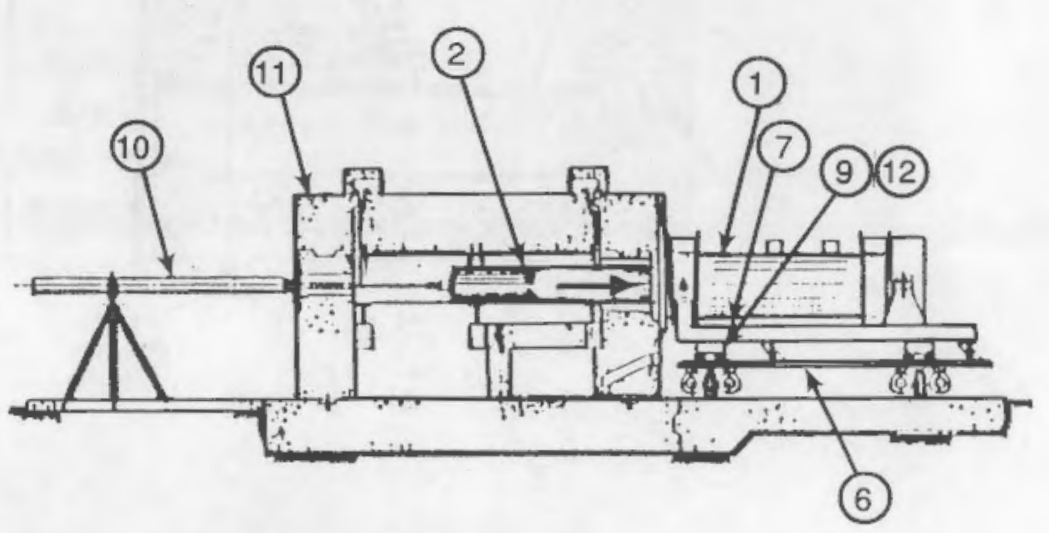

Module Unloading (Retrieval)

Figure 3-4. Basic Operations for the NUHOMS Dry Storage System 

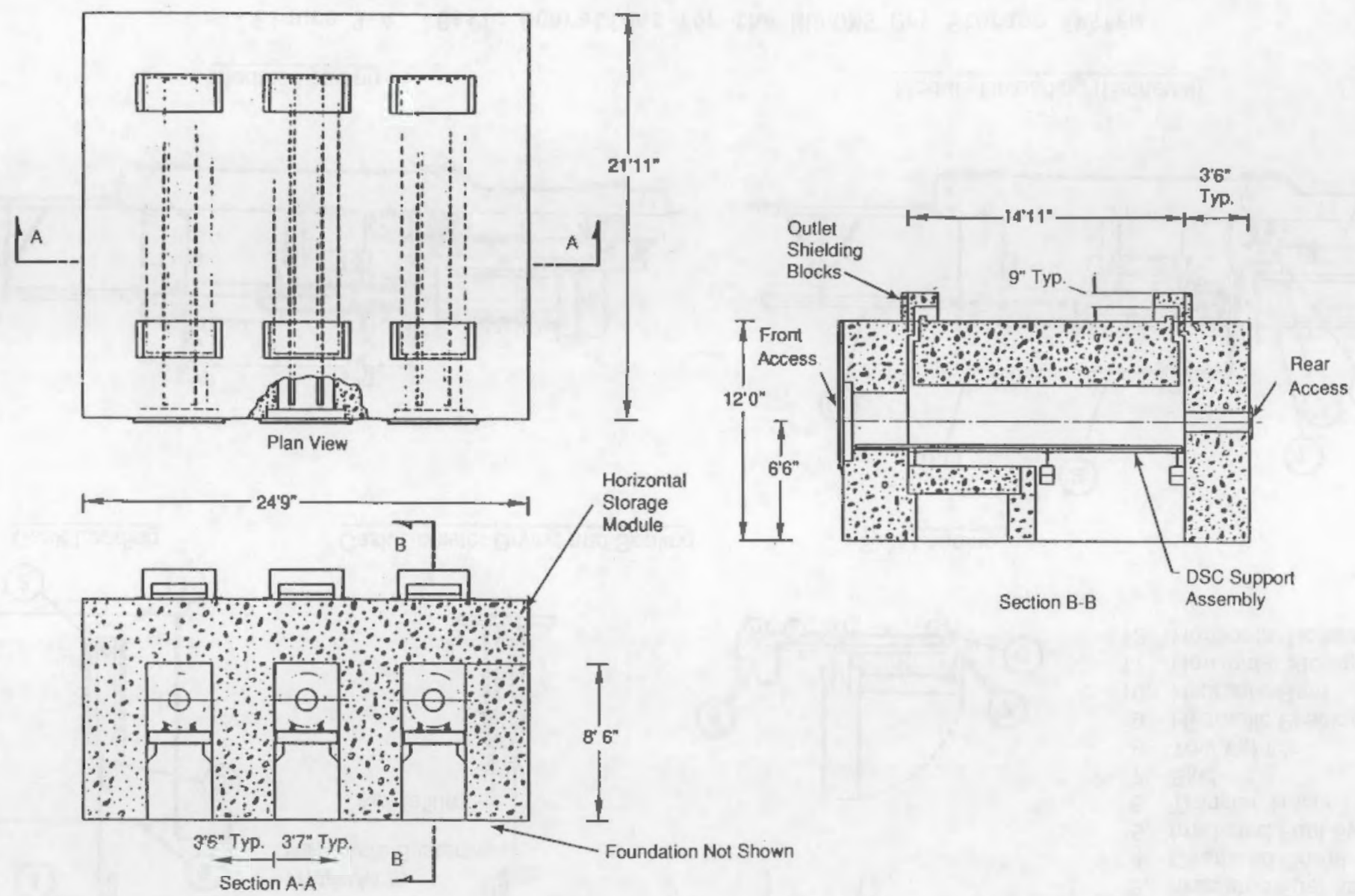

Figure 3-5. The NUHOMS Horizontal Storage Module 
biological shield and impact protection for the DSC. Each module is isolated from the others by concrete inner walls and contains a large docking port in one end and a small access port in the other. When the transfer cask is aligned with the docking port, a hydraulic ram is extended through the small access port to grapple the DSC and pull it onto a set of rails extending from the docking port toward the back of the module. When the DSC is in place, its outer skin is cooled primarily by convective air currents generated in the module by the elevated temperature of the DSC. Ambient air enters the module through two shielded vents below the docking port. It is then distributed along the length of the DSC and exits the module through two shielded vents on top of the module (see Figure 3-6).

The NUHOMS system is designed to be a totally passive storage system and requires no safety-related instrumentation. However, two of the HSMs and two DSCs were instrumented with thermocouples to provide thermal data to characterize the performance of the NUHOMS system as part of the CP\&L/DOE demonstration project.

The desire to use the CP\&L-owned General Electric IF-300 transportation cask for onsite transfers of the DSCS, in large part, determined the size and basic configuration of the NUHOMS system employed by CP\&L at the H. B. Robinson ISFSI. The generic NUHOMS system designed by PNFS consists of a basic unit of two modules arranged back-to-back (NUTECH 1984). The system is expanded with additional twomodule units placed beside the first until the required storage capacity is reached (2 $\times$ n array).

The generic configuration requires an onsite transfer cask with an access port in the bottom to allow a hydraulic ram to push the canister from the cask into the module. Since the IF-300 does not have an access port, the hydraulic ram had to be inserted through the back of the module to pull the canister into the module. To allow access to the back of the modules, the system used in the ISFSI was configured so that the three modules are side-by-side ( $1 \times 3$ array) (see Figure $3-7)$.

For reference, the modules have been arbitrarily numbered HSM-1 through HSM-3 from left to right as viewed from the docking port end (front) of the modules. The three-module monolith is symmetrical about the axial centerline of the center module (HSM-2). Taking advantage of this symmetry, half of the structure (all of HSM-3 and half of HSM-2) was instrumented with thermocouples to provide an estimate of the thermal performance of the overall structure. 


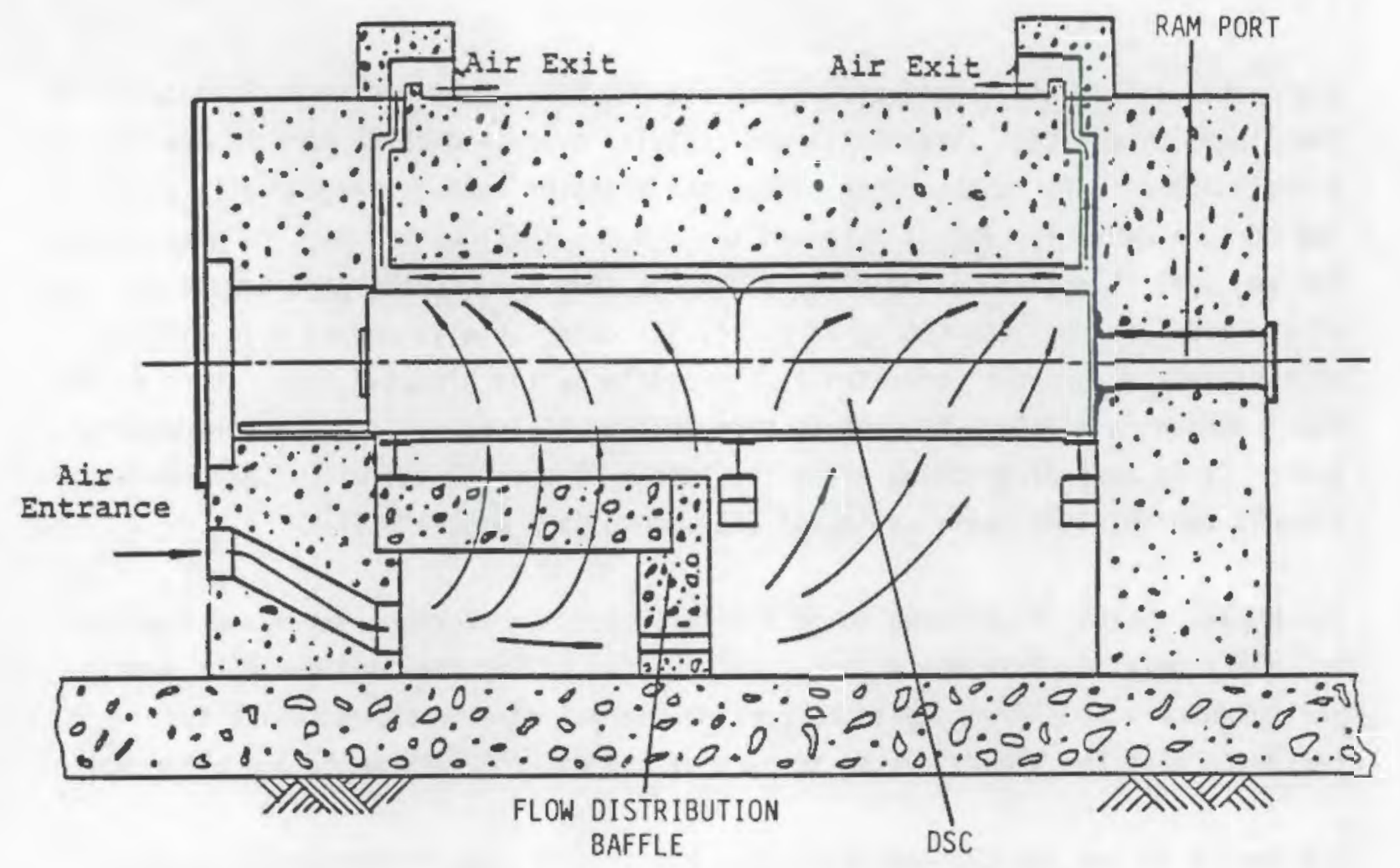

Figure 3-6. Air Flow Through the NUHOMS Dry Storage Module

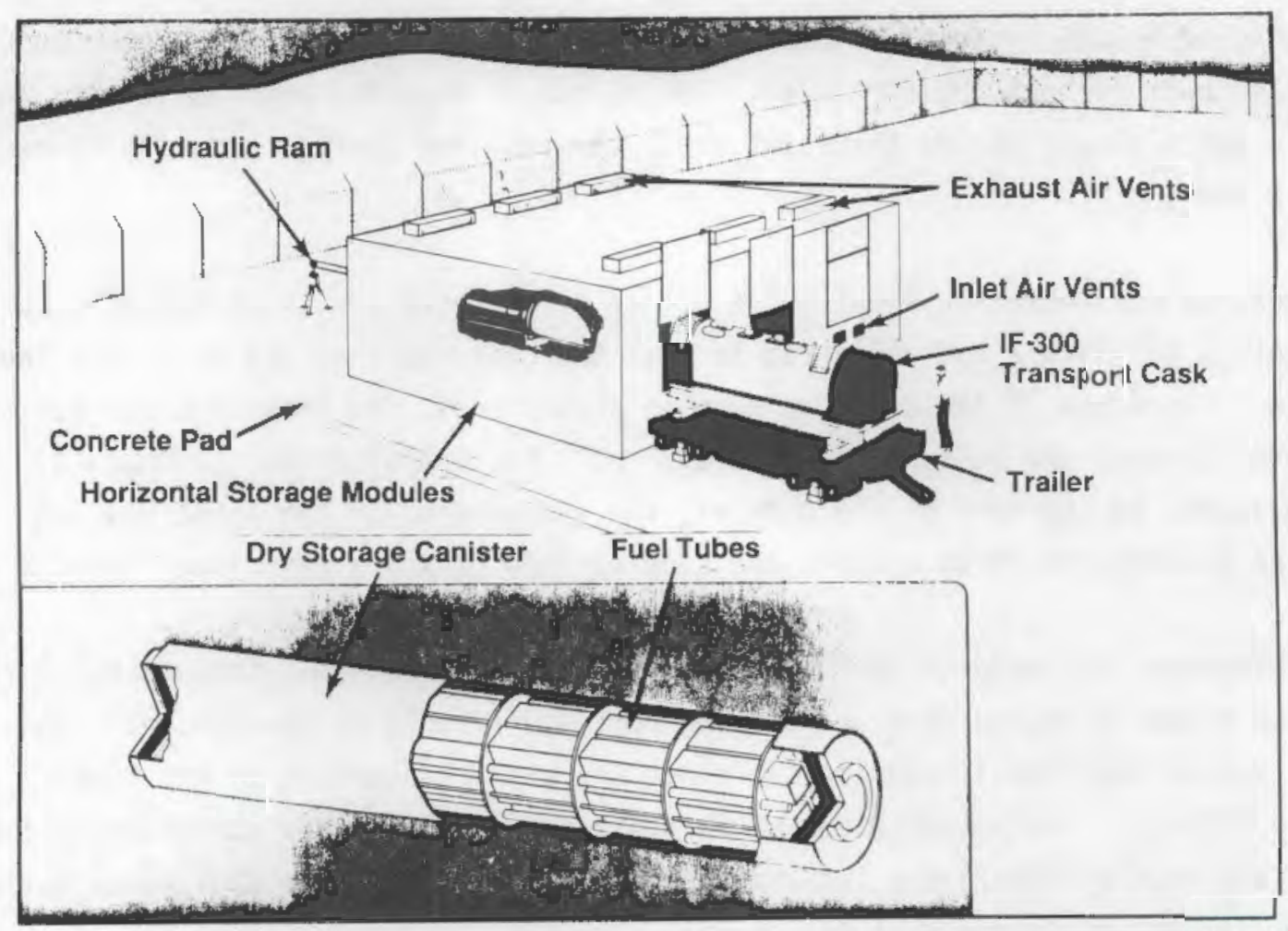

Figure 3-7. Three-Module H. B. Robinson NUHOMS System 
The two-storage modules were instrumented with 54 type $\mathrm{J}$ thermocouples (ironconstantan), most of which are imbedded in concrete in three vertical planes along the length of the storage modules, one at the axial center of the modules, and one at either end near the outlet vent (see Figure 3-8). The center array contains 18 thermocouples while the arrays near the vents contain 10 each. In addition, 16 thermocouples have been placed on the sheet metal heat shields located between the top of the canisters and the module ceilings. Each thermocouple is a continuous run of thermocouple wire from its location in the module to a terminal board near the data acquisition system. A short run of thermocouple extension wire connects the terminal board to the data acquisition system (DAS).

\section{DRY SHIELDED CANISTER AND ASSOCIATED INSTRUMENTATION}

The DSC provides the primary containment and structural support for the spent fuel assemblies in storage. The DSC consists of a stainless steel cylindrical shell with shield plugs at each end and an internal basket to support seven PWR spentfuel assemblies.

The cylindrical shell is made of rolled 0.6 -in.-thick stainless steel, 37 in. in diameter, and $180 \mathrm{in.}$ long (see Figure 3-2). The shielded end plugs contain approximately 5 in. of lead in a stainless steel casing and are welded to the outer shel1. The shield plugs reduce the radiation dose to operating personnel during canister loading, drying, and sealing operations and during transfer procedures at the HSM.

The internal basket of the DSC contains seven square fuel tubes made of a boron/ aluminum alloy with stainless steel cladding. The tubes are designed to support the fuel assemblies and maintain criticality control during the fuel-loading process in the spent-fuel pool. The fuel tubes are supported inside the canister by an assembly of seven spacer discs mounted on four longitudinal rods. The diameter of the spacer discs closely fits the inside diameter of the outer shell and is longitudinally placed to support the fuel tubes at the location of every spacer grid of the stored fuel assemblies.

During the fuel-loading process, the DSC is vacuum dried and backfilled with a helium cover gas at 1 atmosphere, then sealed with welds at all penetrations. The helium cover-gas provides an inert atmosphere to limit oxidation of the spent fuel and provides a relatively high thermal conductivity to optimize the transfer of decay heat to the outer shell of the canister. 
Top View

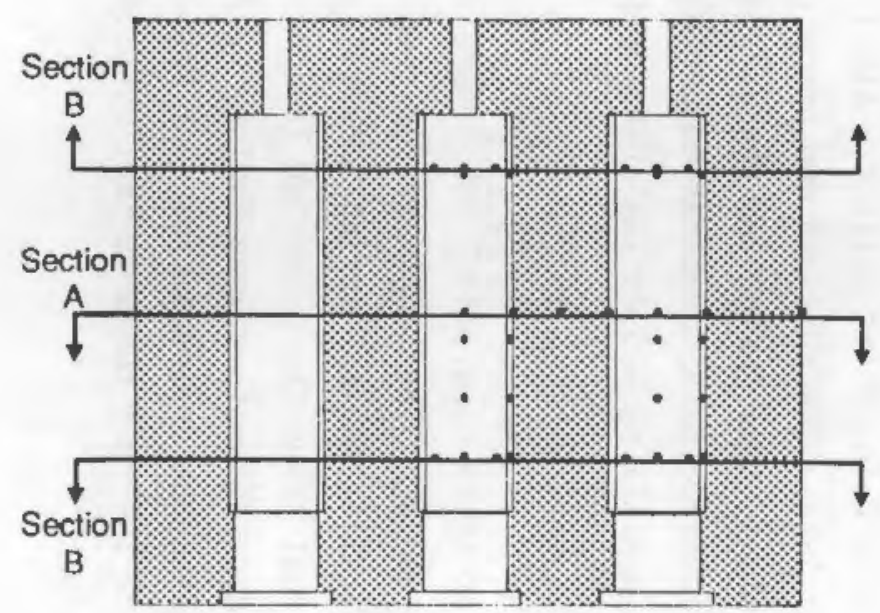

Side View

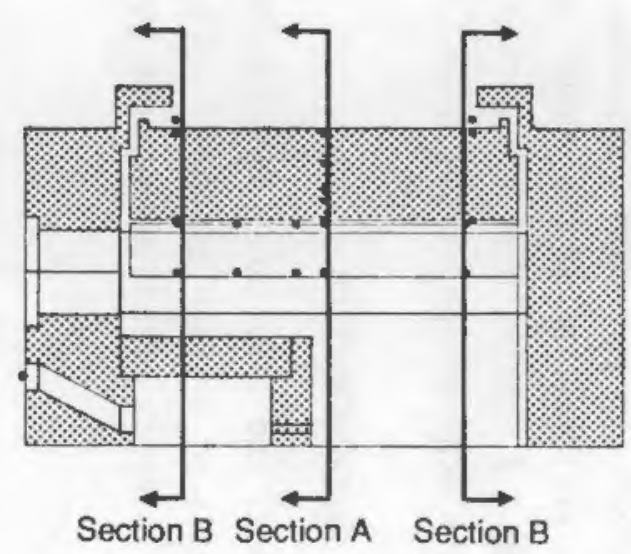

Section B Section A Section B

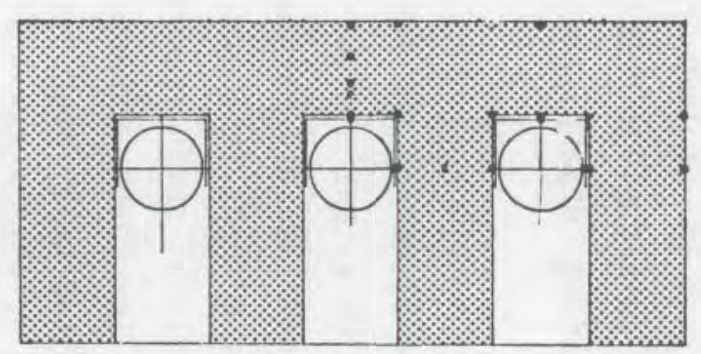

Section A

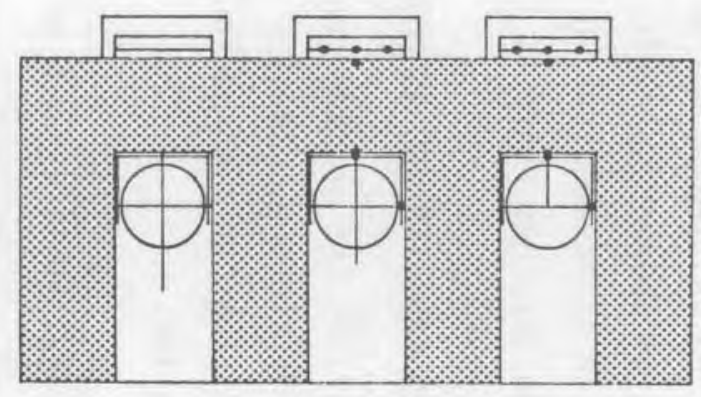

Section B

Figure 3-8. Thermocouple Locations in the Horizontal Storage Module 
Two DSCs, arbitrarily numbered DSC-1 and DSC-2, were instrumented to provide thermal data to support the CP\&L/DOE demonstration. Each DSC contains 25 type $\mathrm{J}$ thermocouples (iron-constantan) to monitor the temperature of the outer shell of the canister, the end caps, the center spacer disc, and the center guide tube in five of the stored fuel assemblies (see Figure 3-9). The thermocouple leads are routed to the end of the canister and exit through a specially designed fitting that provides a redundant seal to maintain canister integrity. The leads are then terminated in a multi-pin connector. A continuous run of thermocouple extension wire connects the mating plug to a terminal board near the data acquisition system. A short run of thermocouple extension wire connects each thermocouple pair on the terminal board to the DAS.

\section{ONSITE TRANSFER CASK}

The cask used by CP\&L to transfer the loaded DSCs from the reactor building to the ISFSI is a General Electric IF-300 transportation cask licensed by the NRC under Part 71 of Title 10, Code of Federal Regulations (10CFR72) (see Figure 3-10). The IF-300 cask is part of an irradiated fuel transportation system designed to transport spent fuel in accordance with the requirements of the NRC and the Department of Transportation (DOT). The cask can be configured to transport either PWR or boiling-water reactor (BWR) fuel by changing the internal basket and the closure head. The BWR configuration holds 18 assemblies, and the PWR version has a capacity of 7 assemblies. Both configurations weigh approximately 135,000 lb fully loaded.

The cask body is nominally 64 in. OD, 37.5 in. ID, and 169 in. long. The cask contains an inner basket that provides structural support and criticality control for the contained fuel assemblies. The cask module length varies depending on which closure head is in place; 169 in. with the PWR and 180 in. with the BWR head. The cask body, bottom, and closure head are made of stainless steel clad-depleted uranium to provide radiation shielding. The outer body of the cask is encircled by a thin-walled corrugated stainless steel water jacket extending axially over the active length of the contained fuel assemblies to provide neutron shielding. The bottom of the cask and the closure heads are fitted with an array of radial fins designed to absorb impact energy in the event of an accident (see Figure 3-10).

The use of the IF-300 cask to service the NUHOMS system at $\mathrm{H}$. B. Robinson required a configuration significantly different than the licensed configuration of the 


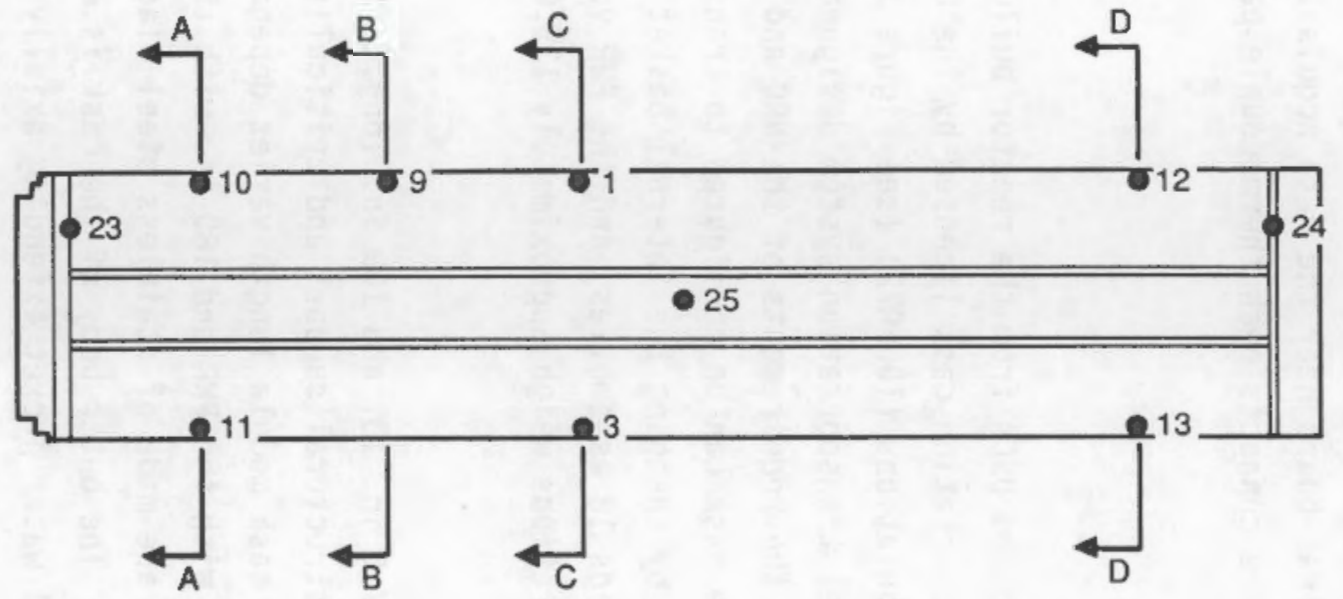

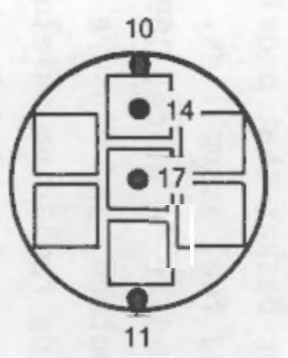

Section A-A

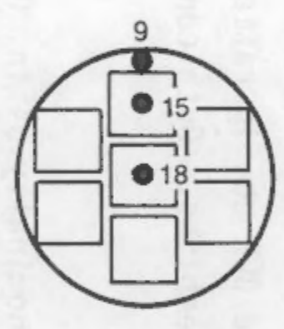

Section B-B

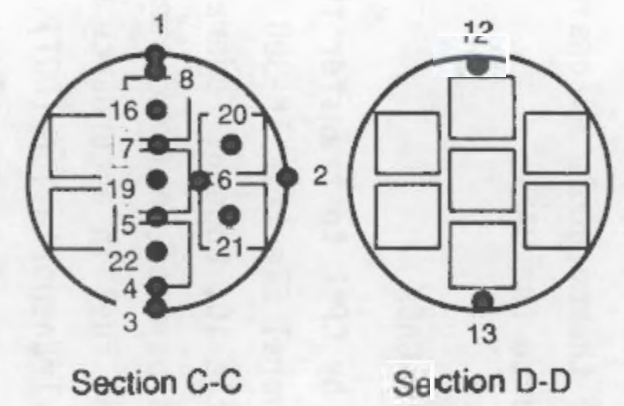

Figure 3-9. Thermocouple Locations in the Dry Shielded Canister 


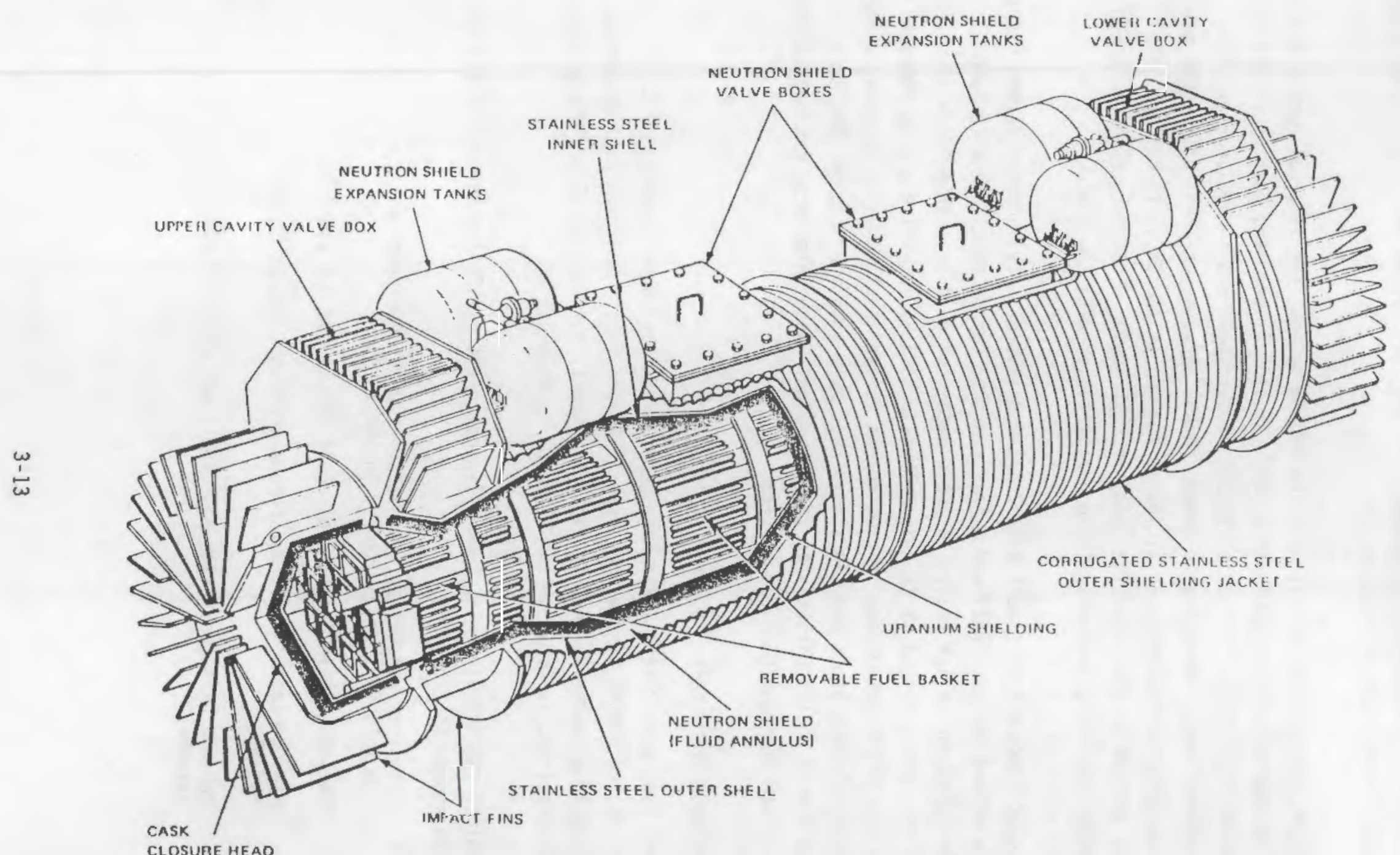

Figure 3-10. GE IF-300 Spent Fuel Transportation Cask 
cask. CP\&L was successful in modifying the configuration of the cask without making changes to the existing components of the cask system that might compromise the 10CFR71 transportation license.

To adapt the IF-300 cask for use with the NUHOMS system, the internal basket was removed to accommodate the DSCS and a new cask closure head and cask extension were designed and fabricated. The existing BWR closure head would have provided the minimum module length necessary to house the DSC; however, removal of the BWR head would have exposed approximately 11 in. of the end of the DSC. To perform this procedure outside of the spent-fuel pool or to transfer a DSC into a module would have exposed operating personnel to an unacceptable radiation field.

The new cask closure head (see Figure 3-11) consists of a cylindrical carbon steel collar to extend the cask wall and a flat circular carbon steel plate to form a 1id. The extension collar has an inside diameter of 37.4 in., an outside diameter of $49.75 \mathrm{in.}$, and a length of $12.5 \mathrm{in}$. The lid is $1.25 \mathrm{in}$. thick and is recessed into the top of the extension. The extension collar is attached to the cask using the existing closure studs and the sleeve nuts used with the original BWR head. The plate lid is bolted directly to the extension. Both interfaces are sealed with 0.25-in.-thick impregnated fiber gaskets.

\section{H. B. ROBINSON SPENT FUEL}

Individual fuel assemblies, their heat generation rates when loaded, and their locations in the NUHOMS system are shown in Figure 3-12. Specific fuel assembly data including assembly number, initial enrichment, burnup, calculated decay heat, and other pertinent information can be found in Appendix A.

The technical specifications of CP\&L's license place the following limitations on fuel to be stored in the ISFSI.

1. Only fuel assemblies irradiated at H. B. Robinson Unit 2 (15 x 15 PWR) may be stored in the ISFSI.

2. Maximum initial enrichment shall not exceed 3.5 wt\% $235 \mathrm{U}$.

3. Maximum assembly average burnup sha11 not exceed 35,000 MWd/MTU.

4. Maximum heat generation rate shall not exceed $1 \mathrm{~kW}$ per fuel assembly. 


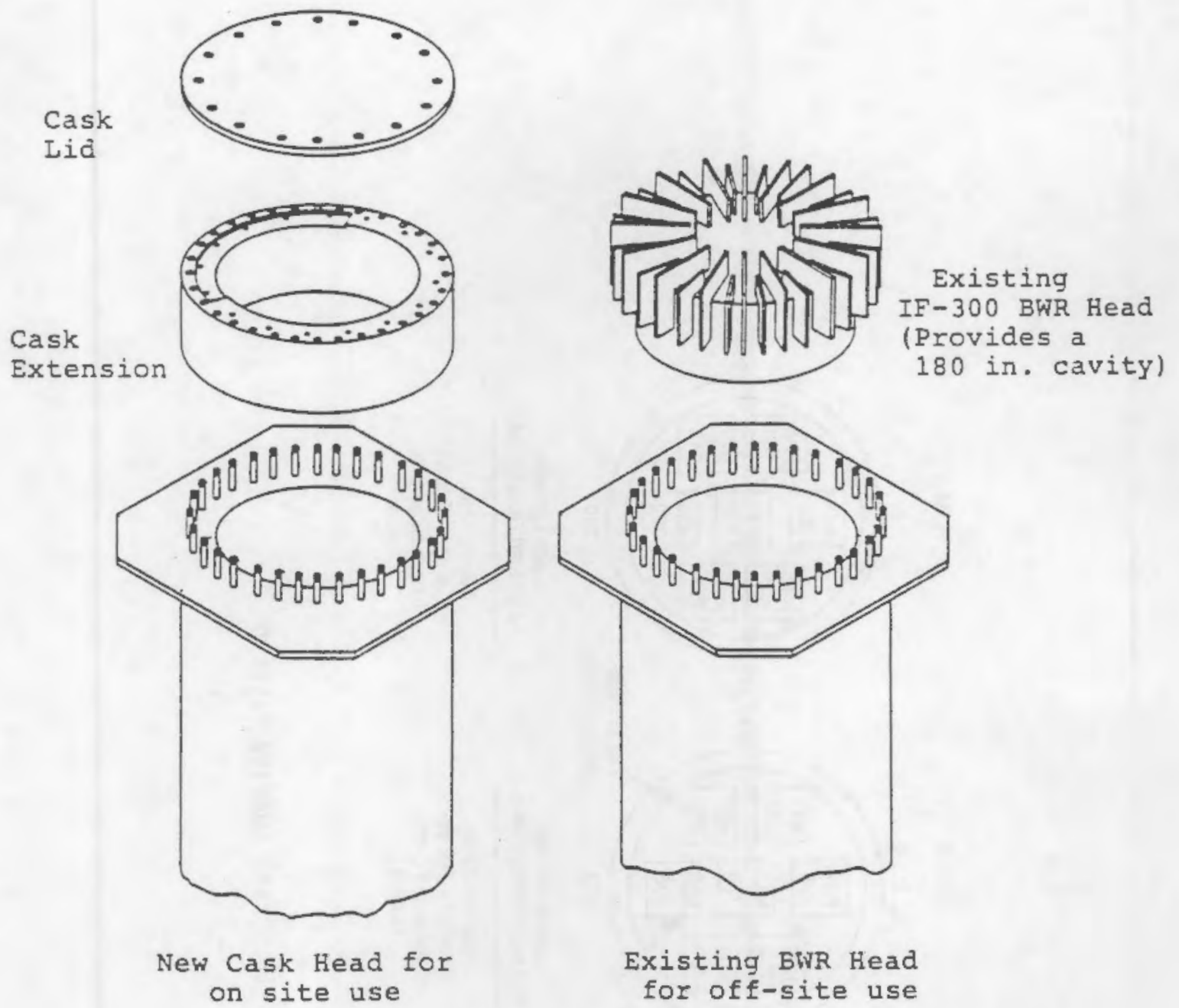

Figure 3-11. Cask Extension and Lid for the IF-300 Transportation Cask

5. Fuel assemblies shall have cooled a minimum of five years after reactor discharge and prior to storage in the ISFSI.

6. Fuel assemb1ies shall be intact, unconsolidated fuel.

7. Maximum assembly mass shal1 not exceed $660 \mathrm{~kg}$.

8. Prior to insertion of a spent-fuel assembly into a DSC, the identity of the assembly shall be independently verified.

The fuel assemblies are square in cross section, nominally 8.426 in. per side, and have a total length of 159.710 in. The fuel column was 144 in. long. The overall configuration is shown in Figure 3-13. 


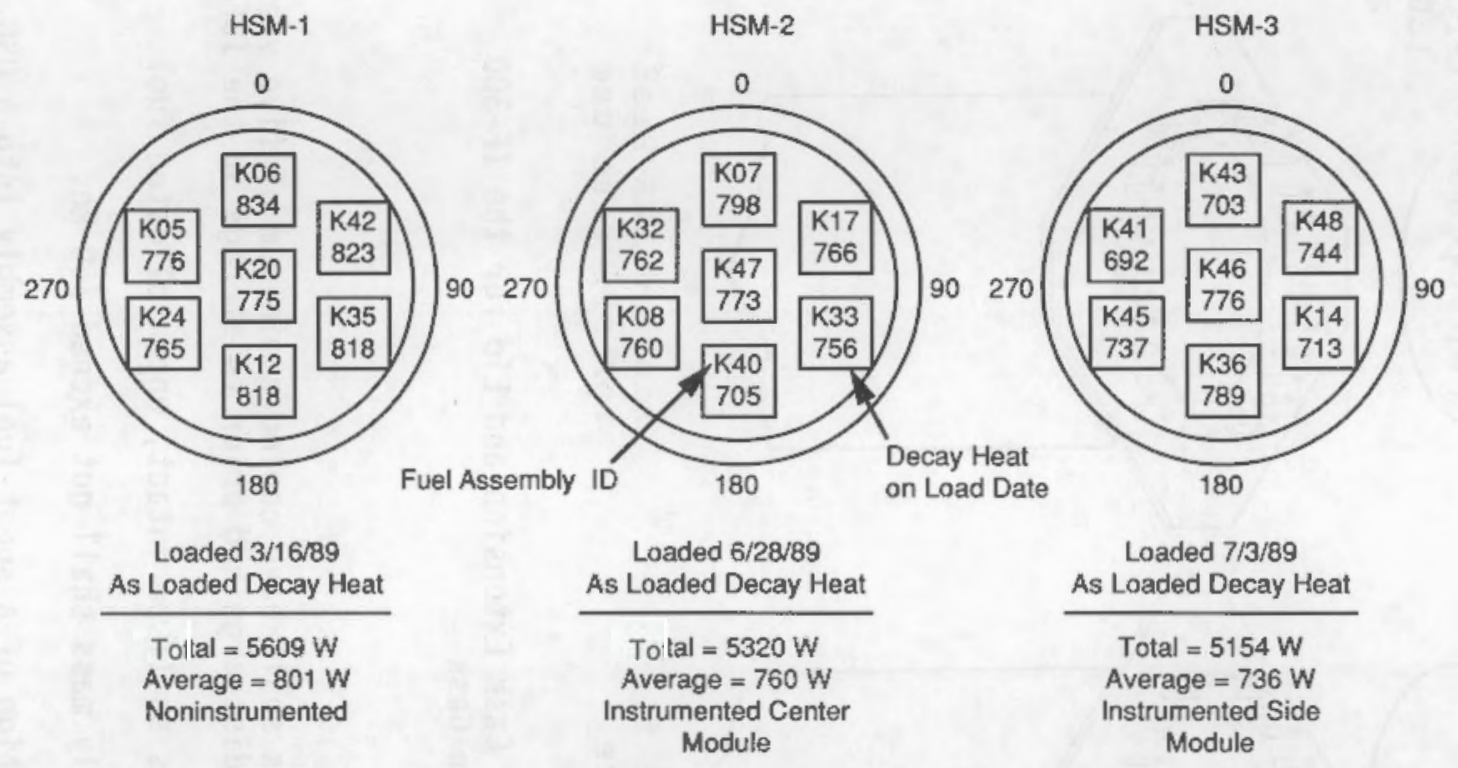

Figure 3-12. Fuel Loading Pattern 


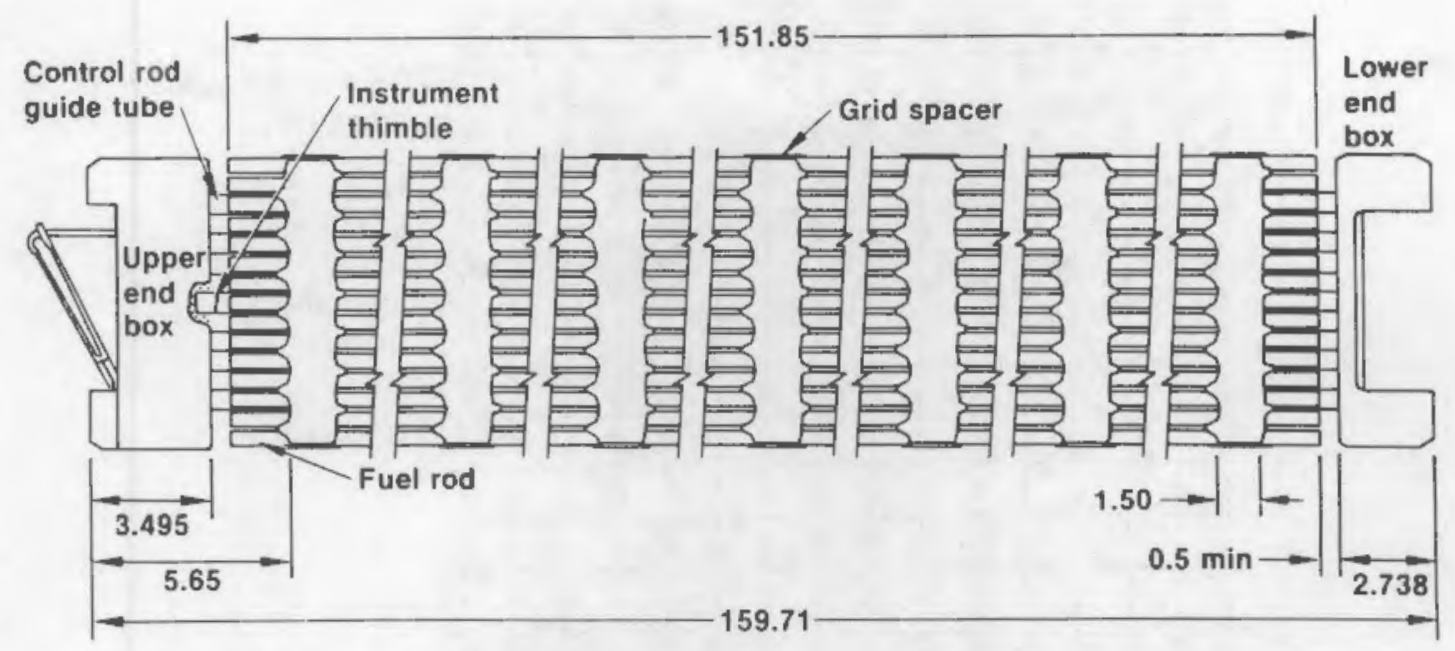

Figure 3-13. H. B. Robinson $15 \times 15$ PWR Fuel Assembly Side View (dimensions in inches)

The fuel rods in a fuel assembly are arranged in a square array with 15 rod locations per side and a nominal rod-to-rod centerline pitch of $0.563 \mathrm{in}$., as shown in Figure 3-14. Of the possible 225 rod locations per assembly, 20 are occupied by guide tubes for control rods and burnable poison rods, and one central thimble is reserved for in-core instrumentation. The remaining 204 locations contain fuel rods.

In addition to fuel rods, a fuel assembly includes a top nozzle, a bottom nozzle, and seven grid spacers. The 20 guide tubes and central thimble, in conjunction with the grid spacers and the top and bottom nozzles, form the basic structure of the fuel assembly. The top and bottom ends of the guide tubes are fastened to the top and bottom nozzles, respectively. The grid spacers are fastened to the guide tubes at each location along the length of the fuel assembly at which lateral support for the fuel rods is required. Within this skeletal framework, the fuel rods are contained and supported, and the rod-to-rod centerline spacing is maintained along the assembly.

\section{DATA ACQUISITION SYSTEM}

As part of the CP\&L/DOE demonstration project, two HSMs and two DSCs were instrumented with thermocouples (TC) to provide the data necessary to evaluate the 


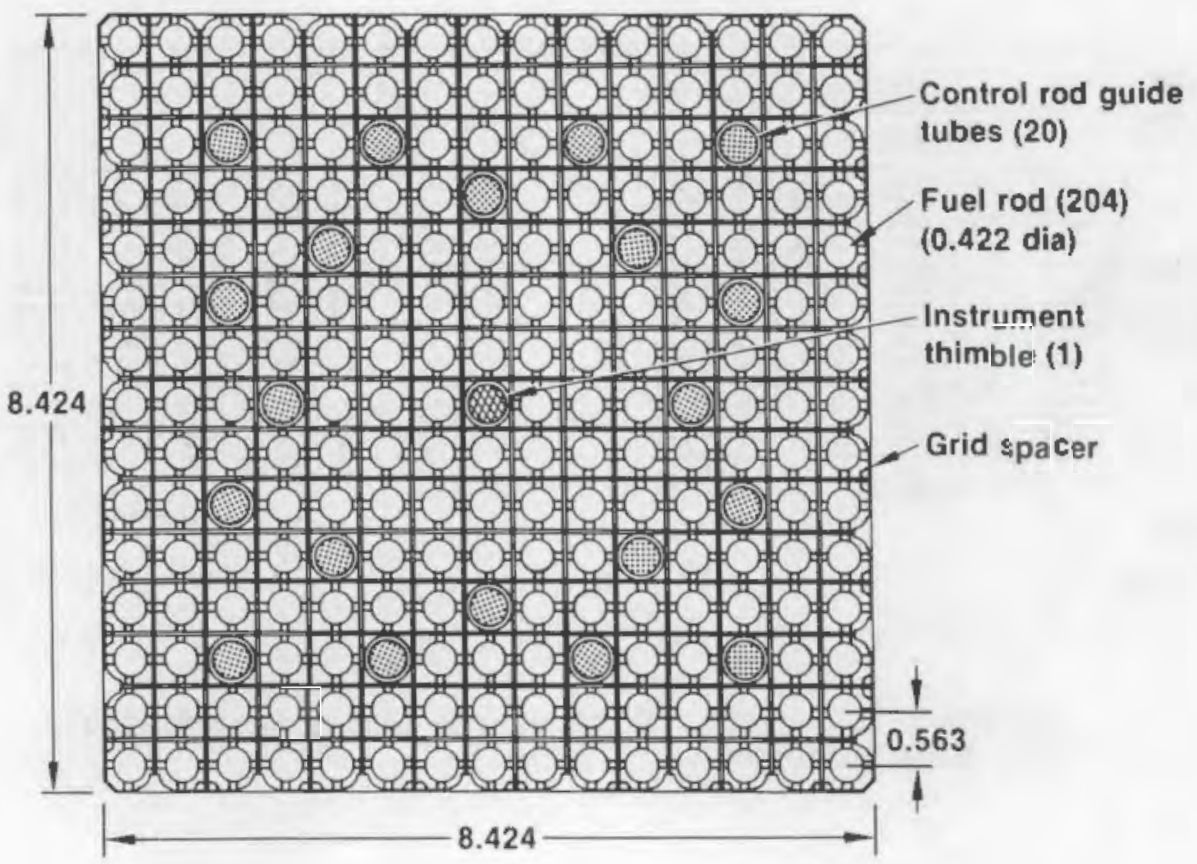

Figure 3-14. H. B. Robinson $15 \times 15$ PWR Fuel Assembly Cross Section (dimensions in inches)

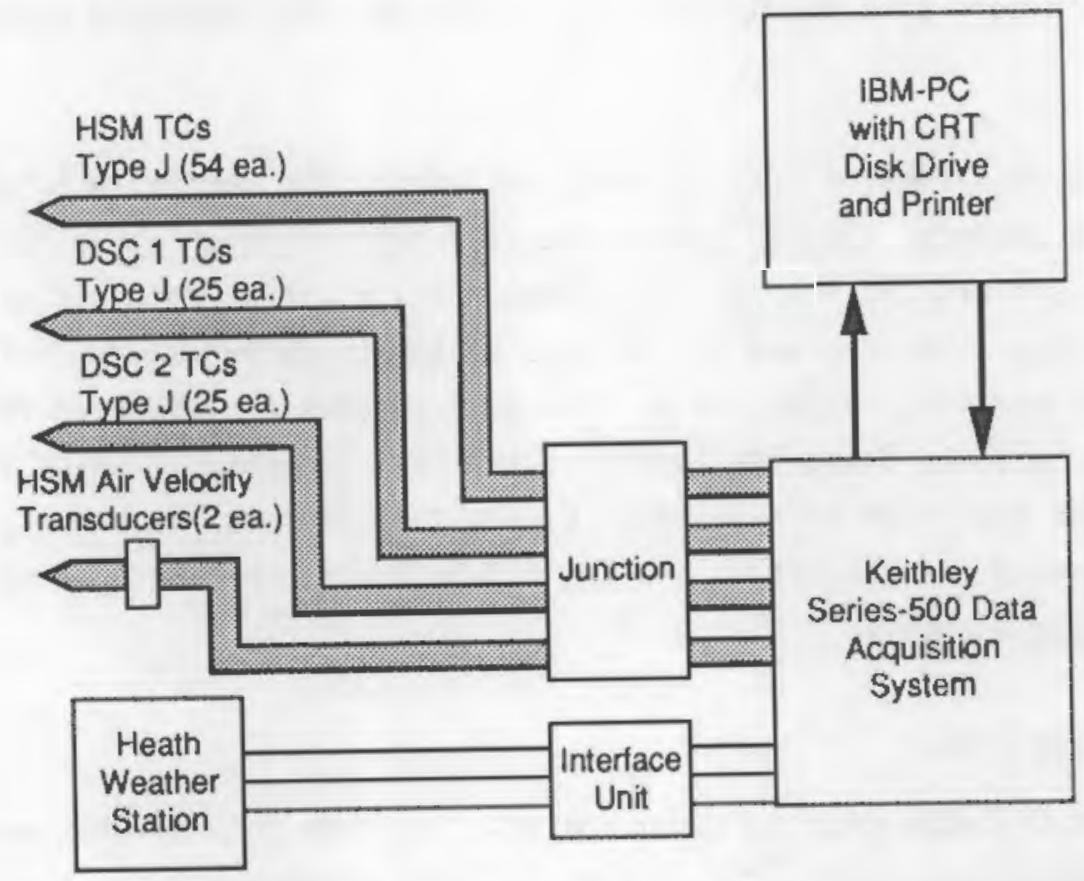

Figure 3-15. Schematic of Data Acquisition System for H. B. Robinson ISFSI 
performance of the NUHOMS system. A Keithley Series $500^{\circ}$ DAS was used to read and store the data from the TCs installed in the modules and the canisters. A simplified schematic of the DAS is shown in Figure 3-15.

The Keithley Series 500 DAS is a general-purpose data acquisition and control system made up of an IBM-XT computer and a Keithley Series 500 mainframe. The Keithley mainframe provides an intelligent interface between the instrumentation sensors and the computer. The IBM-XT is used to reduce the data and controls the operation of the system. The computer was configured with a CRT monitor, a printer, and hard disk and floppy disk drives.

The Keithley Series 500 mainframe is a modular system, centered around a low-noise chassis containing a precision power supply and back-plane with slots for 10 plugin input/output $(\mathrm{I} / 0)$ modules. The $\mathrm{I} / \mathrm{O}$ family of modules provides all of the conditioning, conversion, and control capability needed for most laboratory and industrial automation tasks. Analog input, analog output, digital input, and digital output can be conditioned by one of the I/0 modules.

For this configuration, the mainframe contained an analog-to-digital converter $(A D C)$, a multiplexer, and eight low-level voltage input modules (Keithley type-AIM3) suitable for thermocouples. Each module conditions 16 inputs and a reference junction to provide cold-junction compensation of thermocouple data. Several of the 128 inputs were configured to condition wind speed and direction signals from a small weather station and input from two air flow transducers mounted in the outlets of the modules.

Signals from the Keithly Series 500 mainframe were received, converted to engineering units, and stored on the hard disk in the IBM-XT. Additional data processing and printing could be performed on the system computer or the data could be transferred to a floppy disk for processing on other systems.

"Keithly Series 500 is a registered trademark of Keithly Instruments, Incorporated, Cleveland, Ohio.

-IBM-XT is a registered trademark of IBM Manufacturing Systems Products, Boca Raton, Florida. 
DATA UNCERTAINTY ESTIMATES

As a first step in the reduction of the test data, critical components of the test system were tested to verify proper operation and each was evaluated to determine its probable accuracy. The components critical to these tests were the electric heaters and their power controller, the DSC- and HSM-mounted thermocouples, the airflow transducers, the DAS, and the radiological instruments. The validation of each component and its probable accuracy are discussed below.

\section{Electric Heaters and Power Controller}

During the electrically heated test runs, simulated decay heat was supplied by seven 2-kW heaters; one heater in each of the seven canister fuel storage sleeves. The power to the heaters was regulated by a common power controller that was adjustable from $0 \%$ to $100 \%$ of the rated power of the heaters.

The heaters used were Chromalox calrod units manufactured by the Emerson Electric Company. The manufacturer reports the production-line accuracy of the power rating of these units to be $\pm 5 \%$.

The power controller used to vary the power of the heaters during the tests was a proportional controller manufactured by the Emerson Electric Company. The unit controlled the power to the heaters by utilizing a time-on, time-off proportioning scheme with a cycle time of about 0.75 seconds. A series of tests was performed on the power controller to determine its linearity and accuracy. The tests indicated that heater power was not a linear function of the control setting, and a curve was developed relating the control settings to actual heater power. The curve is shown in Figure 3-16. The curve is judged to be accurate to within $\pm 1 \%$.

The heater powers used in this report have been adjusted to the values indicated by the developed heater power curve and are considered accurate to within $\pm 5 \%$.

\section{DSC and HSM Thermocouples}

The thermocouples installed in the NUHOMS system were tested for proper operation using two criteria. First, a continuity test of all thermocouples was performed in October 1989. Thermocouples with resistance readings of $100 \mathrm{ohms}$ or higher were judged to be defective. Second, all the data from each thermocouple was plotted and reviewed for predictable behavior. Thermocouples exhibiting erratic behavior 


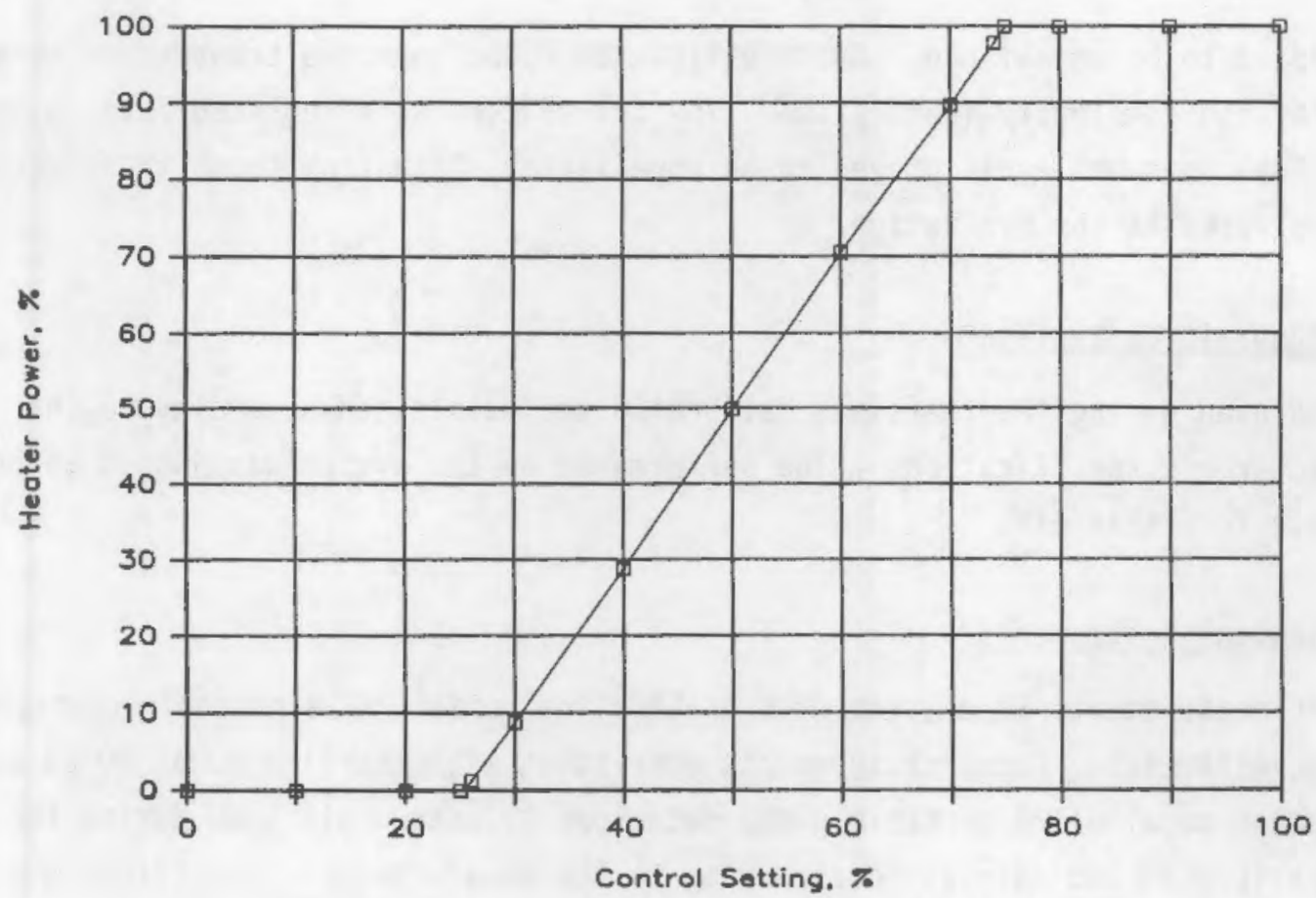

Figure 3-16. Heater Controller Performance Curve

from electrical noise or abrupt shifts in apparent temperature, not reflected by adjacent thermocouples, were judged to be defective. Data from all defective thermocouples were deleted from the data sets used in the evaluation.

As with any data collection effort, a statistical uncertainty exists in the absolute value of the temperatures recorded by the DAS. The uncertainty reflects the combined effect of the statistical error probability of each component in the instrumentation system.

An analysis (see Appendix B) was performed to determine the overall uncertainty of the instrumentation system used to record temperature in the NUHOMS system. The results of the analysis indicated the uncertainty for temperatures in the DSC and the HSM were $\pm 4^{\circ} \mathrm{C}$.

\section{Air Flow Transducers}

Two airflow transducers were installed in the module air inlets during the electrically heated test runs. The early data from the transducers were erratic 
and judged to be unreliable. An investigation found that the transducers were full of water and completely inoperative. The transducers were replaced late in the spent fuel test but again proved to be unreliable. Data from these transducers were not used in the evaluation.

\section{Data Acquisition System}

The DAS used during the tests was calibrated and maintained according to the manufacturer's specifications. The performance of the system was judged to be accurate to within $\pm 1 \%$.

\section{Radiological Instruments}

Neutron measurements were taken with an Eberline model PNR-4 portable neutron survey instrument. Gamma measurements were taken with Eberline model R0-2A and Teletector model $6112 \mathrm{~B}$ portable gamma detectors. Instruments used during the tests were calibrated and maintained according to the manufacturer's specifications.

\section{TEST PLAN}

Early in the design of the H. B. Robinson ISFSI, a test plan was developed to evaluate the performance of the NUHOMS system. The test plan contains a series of test runs and procedures designed to accomplish three objectives: 1) verify the adequacy of system hardware and procedures, 2) satisfy ISFSI technical specifications, and 3) provide training exercises for CP\&L personnel who will be operating the NUHOMS system. The test plan was also intended to provide information to verify computer models, aid future NUHOMS licensing efforts, and add to the database concerning the behavior of spent fuel in dry storage.

The test plan contains preoperational and operational tests in three areas of concern: 1) component handling, 2) heat transfer and thermal hydraulics, and 3) radiation shielding. The purpose of the handling tests was to verify that the hardware and procedures were adequate to perform the operations required to load the DSC, transfer it to the modules, and insert and retrieve it. The tests were intended to identify deficiencies, streamline the operating procedures, and provide training exercises for loading and handling activities as required by the technical specifications.

\footnotetext{
'Eberline is a registered trademark of Eberline Instrument Corp., Santa Fe, New Mexico.
} 
The heat transfer and thermal hydraulic tests were designed to 1) verify the thermal performance of the NUHOMS system under normal and accident conditions, 2) validate the heat transfer and thermal hydraulic analyses, 3) identify the level of conservatism in the licensing analyses, and 4) provide data for the heat transfer and thermal hydraulic behavior of spent fuel in horizontal dry storage. The purpose of the radiation shielding test was to verify that the NUHOMS system provides adequate shielding from nuclear radiation.

The test matrices for the handling, heat transfer and thermal hydraulics, and radiation shielding tests are presented in Tables $3-1,3-2$, and $3-3$, respectively. The results of the test are discussed in Section 4 .

\section{OPERATIONAL EXPERIENCE WITH THE NUHOMS SYSTEM}

This section describes the operational experience gained during fuel loading, testing, and performance monitoring of the NUHOMS system. Tasks required to perform fuel loading of the NUHOMS modules included assessment of facilities and equipment, documentation development, operational training, DSC receipt and preparation, cask receipt and preparation, operational dry runs, load tests, air evacuation tests, cask/DSC performance tests, annulus seal tests, weld mockups and weld improvement, coating of DSCs, spent-fuel selection and inspection, vacuum drying, helium back-filling and leak testing, trailer loading, transport to modules, trailer/skid alignment, loading with hydraulic ram and HSM closure, radiation dose control, contamination control, measuring of HSM contact doses, environmental monitoring, and long-term surveillance/inspections.

Due to its demonstrative nature, the loading of spent fuel in the NUHOMS modules was preceded by extensive procedure and documentation development, dry run testing, and the use of mockups. Some challenges were created by the design of the data acquisition instrumentation, a feature unique to the demonstration modules, which will not be part of future NUHOMS designs. Dry runs to shake down procedures and equipment and to train personnel were key to the successful loading of the NUHOMS modules.

\section{Facilities and Equipment}

Existing equipment at the H. B. Robinson plant was utilized to the greatest extent possible. Since spent fuel had been shipped in the late 1970s, a majority of the 
Table 3-1

HANDLING TEST MATRIX

\begin{tabular}{|c|c|c|c|}
\hline Test Number & Location & Purpose & Data Collection \\
\hline $\mathrm{H}-1$ & HSM & $\begin{array}{l}\text { Test positioning con- } \\
\text { trols and pulling } \\
\text { capabilities of ram }\end{array}$ & $\begin{array}{l}\text { - Deflection of extended } \\
\text { ram }\end{array}$ \\
\hline $\mathrm{H}-2$ & $T B A^{a}$ & $\begin{array}{l}\text { Test positioning con- } \\
\text { trols of skid and } \\
\text { trailer }\end{array}$ & $\begin{array}{l}\text { - Longitudinal movement } \\
\text { of skid on trailer } \\
\text { - Lateral movement of } \\
\text { skid on trailer } \\
\text { - Maximum and minimum } \\
\text { height of trailer } \\
\text { - Rotation of skid about } \\
\text { front and rear rollers }\end{array}$ \\
\hline$H-3$ & HSM & $\begin{array}{l}\text { Test adequacy of } \\
\text { al ignment hardware } \\
\text { and procedures }\end{array}$ & - Operational test \\
\hline$H-4$ & $\begin{array}{l}\text { Cask } \\
\text { handling } \\
\text { area }\end{array}$ & $\begin{array}{l}\text { - Test fit of DSC and } \\
\text { cask }\end{array}$ & - Optional test \\
\hline & HSM & $\begin{array}{l}\text { - Test DSC loading } \\
\text { and retrieval of } \\
\text { hardware and pro- } \\
\text { cedures }\end{array}$ & \\
\hline$H-5$ & $T B A^{a}$ & $\begin{array}{l}\text { - Test seal welding } \\
\text { equipment and } \\
\text { procedure } \\
\text { - Test NDE procedures }\end{array}$ & - Weld defects \\
\hline
\end{tabular}

aTBA - to be announced. 
Table 3-2

HEAT TRANSFER TEST MATRIX

\begin{tabular}{|c|c|c|c|c|c|c|c|}
\hline $\begin{array}{l}\text { Run } \\
\text { No. } \\
\end{array}$ & $\begin{array}{l}\text { Location } \\
\text { of DSC } \\
\end{array}$ & $\begin{array}{c}\text { DSC } \\
\text { Atmosphere }\end{array}$ & $\begin{array}{l}\text { Operating } \\
\text { Conditions }\end{array}$ & $\begin{array}{c}\text { Heat } \\
\text { Source } \\
\end{array}$ & $\begin{array}{c}\text { Power } \\
\text { Level (KW) }\end{array}$ & $\begin{array}{l}\text { Duration } \\
(\mathrm{hr})\end{array}$ & Date \\
\hline HT-1 & Cask & Water & Normal & $\begin{array}{l}\text { Electric } \\
\text { heater }\end{array}$ & 7 & 40 & $\begin{array}{l}\text { - Temperatures of DSC and } \\
\text { cask }\end{array}$ \\
\hline HT -2 & Cask & Vacum & Normal & $\begin{array}{l}\text { Electric } \\
\text { heater }\end{array}$ & 7 & 24 & $\begin{array}{l}\text { - Temperatures of DSC and } \\
\text { cask } \\
\text { - Pressure of DSC }\end{array}$ \\
\hline HT -3 & Cask & Air & Normal & $\begin{array}{l}\text { Electric } \\
\text { heater }\end{array}$ & 7 & 52 & $\begin{array}{l}\text { - Temperatures of DSC and } \\
\text { cask } \\
\text { - Pressure of DSC }\end{array}$ \\
\hline НT -4 & Cask & Hel ium & Normal & $\begin{array}{l}\text { Electric } \\
\text { heater }\end{array}$ & 7 & 72 & $\begin{array}{l}\text { - Temperatures of DSC and } \\
\text { HSM } \\
\text { - Pressure of DSC } \\
\text { - Air and temperature } \\
\text { velocity through HSM } \\
\text { - Weather }\end{array}$ \\
\hline HT -5 & HSM & Helium & Norma! & $\begin{array}{l}\text { Electric } \\
\text { heater }\end{array}$ & 7 & 72 & $\begin{array}{l}\text { - Temperatures of DSC and } \\
\text { HSM } \\
\text { - Pressure of DSC } \\
\text { - Air and temperature } \\
\text { velocity through HSM } \\
\text { - Weather }\end{array}$ \\
\hline HT -6 & HSM & Hel ium & $\begin{array}{l}\text { Accident-- } \\
\text { complete } \\
\text { blockage of } \\
\text { all inlets }\end{array}$ & $\begin{array}{l}\text { Electric } \\
\text { heater }\end{array}$ & 7 & 48 & $\begin{array}{l}\text { - Temperatures of DSC and } \\
\text { HSM } \\
\text { - Pressure of oSC } \\
\text { - Air and temperature } \\
\text { velocity through HSM } \\
\text { - Heather }\end{array}$ \\
\hline HT-7 & HSM & Hel ium & $\begin{array}{l}\text { Accident-- } \\
\text { complete } \\
\text { blockage of } \\
\text { all inlets } \\
\text { and outlets }\end{array}$ & $\begin{array}{l}\text { Electric } \\
\text { heater }\end{array}$ & 7 & 48 & $\begin{array}{l}\text { - Temperatures of DSC and } \\
\text { HSM } \\
\text { - Pressure of OSC } \\
\text { - Air and temperature } \\
\text { velocity through HSM } \\
\text { - Weather }\end{array}$ \\
\hline HT -8 & HSM & Helium & Normal & $\begin{array}{l}\text { Electric } \\
\text { heater }\end{array}$ & 1 to 22 & 300 & $\begin{array}{l}\text { - Temperatures of DSC and } \\
\text { HSM } \\
\text { - Pressure of DSC } \\
\text { - Air and temperature } \\
\text { velocity through HSM } \\
\text { - Weather }\end{array}$ \\
\hline HT-9 & HSM & Air & Normal & $\begin{array}{l}\text { Electric } \\
\text { heater }\end{array}$ & 1 to 22 & 300 & $\begin{array}{l}\text { - Temperatures of DSC and } \\
\text { HSM } \\
\text { - Pressure of DSC } \\
\text { - Air and temperature } \\
\text { velocity through HSM } \\
\text { - Weather }\end{array}$ \\
\hline HT- 10 & Cask & $\begin{array}{l}\text { Water/vacum } \\
\text { hel ium }\end{array}$ & Normal & $\begin{array}{l}\text { Irradiated } \\
\text { fuel }\end{array}$ & a & - & - Temperature of cask \\
\hline HT-11 & HSM & Hel ium & Normal & $\begin{array}{l}\text { Irradiated } \\
\text { fuel }\end{array}$ & a & $6 \mathrm{mo}$ & $\begin{array}{l}\text { - Temperatures of fuel, } \\
\text { DSC, and HSM } \\
\text { - Air and temperature } \\
\text { velocity through HSM } \\
\text { - Weather }\end{array}$ \\
\hline
\end{tabular}

aased on irradiated fuel. 
Table 3-3

RADIATION SHIELDING TEST MATRIX

\begin{tabular}{|c|c|c|c|}
\hline $\begin{array}{l}\text { Test } \\
\text { No. }\end{array}$ & Timing & Purpose/Comment & Location \\
\hline $\mathrm{R}-1$ & Preoperational & $\begin{array}{l}\text { Obtain background radiation } \\
\text { during full-power operation and } \\
\text { shutdown mode of HBR Unit } 2\end{array}$ & $\begin{array}{l}\text { As specified by the } \\
\text { plant's existing } \\
\text { radiation monitoring } \\
\text { procedures }\end{array}$ \\
\hline$R-2$ & $\begin{array}{l}\text { Fuel loading } \\
\text { operations }\end{array}$ & $\begin{array}{l}\text { Obtain radiation levels } \\
\text { during handling and storage } \\
\text { operation }\end{array}$ & $\begin{array}{l}\text { - DSC surfaces } \\
\text { - Cask surface } \\
\text { - HSM surface and } \\
\text { inlet/outlets }\end{array}$ \\
\hline$R-3$ & Post loading & $\begin{array}{l}\text { Monitor radiation levels of } \\
\text { HSM containing irradiated } \\
\text { spent fuel }\end{array}$ & $\begin{array}{l}\text { - HSM surfaces and } \\
\text { air inlets/outlets } \\
\text { - Perimeter of HBR- } \\
\text { ISFSI }\end{array}$ \\
\hline
\end{tabular}

facilities, equipment, and procedures were already established. The following pieces of equipment required no modifications for use with the ISFSI fuel transfer:

- $\quad$ spent fuel pool, including miscellaneous support systems

- fuel-handling tools

- fuel-handling bridge crane

- 100-ton gantry crane

- standard lifting yoke

- redundant lifting yoke

- decontamination pit staging area.

In addition, an IF-300 shipping cask was onsite and, although some additional cask equipment was required, the additional equipment costs were minor when compared with the cost and schedule impact of procuring a new transfer cask.

The use of existing equipment provided direct cost and time savings for the demonstration project. A not-as-visible savings resulted from the use of existing procedures, training, and personnel with prior experience in the transfer of spent fuel at the H. B. Robinson plant. Although almost 10 years had elapsed since the 
spent fuel transfer, existing procedures were available that could be revised, training modules on the existing equipment were still valid, and the hands-on experience of the maintenance personnel had enhanced the testing and operational process.

New facilities or equipment required for the ISFSI fuel transfer process included a vacuum drying system, a transfer trailer with an hydraulic skid, an hydraulic ram, equipment for the IF-300 cask, a DAS, and a concrete haut road between the Fuel Handling Building and the HSM.

A11 equipment was tested using "dry run" procedures to detect and resolve startup problems and provide hands-on training of personnel.

\section{Documentation Development}

One of the preoperational license conditions was that a training exercise or dry run be performed for fuel handling, loading, and unloading activities. Cask movement was also to be performed using written procedures. Coupling these requirements with the extensive test plan requirements for the demonstration project required a significant effort in developing procedures. Special procedures were developed for all testing and training activities. For fuel handling, permanent plant operating manual procedures were developed. In order to demonstrate the readiness and ability to perform according to permanent plant procedures, a final dry run was performed using the approved permanent plant procedures.

An existing fuel-handling procedure was used to begin the process of writing the special procedures for the various test requirements. All special procedures were approved using the same approval process as the permanent plant procedures.

Portions of these procedures were used during testing more than once; and each time they were reused, improvements were made to incorporate lessons learned from the previous test. During actual implementation of the tests, any revisions that were required were approved under the existing Plant Operating Manual requirements for revising special procedures.

The contents of the procedures provided detailed step-by-step instructions for performing the specific tasks. Included in these instructions were warnings regarding safety, high temperatures, contamination, radiation, and license 
requirements. The individual steps required approval signatures as appropriate for maintenance, engineering, quality assurance, health physics, and operations. A list of operating and special procedures is provided in Table 3-4.

\section{Operational Training}

Operational training for the demonstration project consisted of project overview training, equipment training, and procedural training.

Table 3-4

SUMMARY OF NEW PLANT AND SPECIAL PROCEDURES

Designation

AOP -028

EMP-029

EST -100

ISFS-001

ISFS-002

ISFS- 003

ISFS-004

ISFS-005

ISFS-006

ISFS-008

ISFS-009

ISFS -010

MST-922

MST-923

MST- 924

RST -025

SD-061

Designation

SP-789

SP-801

SP-802

SP-804

SP-806

SP-810

SP-815

SP-816

SP-818

SP-819

SP-857
New Plant Procedure

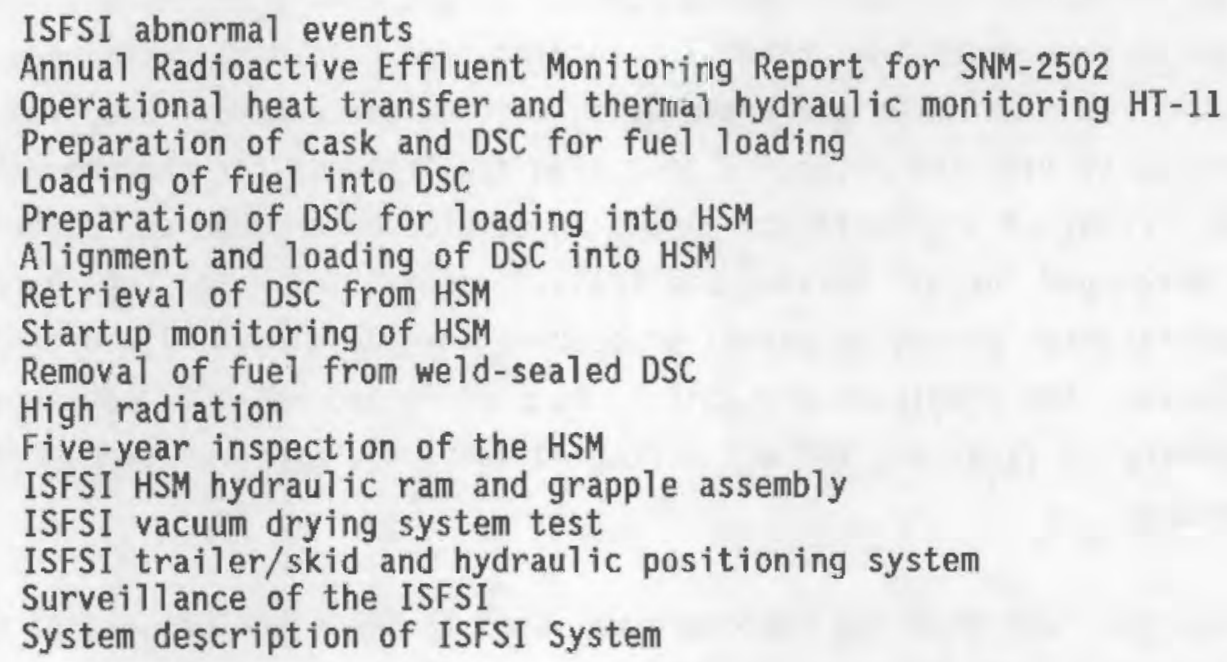

IF-300 cask decontamination Heat transfer and thermal hydraulic test of DSC in the cask Heat transfer and thermal hydraulic test of DSC in the HSM Operational heat transfer and thermal hydraulic monitoring Evacuation of DSC

Sealing of the DSC "mock-up" test

Cask/DSC performance test

Shipping cask/cask collar basket installation IF-300 cask vent and drain line decontamination Removal/replacement of the IF-300 cask drain line Operational testing procedures Rl through R3 radiation monitoring of HBR ISFSI 
To accomplish overview training, the onsite training unit developed a training module which briefly discussed the purpose of the ISFSI system, the basic design criteria, major equipment requirements, a description of the fuel loading process, and some of the license requirements. A11 personnel involved with the fuel transfer process were required to attend the training course.

Equipment training was either performed by new methods or approved procedures. For new equipment, personnel were trained using the hands-on experience gained during the testing program. Prior to actual fuel loading, the maintenance foreman designated which individuals had sufficient experience to operate specific pieces of equipment. To parallel this effort, training modules for new pieces of equipment (vacuum drying system, transfer trailer, and hydraulic ram) were developed. In the future, if additional personnel require formal training on the equipment, training classes consisting of both in-class training and hands-on operation of the equipment will be scheduled.

Procedural training was performed by having each person involved in the training read the procedure prior to implementation. This was documented on a standard training form. Prior to testing and fuel loading operations, review sessions were held, at which time the procedures were reviewed and discussed prior to implementation to ensure understanding of each procedure.

Specific training for all personnel was documented on training certification forms which described the classroom training, equipment training, and procedural training that each of the individuals had passed.

\section{Dry Shielded Canister Receipt and Preparation}

The DSCs were received at the H. B. Robinson plant from a fabrication shop in Spain and were receipt-inspected by Quality Control (see Figure 3-17). It was at that time that discrepancies were identified in the fit-up of the canister, lead plug, and top cover plate. Engineering change notices were issued to resolve the discrepancies. These changes required balancing several design parameters such as tight tolerances, minimum thicknesses, maximum gaps required for fit-up, and minimum gaps required for as low as reasonably achievable (ALARA) purposes. These design changes were implemented during the testing program. Most of the changes were performed on the lead plug by grinding in some areas and adding weld metal in other areas. These changes are described further in the Cask/DSC Performance Test and Weld Improvement Program sections. 


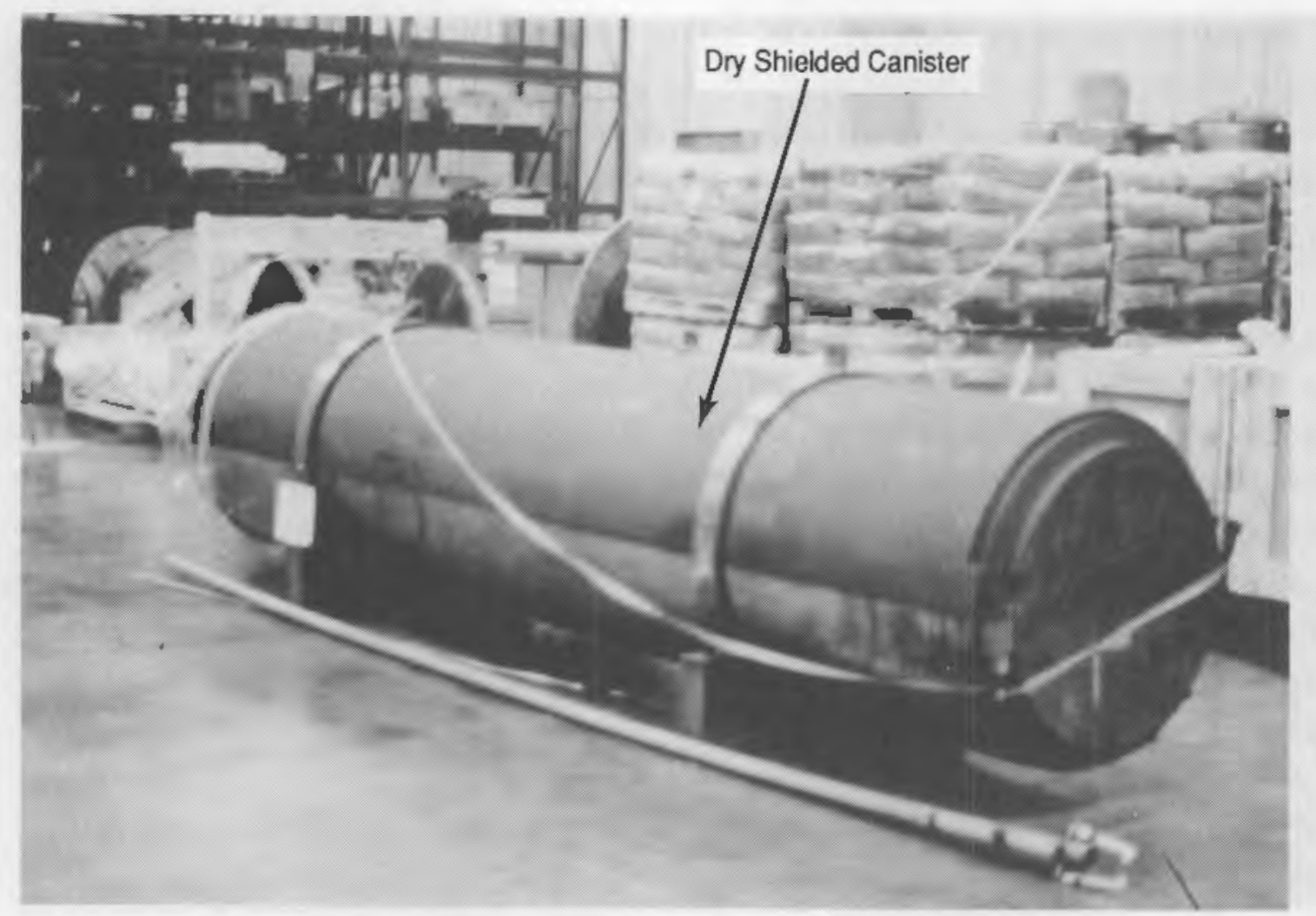

Figure 3-17. Dry Shielded Canister During Receipt at H. B. Robinson

\section{Cask Receipt and Preparation}

The existing IF-300 cask system required minimal additional equipment prior to its use with the IFSFI fuel transfer process. A cask extension collar was fabricated to allow the canister to be completely enclosed for the pool-to-the-module transfer process. A new cask collar lid was bolted to the cask collar to keep the canister stable during transfer onto the transfer trailer.

The IF-300 cask was originally believed to have minimum internal contamination following initial decontamination. However, considerable effort was required to bring the contamination down to the smearable contamination limits in the technical specifications. Normal decontamination procedures were initially used, but the smears indicated contamination higher than the 1icense allowed. Use of a strippable decontamination coating was also unsuccessful. After several attempts at washing, contamination levels were temporarily reduced only to identify longterm problems. After washing, the levels in the cask would gradually increase over 
time, indicating leaching of contamination from inside the cask. The license limit for the external surface of the DSC was $2200 \mathrm{dpm} / 100 \mathrm{~cm}^{2}$ after unloading a DSC onto the HSM.

A dual approach was used to resolve this problem. The first approach was to seek an amendment to the 10CFR72 license to increase the contamination limit to 22,000 $\mathrm{dpm} / 100 \mathrm{~cm}^{2}$ prior to fuel loading and $220,000 \mathrm{dpm} / 100 \mathrm{~cm}^{2}$ after loading. An analysis performed using the GASPAR code demonstrated that, even with these increases in contamination levels, potential offsite releases would still be significantly less than the 10CFR20 license allowed. This license amendment was submitted in September 1988 and approved in March 1989.

The second approach was to decontaminate the cask using more rigorous methods. The inside of the cask was electropolished, and the contamination levels were reduced with two exceptions. The area around and below the drain line could not be electropolished because it was inaccessible. The interior of the cask also continued to leach contamination over time. This was especially evident when the cask was subjected to heat during the heater tests. The decision was made to solve the problem by replacing the drain line with a new clean drain line and to chemically decontaminate the portion of the drain line that penetrated the cask wal1. After the existing drain line was removed, the interior of the cask was electropolished again so that the area behind and below the drain line could be cleaned. After the cask was electropolished, the drain and vent lines that penetrated the cask wall were chemically decontaminated. After successful decontamination of these areas, the new drain line was reinstalled. Although this was a major effort, the IF-300 was then ready to be utilized for the ISFSI fuel transfer process.

During decontamination and replacement of the drain line, special procedures were used to lay out step-by-step directions on how to perform the work. Documentation from these procedures demonstrated compliance with the cask requirements as well as the ISFSI license.

\section{Operational Dry Runs}

This section describes the load tests, air evacuation tests, cask/DSC performance tests, annular gap seal test, and the dry run loading. The primary purposes of these tests was to verify that the operational handling and loading could be accomplished in an efficient manner. The tests covered the entire fuel-loading 
process with the exception of placing fuel assemblies into the DSC. Some of the tests were mandated by the site license as a preoperational test requirement. other tests were performed based on prudence and training. After each test, the lessons learned were incorporated into the appropriate procedure. A11 tests were performed using approved procedures.

\section{Load Tests}

The load tests were the first of the major tests performed. One canister was loaded with dummy fuel assemblies to simulate the weight of a fuel assembly. Lead brick was used to fill stainless steel pipes which were then inserted into the guide sleeves of the DSC. The successful completion of this test demonstrated that the trailer, tractor, and hydraulic ram were capable of transporting and inserting a fully loaded DSC into and out of the concrete storage module. A1though valuable lessons were learned during the load test, two items of concern were identified. One was the delicate design of the data acquisition instrumentation. Three of the five thermocouple spears in the canisters were damaged and needed to be cut from the guide sleeves. Similar problems were encountered with subsequent tests; when the instrumented canisters were finally loaded, only 2 of the 10 thermocouples measuring fuel assembly centerline temperatures in the guide sleeves were still intact. A second concern was the coating of the canisters. Minor scratch marks occurred on both the DSC and the cask because of the DSC sliding along the cask bottom and the steel rails inside the concrete storage modules. These marks were evaluated and required only minor buffing. However, it did point out a deficiency in the coating application that was highlighted in other tests. In conclusion, during the load test, all of the equipment performed within design limits.

\section{Air Evacuation Test}

During the first set of heater tests, the requirement to evacuate the DSC to a vacuum of 1 torr for 1 hour was included. This was also a license requirement. The heater test was performed and appropriate test data were obtained. However, the DSC could not be brought to a vacuum of 1 torr. A value of 6 torr was the minimum pressure achieved after approximately three continuous days of vacuum drying. The test was discontinued until a solution could be found. Several changes were made to the system including changeout of all piping and valves, insulating and heat tracing of the pipes, and increasing the size of the piping. The vacuum pump vendor and DOE were consulted in an effort to improve all aspects of the system. The test was restarted and, although the vacuum system worked better, the license requirement of maintaining 1 torr for 1 hour was still not 
achieved. A value of 0.95 torr was reached but increased to above 3 torr within 10 minutes after valving out the vacuum drying system. Part of the problem with the testing phase 1 torr limit resulted from the mechanical seal $(0-$ ring) being used to simulate the structural seal weld that would be in place during the fuelloading process. Additional points of leakage were seven heater assembly penetrations through the test head. However, it was also recognized that achieving a value of 1 torr and holding it for 1 hour would be time and radiation dose intensive and the uncertainty in achieving the value during the actual fuel loading would still exist. Therefore, it was decided to request an amendment to the license for a value of 3 torr maintained for a 10 -minute period. An analysis was performed to demonstrate that a decrease in the vacuum limit from 1 to 3 torr was acceptable.

\section{Cask/DSC Performance Test}

Since it had been nearly 10 years since the cask had been placed in the fuel pool for spent fuel transfer, the decision was made to perform a dry run on placing the cask/DSC in the fuel pool and placing the lead plug and cover plate on the cask while the cask was in $30 \mathrm{ft}$ of water. In addition to providing training, two items could be checked: 1) the minimum gap that could be allowed between the lead plug and the canister shell while still properly seating the lead plug and 2) how well the seal between the canister shell and the cask would keep contaminated fuel pool water out of the annular gap.

The actual equipment movement portion of the test was successful. Valuable experience and training were gained from working with the redundant yoke, the instrument air system, the underwater cameras, and the other fuel pool systems. A new procedure was developed to allow the fuel pool level to be lowered to prevent water from overflowing into the heating, ventilating, and air conditioning (HVAC) ducts located just below the fuel pool deck.

With respect to the minimum acceptable gap allowed, the canister and lead plug with the tightest fit were selected to represent the worst-case scenario. This was especially critical at this time of the testing because the weld improvement program was determining the maximum gap between the DSC shell and the lead plug, based on welding criteria. A balance between these competing issues was sought in the performance of the cask/DSC performance test. The actual placement of the lead plug onto the DSC was successful on the second attempt. The first placement 
resulted in the lead plug being skewed on the DSC. The second placement resulted in the lead plug being properly seated. This was accomplished with gaps as small as $1 / 16$ in. over portions of the circumference.

The seal also appeared to be successful in that the pool water did not enter the annulus. This was verified by a gamma scan of water samples and by taking smears of the canister exterior. Both tests indicated that contamination of the annulus had not occurred. However, fuel was not present in the DSC; therefore, temperature differences between the interior and the exterior of the DSC were not present. During the first fuel loading attempt, this temperature difference created a problem and the fuel loading was aborted (see Annulus Seal Test section).

\section{Annulus Seal Test}

During the first fuel-loading attempt, loading was aborted because the annulus seal did not prevent fuel pool water from entering the annulus. The result was contamination of the annulus and the exterior surface of the DSC. Contamination was initially verified by gamma scans of the fluid within the annulus and later confirmed by smears of the DSC exterior. If fuel loading had continued, the DSC would have had to be removed from the HSM because of the contamination of the cask interior. Seal failure resulted from one of two causes: 1) The seal may have been inserted into the annulus with a sharp instrument, thereby weakening the seal. Upon removal of the seal, it was noticed that the seal was severed in one location. 2) The water in the annulus may have heated after the fuel assemblies were inserted into the cask. This, in turn, would have caused the water to exert pressure on the seal and potentially force it out of the annulus gap, allowing fuel pool water to enter.

A new seal design was prepared consisting of a hollow 0 -ring-type seal held in place with a retainer ring. The hollow 0-ring was designed to be soft and flexible, and the diameter was larger than the annulus gap so that it would not "slip" into the gap. The retainer ring's outside diameter was designed to be inserted into the inside diameter of the cask and to lay down on the seal, keeping continuous pressure on the seal. The retainer ring was secured in place using set screws which were tightened against the inside diameter of the cask. A procedure was developed to test the seal under both pressure and vacuum conditions expected during fuel load. The pressure limit was designed for the seal to release and allow the pressure within the annulus to be released. This would keep pressure from building up in the annulus area and having the seal expand out of the annulus 
gap area. The vacuum limit was based on the hydrostatic pressure anticipated with $40 \mathrm{ft}$ of head. Both conditions were tested acceptably prior to fuel loading and the seal then functioned well during fuel loading.

\section{Dry Runs}

One of the license requirements was to perform a dry run of the fuel loading to simulate loading and unloading of the DSC from the decontamination area to the HSM, into and out of the HSM, and back to the decontamination area. This dry run was to be performed using approved permanent plant procedures. Since fuel would not be in the DSC and because the lead plug and cover plate would not be welded on, temporary changes were made to the plant procedures to allow the dry run to be performed. The first dry run was difficult because of procedural shortcomings, equipment problems, and unfamiliarity of personnel with the equipment. The major items identified in the lessons-learned meeting were the machining of the front door of the HSM, alignment of the hydraulic ram to latch onto the grapple ring, failure of the hydraulic skid to operate, and realization that the trailer had to be moved horizontally prior to the completion of lowering the front access door. The door was machined, the hydraulic skid repaired, and the procedures revised. The repeated dry run went successfully except for the centering of the hydraulic ram in the grapple. This was corrected by stiffening the grapple to allow it to resist eccentric loading and by extending the grapple to within 6 in. of the grapple ring's predetermined location after the cask was seated inside the HSM. The ram grapple was centered at this location so there was little chance that it would miss the grapple ring after full extension. With this dry run complete, the Plant Nuclear Safety Committee approved the loading of fuel.

\section{Weld Mockups and Weld Improvement Program}

Another license requirement was the performance of a weld mockup test on a "dummy" canister as well as the removal of the cover plate and lead plug to demonstrate the ability to retrieve fuel assemblies. The original design called for the lead plug to be fillet welded to the DSC and for a full penetration weld to be performed in welding the top cover plate to the DSC shell. Welding of the dummy canister began by welding the lead plug to the DSC. Although the welding process was successful, the DSC shell was drawn in during the welding, resulting in a tight fit for the cover plate to seat itself past the drawn-in portion of the DSC. Once past that point, the drawn-in shell resulted in a larger-than-anticipated gap on the land area where the top cover plate would be welded to the DSC. The welding procedure called for first tacking the cover plate in place before beginning the full 
penetration weld. The first tack was manually welded. When the second tack was made, the weld cracked. Two additional manual welds were attempted and both of them cracked as we11. An automatic welder was brought in to try to control the heat during the tacking process, but these welds also cracked. At that point, the test was discontinued and the weld design and parameters were re-evaluated.

Root causes of the cracked weld were thought to be

1. Too much shrinkage occurred during the welding of the lead plug; the top of the DSC had drawn in during welding. Consequently, when the top cover plate was being welded, the weakest place was the weld itself. When residual stresses in the weld needed relief, the tack weld was the location at which the stress was relieved.

2. The heat input was too high, resulting in excessive shrinkage.

3. The gap between the top cover plate and the DSC shell was too great.

To resolve these concerns, a weld development program was begun that instituted welding of six additional mockup DSCs. Principal improvements made during this program were as follows:

1. A change was made from a fillet weld to a bevel weld, which required chamfering the lead plug, but resulted in much less weld metal being added to the DSC; thus, less shrinkage occurred.

2. Using a high ferrite content weld metal, again resulted in less shrinkage.

3. Sequencing the welding pattern allowed more control over the heat input into the weld.

4. Reducing the gap between the cover plate and DSC shell resulted in reducing the amount of weld metal.

A11 weld mockups were performed by the contractor who was to perform the welding during actual fuel loading using controlled welding techniques. Measurements were taken before and after welding the lead plugs and cover plates so that optimum weld design and gap geometry could be determined and so that shrinkage could be estimated. The tests with the mockup canisters were all successful and resulted in specific detailed welding parameters that were incorporated into the operating procedures.

The final mockup DSC was performed under CP\&L direction and was used as the final test, proving that the DSC, lead plug, and cover plate could be successfully welded and successfully cut open. Although the cutting of the lead plug and cover plate took significantly longer than anticipated, the test itself was successful. 


\section{Dry Shielded Canister Coatings.}

As identified earlier, difficulties were experienced with the quality of the dryfilm lubricant coating installations on the DSC when used in accordance with the manufacturer's recommendations. One difficulty was the minor blemishes that resulted from using the DSCS for testing. These blemishes were insignificant and were not a concern. Another difficulty resulted from the unanticipated decontamination of the DSC during the testing program. Contamination within the cask had spread to the DSC during testing. ATthough the contamination could be removed easily by washing it down, it was discovered that the washing was also removing the dry film lubricant. Prior to fuel laading, eddy-current testing was performed to determined the thickness of the dry film lubricant. Two of the canisters had less than the minimum design thickness, so the existing coating was stripped from the DSC and a different type of dry film lubricant was applied. The friction factor remained unchanged, and the process was successfut.

\section{Spent Fuel Selection and Inspection}

The selection and characterization of the spent fuel placed into the NUHOMS system was conducted under a Nuclear Fuel selection procedure. Candidate spent-fuel assemblies were carefully received to ensure that they met all the requirements of the ISFSI Safety Analysis Report and the ISFSI Material License No. SNM 2502 and corresponding technical specifications.

The following steps were included in fuel selection process:

- verifying fuel parameters (i.e., burnup, cooling time, enrichment, decay heat, assembly weight, etc.) with the limits imposed in the above section

- verifying that each assembly selected had been leak tested by either sipping or ultrasonic testing (UT) (each assembly was also visually inspected prior to loading in the DSC).

The selection process ended with the approval of an Assembly Characteristics Verification Form and a Dry Shielded Canister Fuel Assembly Location Form. These forms were transmitted to the H. B. Robinson site for incorporation into the plant NUHOMS loading procedure.

\section{Dry Shielded Canister Seal Welding}

The welding process began with the intent that all welding would be manual. This was due partially to the fact that only three DSCs were to be loaded and an automatic welder could not be economically justified. When a decision was made to 
construct five additional HSMs and load five additional DSCs, use of a welding machine was reconsidered. The decision was then made to use a welding machine for the lead plug and cover plate welds. Motivating factors were reduction in welding time, consistency in weld quality, and reduction in radiation dose. Even though some experience had already been gained with the welding machine during testing, welding time and radiation dose were significantly reduced by the time the third DSC was loaded.

\section{Yacuum Drying}

The vacuum drying system was observed to be sensitive to surrounding conditions and operator expertise. During testing, the following items were changed:

1. The piping between the vacuum pump and the DSC was changed to provide pipe that was more leak tight and to provide valves that could be closed. It was found that the initial piping had minor leaks that would keep the system from achieving the required vacuum.

2. The piping system was insulated and heat traced. Since the supersaturated air being withdrawn from the DSC was at high temperatures, moisture would condense once it entered the piping system. This caused moisture contamination of the vacuum pump and resulted in inefficient pump operation.

3. Moisture had to be removed from the system before a low-level vacuum could be achieved. This required operator skill to balance the vacuum pump operation. To remove the moisture from the oil of the vacuum pump, a purge valve had to be opened, which brought outside air into the system and effectively eliminated the water from the 011 ; however, this kept the pump from achieving a low-level vacuum. Therefore, the operator had to exercise balance between moisture removals to allow the vacuum pump to work at top efficiency and minimize the amount of outside air that was introduced into the system. Both items tended to reduce vacuum pump efficiency.

4. A step was added to minimize residual moisture in the DSC. After the lead plug was welded to the DSC, the next step was to hook up a tubing pump to the vent line and connect the siphon line to the radwaste system. By blowing air into the vent line, a significant portion of the remaining moisture was drained directly into the radwaste system so that it would not have to be removed by the vacuum drying system. This significantly reduced the vacuum drying time.

Through implementation of the above items, the required vacuum drying time was reduced from an initial estimate of 72 hours to less than 24 hours. 


\section{Helium Inerting and Leak Testing}

The original license called for the lead plug to be helium leak tested to a value of $1 \times 10^{-6} \mathrm{~atm}-\mathrm{cc} / \mathrm{sec}$. The concept was to use a sniffer probe connected to a leak detector. A sniffer probe was specified based on its ease of setup time. This caused a problem in that $1 \times 10^{-6}$ is close to the background level of normal atmospheric air. During testing, it was difficult to establish a baseline for the sniffer probe using a calibrated leak with a definite peak that could be compared with the sniffer as it encompassed the weld. Alternatives included setting up an accumulation test for the helium leak test or amending the license to allow a leak rate test of $1 \times 10^{-5} \mathrm{~atm}-\mathrm{cc} / \mathrm{sec}$. Both paths were pursued. When it was time for the first fuel load, neither alternative had been completed. A decision was then made to proceed with the $1 \times 10^{-6}$ leak rate requirement. Two items were included to allow the fuel loading to proceed. The time that the sniffer probe "sniffed" the weld was increased to ensure that small leaks would be detected. The second item was to try to control any extraneous helium from being introduced into the area during the backfilling process. Extraneous helium could have led to an unsuccessful test due to the background helium. The first fuel loading proceeded and the test was successfully performed but with an increase in radiation dose due to the increased sniffing time. By the time the second DSC was loaded, the license amendment was approved and the higher leak rate allowed the leak test to be performed at a quicker rate.

\section{Trailer Loading}

The loading of the cask onto the trailer proceeded with little difficulty (see Figures 3-18, 3-19, and 3-20), only two adjustments were made. One was the capture of water that could not be drained from the cask annulus area, and the other was careful height control on the cask as it traversed above the tilting cradle.

The annulus of the cask was drained prior to lifting the cask out of the decontamination area. Because of the geometry of the drain line within the cask, however, the water could not be completely drained and a couple of gallons of water remained in the bottom of the cask. As the cask was tipped in the tilting cradle, the water drained towards the cask collar 1id. To capture this water in a controlled manner, a "diaper" was attached to the bottom of the cask and the cask collar lid was loosened to funnel the water so that it could be captured. This worked well so that when the cask was opened at the HSM no water spilled onto the concrete pad. 


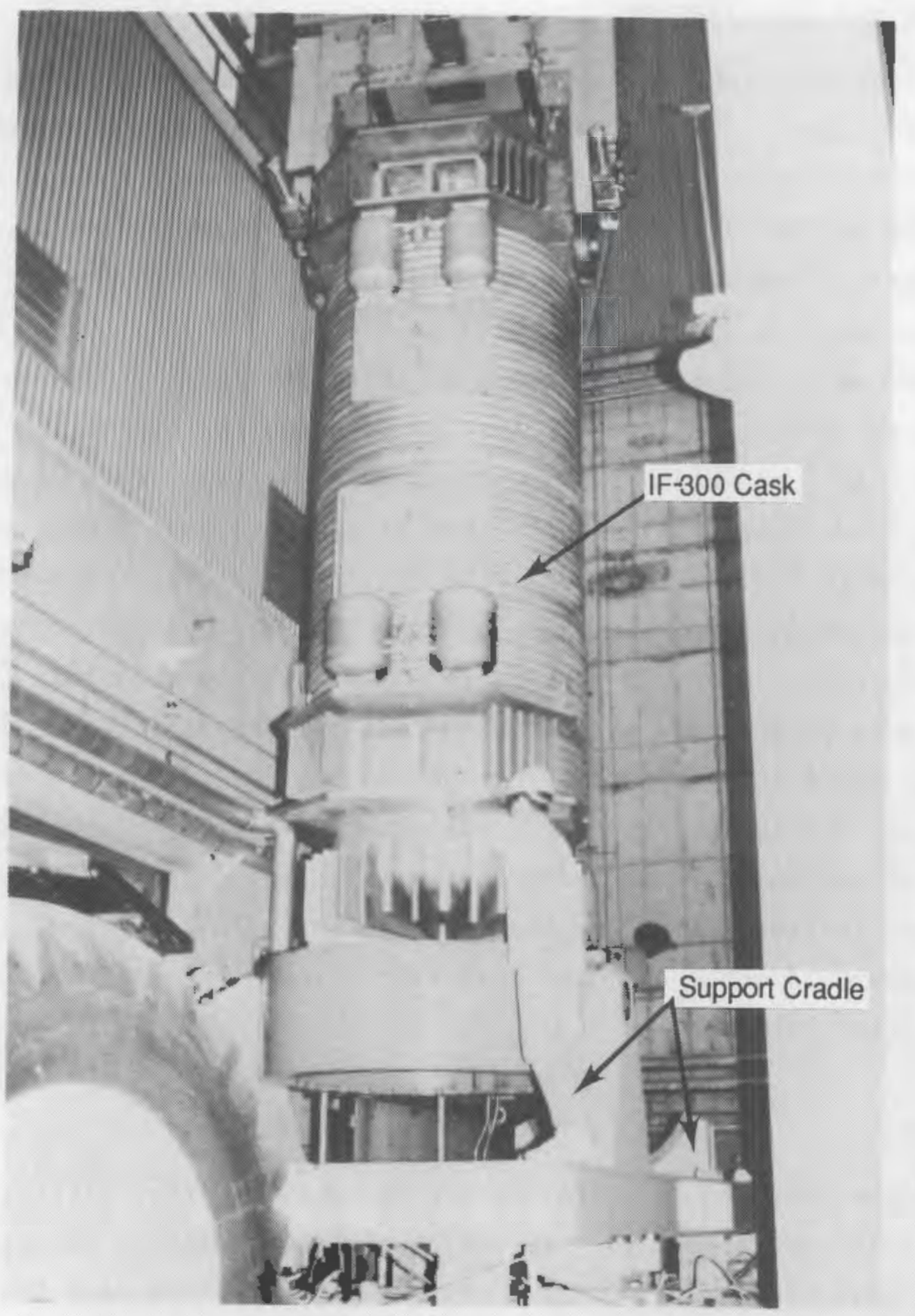

Figure 3-18. IF-300 Transportation Cask Being Loaded Into the Support Cradle of the Transport Trailer

The height of the cask required careful control because a license requirement 1 imited the cask to an $8-\mathrm{ft} 1 \mathrm{ift}$ without the redundant yoke attached. After the cask was removed from the decontamination area and set on the ground, the standard lifting yoke was used to set the cask onto the trailer. To do this permitted a tolerance of only 1-3/4 in. To prevent the overhead crane from 1 ifting the cask too high, an 8-ft piece of PVC pipe was used as a guide for the crane as it 1ifted the cask. 


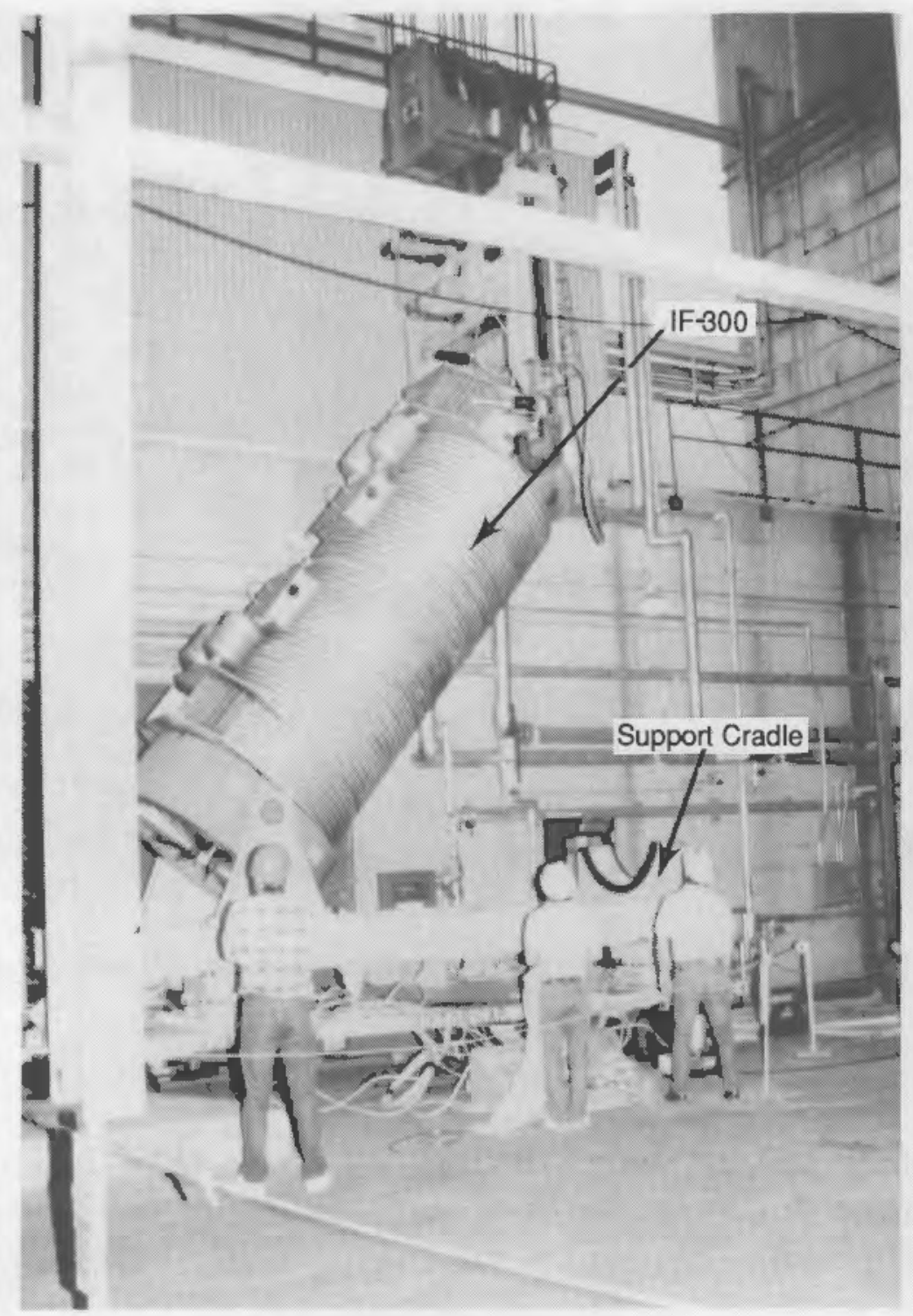

Figure 3-19. IF-300 Transportation Cask Being Lowered to the Horizontal Position in the Trailer-Mounted Support Cradle

\section{Transport to Modules}

The cask with the DSC inside was transported from the decontamination area to the HSM, a distance of approximately $500 \mathrm{ft}$ (see Figures 3-21 and 3-22). The route was along an existing railroad track. The road surface originally conceived was to be made of a compacted aggregate base. However, during testing of the tractor/trailer combination, the tractor was not able to adequately maneuver the trailer. Therefore, an 8-in.-thick concrete road was constructed and reinforced with No. 4 rebar. 


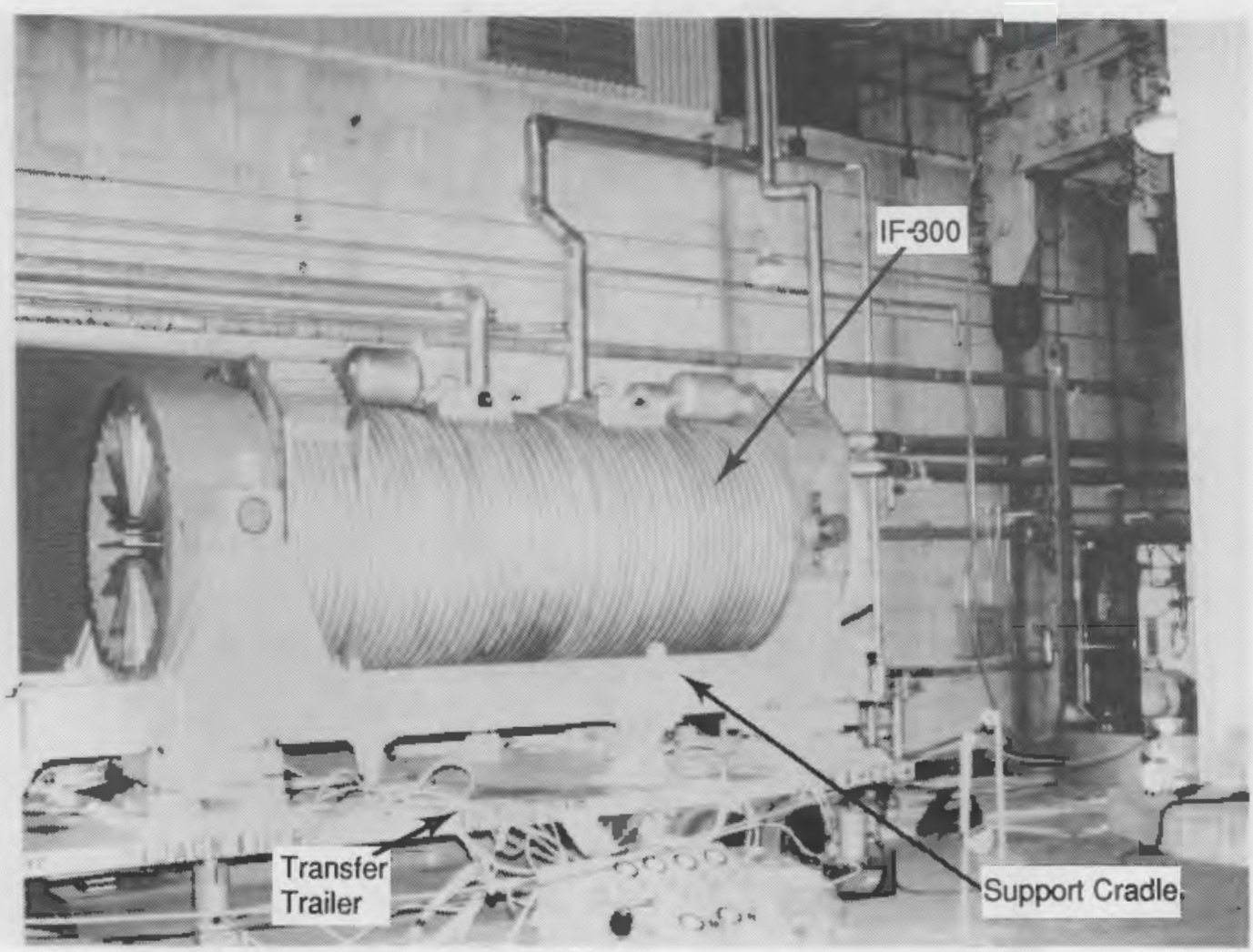

Figure 3-20. IF-300 Transportation Cask Loaded and Secured in the Support Cradle of the Transport Trailer

The total width of the road was $12 \mathrm{ft}$ with the railroad in the center of the roadway. The approach slab and ram-mounting slab were constructed to a grade of $1 / 16 \mathrm{in./ft}$ to minimize difficulty in leveling the trailer, HSM, and ram-mounting slab.

\section{Trailer/Skid Alignment}

The alignment of the cask to the HSM was a critical operation (see Figure 3-23). The alignment had to be relatively precise to prevent the DSC from jamming in the HSM during unloading operations, so that the load on the ram would be minimized, and the eccentric load on the grapple assembly would be minimized. Control points were set up on the HSM and the cask since the cask had to be centered remotely in view of the center of the HSM opening. The trailer was leveled using four hydraulic jacks. Level measurements were taken at each of the four corners of the trailer to ensure that the trailer was level. The hydraulic jacks were individually controlled and adjusted until the trailer was level and the centerline of the 


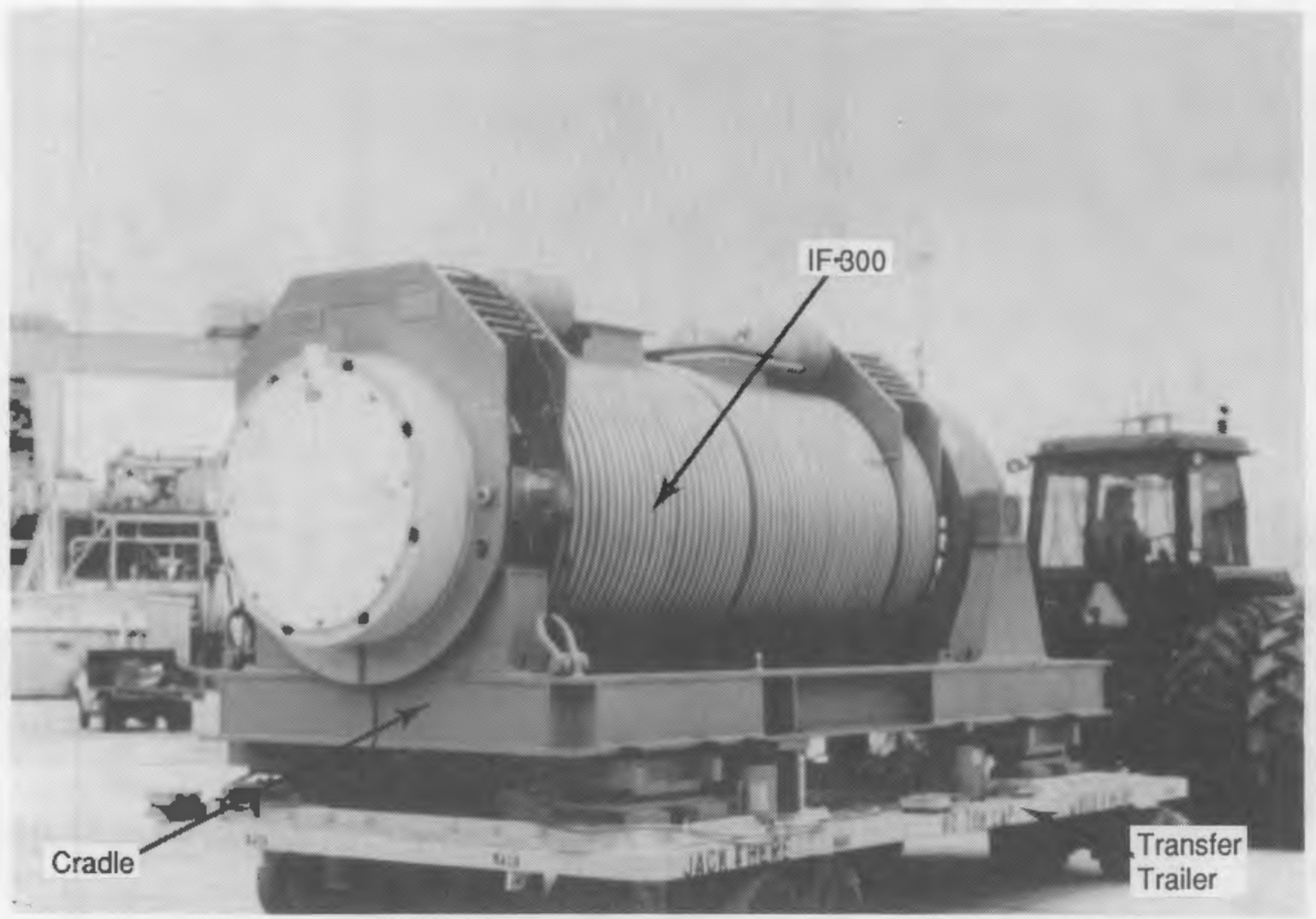

Figure 3-21. Loaded IF-300 Transportation Cask Being Transported to the ISFSI

cask was in the center of the HSM opening. After the trailer was leveled at the correct elevation, the cask was aligned axially. Control points were set up on the front and the back of the cask that coincided with the alignment of two survey instruments that were aligned parallel to the centerline of the opening. The caskpositioning skid could be adjusted horizontally in both directions; the hydraulic control unit provided a11 the necessary adjustments. When the cask was aligned to $1 / 16$ in., the alignment was acceptable. Initially, optical alignment technicians aligned the trailer/skid during testing. For subsequent testing, the onsite surveying group was able to align the cask using conventional equipment, reducing costs and providing enough flexibility to allow the surveying process to be controlled by site personnel.

\section{Loading with Hydraulic Ram and HSM Closure}

After the cask was aligned in the front of the HSM, two pieces of the ram had to be aligned: the main body and the grapple assembly. The main body of the ram was 


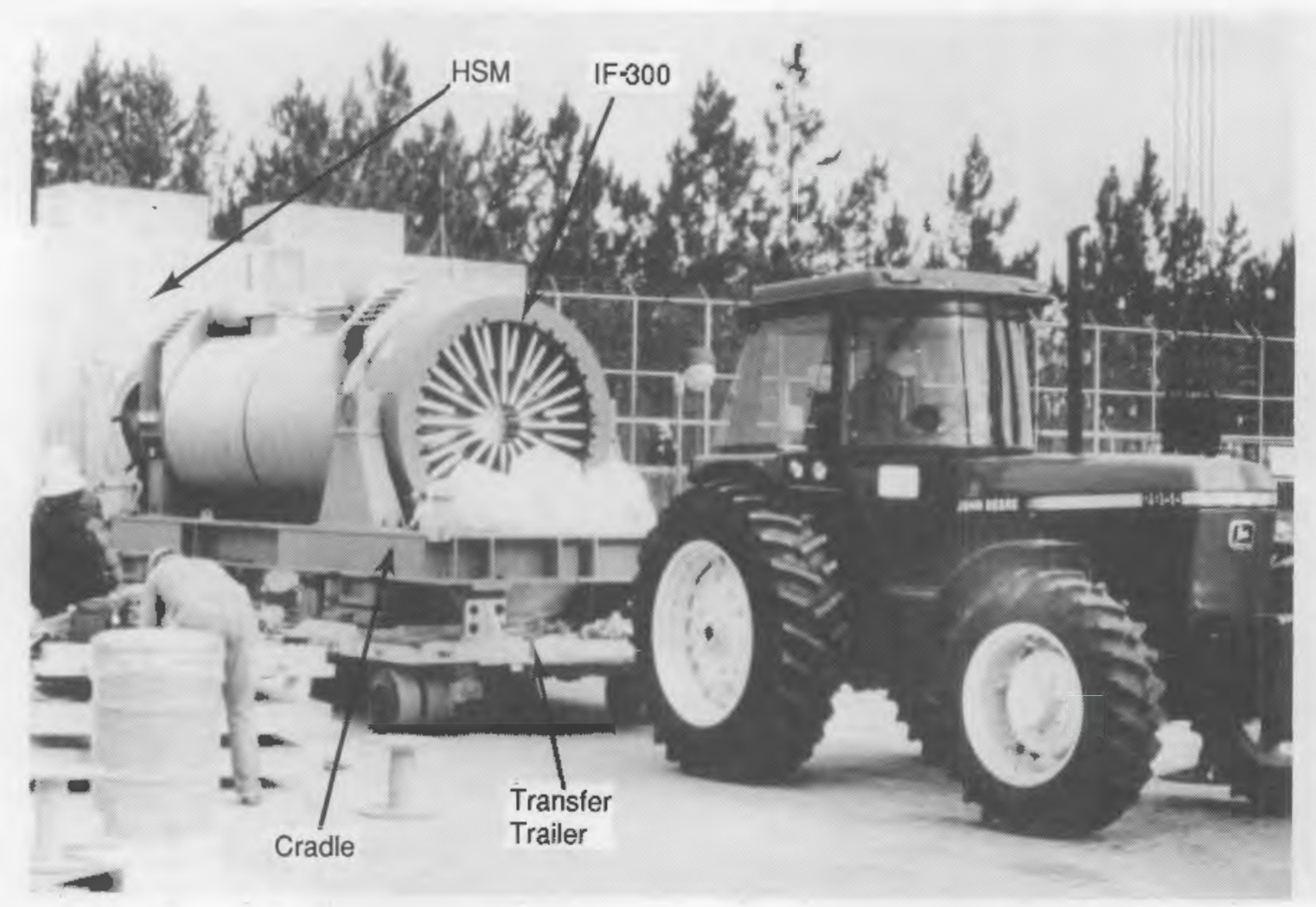

Figure 3-22. IF-300 Transportation Cask Positioned at the Concrete Storage Module

supported by a quadruped and by trunnion supports attached to the HSM. These two elements were aligned during the construction of the HSM, and alignment was reestablished each time the ram was set up. Shims could be added at the trunnion supports for minor horizontal adjustments. A leveling screw on the quadruped allowed vertical adjustments of the main body of the ram (see Figure 3-24).

Alignment of the grapple assembly was not accomplished as easily. Although the grapple assembly was aligned prior to being extended, the alignment was difficult to maintain while being cantilevered $15 \mathrm{ft}$. Adjustment in the vertical direction could be made using the leveling screw on the quadruped without taking the ram apart. However, in the horizontal direction, adjustments could not be made without retracting the grapple and taking down the ram. It was also noted that there was some minor bending of the pin that supported the grapple because of the eccentric loading. A change was made to the design of the grapple assembly to strengthen it. 


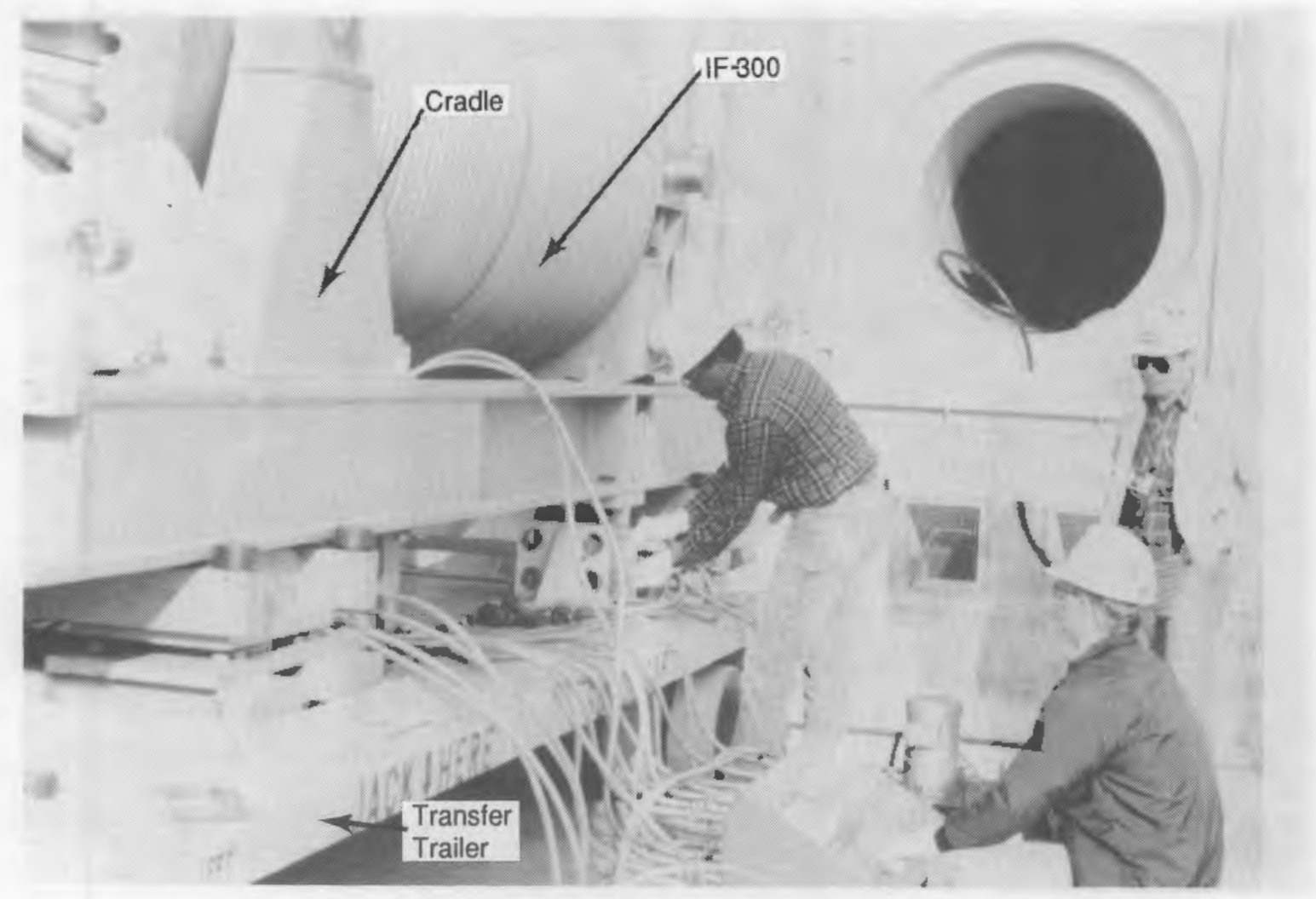

Figure 3-23. Operation of the Trailer-Mounted Hydraulic Positioning System

As the grapple was extended from the rear of the module to the grapple ring on the DSC (15 ft), the tolerance was $3 / 8 \mathrm{in}$. in each direction. Alignment was difficult to maintain for a traveling distance of $15 \mathrm{ft}$. To resolve this problem, a procedural change was made to require the ram to be completely set up and the grapple assembly centered in the extended position before the cask was moved from the decontamination area. This allowed adjustments to be made without exposing personnel to a radiation field; it also allowed physical measurements to be taken to ensure that the grapple was centered. After the cask was aligned and docked to the HSM, the grapple was then extended the final 6 in. Maintaining the $3 / 8$ in. tolerance over the 6-in. distance was not a problem and use of the ram during the loading operations went smoothly. The force capability of the ram was specified assuming a friction coefficient of 1.0. Since the DSCS were coated, the friction coefficient was significantly less and the force required to pull the DSC into the HSM was much less than the capacity of the ram. 


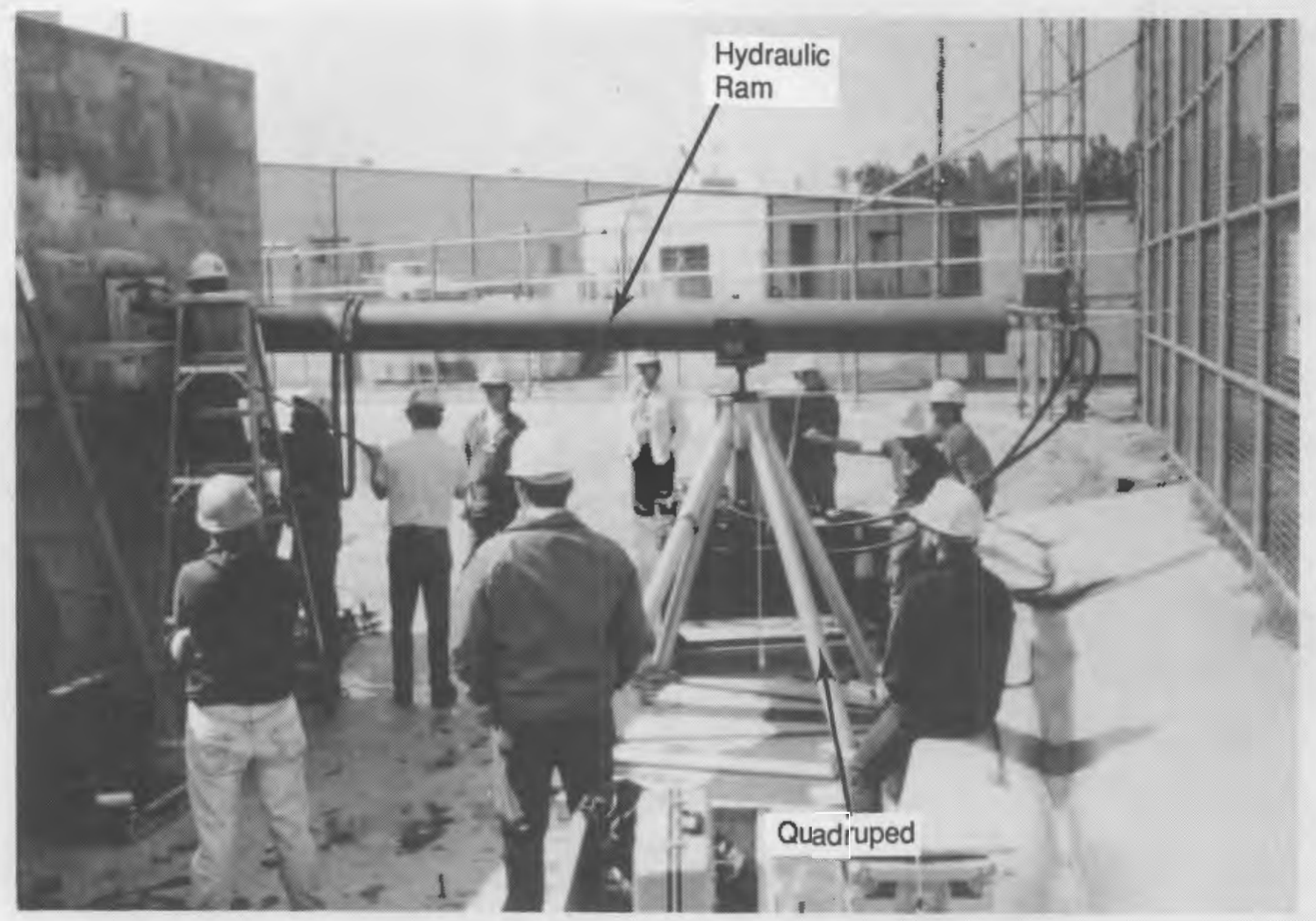

Figure 3-24. Hydraulic Ram at the Rear of the Module

Once the DSC was in the HSM, the ram was removed from the rear access hole and the rear access cover plate was bolted to the HSM. The front access door was then lowered to a position just above the front access opening. The trailer was lowered and pulled away from the HSM about $5 \mathrm{ft}$ to allow the door to be lowered all the way (see Figure $3-25$ ). The door was then tack welded to the front access door frame, and the sealing operation was complete. As described earlier, the thickness of the door prevented it from being lowered all the way prior to moving the trailer away from the HSM. Although there was a concern regarding radiation exposure during this step, the use of ALARA principles minimized exposure.

\section{Dose Rates}

Basic techniques for exposure control were demonstrated effectively in the movement and installation of spent fuel into the NUHOMS. Practice sessions with a mockup were used to familiarize work crews with specific tasks and to identify and resolve procedural problems. Table 3-5 demonstrates the value of experience in working with dedicated work crews. A sequence refers to the complete loading operation for 


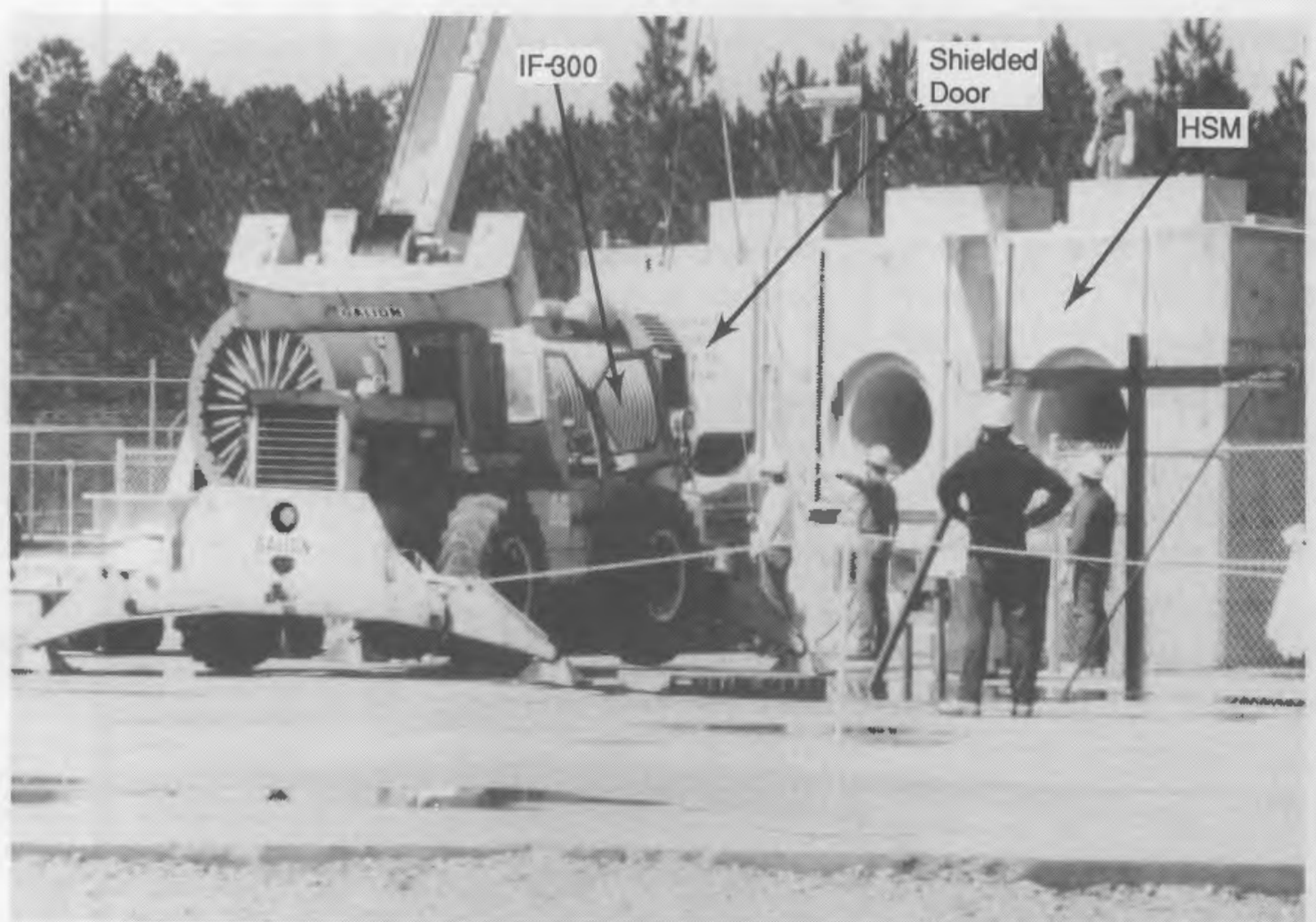

Figure 3-25. Shield Door Lowered to Cover the Front Access Port

Table 3-5

TOTAL RADIOLOGICAL EXPERIENCE FROM THE LOADING OF EIGHT CANISTERS

\begin{tabular}{|c|c|c|c|c|}
\hline Sequence & Start Date & $\begin{array}{c}\text { Completion } \\
\text { Date }\end{array}$ & Total Days & $\begin{array}{l}\text { Total Dose } \\
\text { (man-rem) }\end{array}$ \\
\hline $1^{a}$ & $03-09-89$ & $03-16-89$ & 9 & 2.966 \\
\hline 2 & 04-04-89 & $04-11-89$ & 8 & 3.100 \\
\hline 3 & $04-12-89$ & $04-18-89$ & 7 & 1.823 \\
\hline 4 & $04-19-89$ & $04-24-89$ & 6 & 1.751 \\
\hline 5 & $04-24-89$ & $05-02-89$ & 8 & 1.348 \\
\hline 6 & $05-03-89$ & $05-08-89$ & 6 & 1.746 \\
\hline $7^{a}$ & $06-23-89$ & $06-28-89$ & 6 & 1.110 \\
\hline $8^{a}$ & $06-29-89$ & $07-03-89$ & 5 & D. 941 \\
\hline
\end{tabular}

aDenotes the three demonstration modules. 
one canister. Note that Sequence 8 involved the lowest total dose based on selfreading personal dosimeter (SRPD) readings as compared to Sequences 1 and 2 which were over three times that of Sequence 8.

Television cameras were used during Sequence 2 but were deleted from subsequent sequences since their operation appeared to increase exposure.

The first fuel loading contained various hold points not included in the following fuel loads. Gamma and neutral spectroscopy readings were taken and were not required on any of the following fuel loads. Key man-rem activities are listed in Table 3-6 with a comparison of predicted doses to doses experienced.

In conclusion, the primary lesson learned was the advantage of utilizing trained, experienced, and dedicated work crews for this activity.

Table 3-6

DOSE EXPERIENCE BY TASK

(dose in mrem)

\begin{tabular}{|c|c|c|c|c|c|}
\hline Task & $\begin{array}{l}\text { Initial } \\
\text { Projection }\end{array}$ & Average & Maximum & Minimum & Last \\
\hline Seal weld assembly & 150 & 284 & 605 & 102 & 102 \\
\hline $\begin{array}{l}\text { Vacuum dry/helium } \\
\text { leak test }\end{array}$ & 350 & 118 & 288 & 24 & 24 \\
\hline $\begin{array}{l}\text { Seal weld-prefab plugs; } \\
\text { vent connect cavities }\end{array}$ & 350 & 86 & 156 & 48 & 60 \\
\hline $\begin{array}{l}\text { Position/tack weld/ } \\
\text { root pass cover plate }\end{array}$ & 500 & 231 & 348 & 123 & 126 \\
\hline $\begin{array}{l}\text { Complete cover plate } \\
\text { weld }\end{array}$ & 300 & 553 & 792 & 301 & 461 \\
\hline $\begin{array}{l}\text { Decontaminate/install } \\
\text { cask collar lid }\end{array}$ & 100 & 31 & 82 & 0 & 12 \\
\hline
\end{tabular}




\section{Contamination Control}

The use of dedicated crews and mockup training are credited for the success of the contamination control aspect of the program. Cask smearable 1 imits of $2200 \mathrm{dpm} /$ $100 \mathrm{~cm}^{2}$ were met with smears assaying generally between 600 and $1800 \mathrm{dpm} / 100 \mathrm{~cm}^{2}$. New cask seal designs were effective and cask drain lines demonstrated less than $200 \mathrm{dpm} / 100 \mathrm{~cm}^{2}$ of smearable limits.

\section{HSM Contact Doses}

Once the fuel canisters were in place in the HSM, contact dose rates were observed to be less than expected. Gamma exposure rates at the inlet vent of the HSM were measured from 10 to $15 \mathrm{mr} / \mathrm{hr}$. Outlet vents had exposure rates of 12 to $45 \mathrm{mr} / \mathrm{hr}$. Contact readings on the sides of the loaded HSM were generally $5 \mathrm{mr} / \mathrm{hr}$. Neutron exposures were less than detectable by the available instrumentation.

\section{Environmental Monitoring and Results}

Environmental monitoring related to the ISFSI was performed using environmental thermoluminescent dosimeters (TLDs) which were a part of the H. B. Robinson, Unit 2 environmental program. There are three TLD indicator locations used to evaluate the potential increase in environmental radiation exposure from HBR ISFSI. A fourth TLD location in Florence (26 miles ESE) is a control location. Two of the three indicator locations have been in place for a number of years before the existing program. A third location was added January 1, 1989. Results of the environmental TLD measurements to date are presented in Table 3-7.

Based on the above comparisons, no measurable increase in environmental radiation exposure was detected as a result of the ISFSI.

Based on the results of smears taken at the outlet of the HSM which indicated no detectable activity, it is concluded that there was no release of activity offsite and therefore no radiological dose associated with ISFSI from effluents.

\section{Long-Term Surveillance/Five-Year Inspection}

Only minimum inspections and measurements were required once the DSCs were loaded into the HSMs. Air temperature was taken at the inlet and outlet of the HSM, and the difference had to be less than $37.7^{\circ} \mathrm{C}$ to meet license requirements. Actual differences were less than $4.4^{\circ} \mathrm{C}$. 
Table 3-7

\section{TLD RESULTS \\ $(\mathrm{mr} / \mathrm{wk})$}

\begin{tabular}{|c|c|c|c|}
\hline Location & $\begin{array}{l}1986-1988 \\
\text { Average }\end{array}$ & Range & $\begin{array}{l}\text { 2nd quarter } 1989 \\
\text { ISFSI Completed }\end{array}$ \\
\hline Florence (control) & 1.15 & $1.00-1.30$ & $0.90 \pm 0.10$ \\
\hline $\begin{array}{l}0.2 \text { mile south } \\
\text { of ISFSI }\end{array}$ & 1.13 & $1.00-1.50$ & $1.00 \pm 0.10$ \\
\hline $\begin{array}{l}0.3 \text { mile southwest } \\
\text { of ISFSI }\end{array}$ & 1.08 & $0.90-1.30$ & $0.90 \pm 0.190$ \\
\hline $\begin{array}{l}300 \mathrm{ft} \text { north of } \\
\text { IFSFI }\end{array}$ & NA & NA & $1.10 \pm 0.20$ \\
\hline
\end{tabular}

Daily inspections are also required to ensure that the inlet and outlet vents are not blocked, thus allowing the cooling process to continue. This inspection is done visually outside of the fenced area from a platform constructed to ensure that each of the outlet vents can be seen.

The final inspection was a check of the concrete and structural steel after 5 years. This is required by the license for the first HSM loaded. The concern resulted from predicted concrete temperatures being higher than the $66^{\circ} \mathrm{C}$ allowed by ACI-349 for normal nonlocalized long-term storage conditions. An inspection of the HSM was made just prior to loading, thus allowing any minor irregularities in the concrete or steel to be documented. When the 5-year inspection is made, the two inspections can be compared to determine if the temperatures have had any adverse effect on the concrete or steel. Since the temperature of the concrete is being monitored during the first operational summer, it is possible that the concrete temperatures could be lower than predicted. If the temperatures are lower than the $66^{\circ} \mathrm{C}$ allowed by $\mathrm{ACI}-349$, then it may be possible to revise the license and eliminate the need for a 5 -year inspection. 


\section{Section 4}

HEAT TRANSFER AND SHIELDING PERFORMANCE

Heat transfer and shielding performance based on data obtained from the NUHOMS system are presented and discussed in this section. Concrete, DSC, fuel, inlet air, and outlet air temperatures are presented to assess heat transfer performance. Exterior surface dose rates are provided to evaluate shielding performance.

\section{HEAT TRANSFER}

The heat transfer performance of the NUHOMS system was evaluated using temperature data obtained during an electrically heated test and with spent fuel loaded in the storage system (see Table 4-1). The electrically heated data consisted of eight individual test runs obtained while simulating the various stages in the operation of the system. The spent-fuel data consisted of two test runs taken after spentfuel was loaded in the storage system. The results of the runs are summarized in Table 4-1 and are discussed in the following sections.

\section{Electrically Heated Test Runs}

During the electrically heated test runs, simulated decay heat was supplied by seven 2-kW heaters; one heater in each of the seven canister fuel sleeves. The power to the heaters was regulated by a common power controller that was adjustable from $0 \%$ to $100 \%$ of the rated power of the heaters. The test plan called for DSC power levels of $28 \%(4 \mathrm{~kW}), 33 \%(4.5 \mathrm{~kW}), 50 \%(7 \mathrm{~kW})$, and $72 \%(10 \mathrm{~kW})$. Each test was performed with the power controller set at the desired percentage of full heater power.

During the evaluation of the test data, inconsistencies were noted that suggested the recorded power levels were in error. A series of tests were subsequently performed on the power controller to determine its linearity and accuracy. The tests indicated that heater power was not a linear function of the control setting, 
Table 4-1

TEST MATRIX AND PEAK TEMPERATURES FOR

THE H.B. ROBINSON NUHOMS

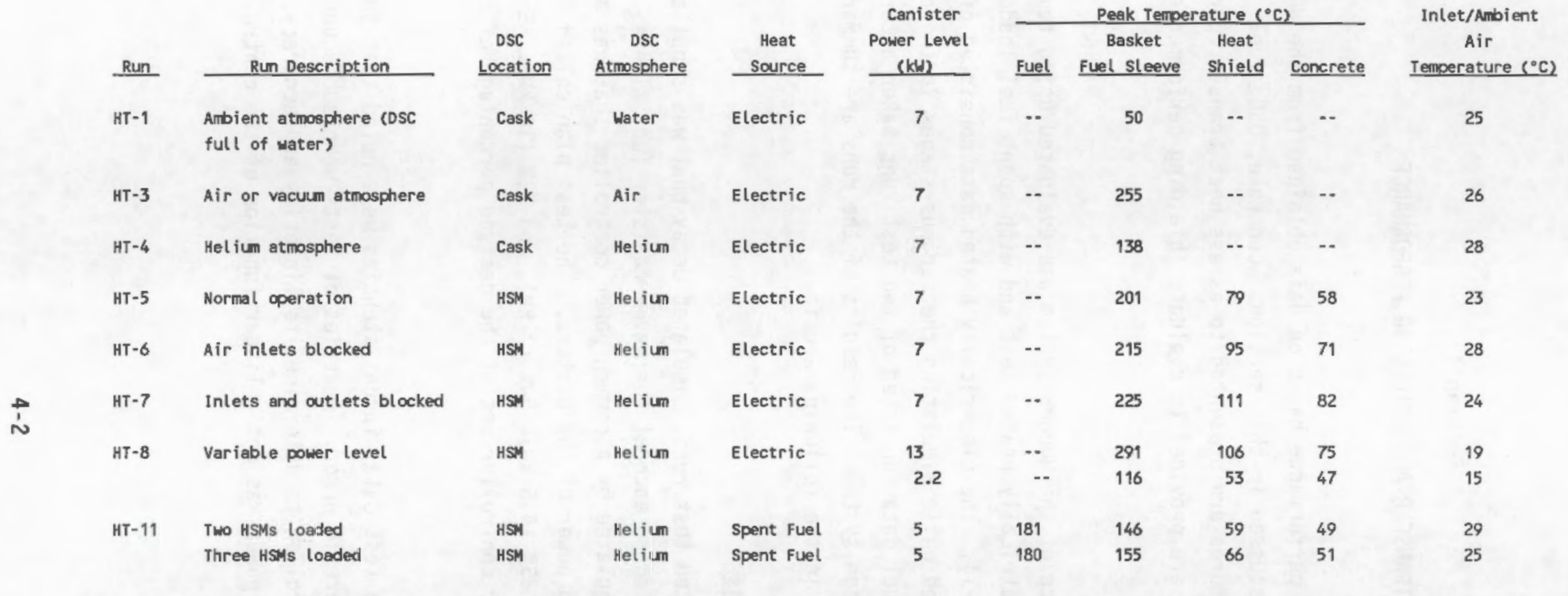


and a curve was developed relating the control settings to actual heater power. In actuality, the heater tests were performed at power levels of $1 \mathrm{~kW}, 2.2 \mathrm{~kW}, 7 \mathrm{~kW}$, and $13 \mathrm{~kW}$.

The electrically heated test runs were used to determine approximate fuel, canister, and transfer cask temperatures to be expected during fuel loading, drying, and backfilling operations and to determine approximate fuel, canister, and concrete temperatures to be expected during storage. To determine these temperatures, two sets of electrically heated test runs were conducted. The first set of test runs were performed with the DSC in the transfer cask to simulate loading the DSC in the spent fuel pool, draining water from the DSC, vacuum drying, and backfilling the DSC with helium. The second set of test runs was conducted with the DSC in the HSM to simulate the performance of the system during normal and offnormal storage operations. The off-normal conditions included higher than licensed heat loads and blockage of the air inlets and/or outlets.

\section{DSC in Transfer Cask}

A CP\&L General Electric IF-300 transportation cask was used to transfer the loaded DSC from the spent-fuel pool to the HSM. The first four heater test runs were conducted with the DSC in the IF- 300 shipping cask to simulate DSC loading, drying, and backfilling operations. Figure 4-1 shows an end view of the DSC loaded in the IF-300 shipping cask. This configuration was used for the first four heater test runs (see Table 4-1).

Fifteen thermocouples were used to assess the thermal performance of the DSC and transfer cask during these test runs. One of the thermocouples recorded ambient temperature, 2 were attached to the top outside surface of the DSC, and the remaining 12 thermocouples were used to monitor temperatures inside the DSC. The location of these thermocouples is shown in Figure 4-2.

Table 4-1 shows the peak recorded temperatures for the dry storage canister in the transfer cask. These temperatures ranged from $50^{\circ} \mathrm{C}$ with the canister filled with water to $255^{\circ} \mathrm{C}$ during the vacuum drying. At the conclusion of the vacuum drying process, the canister was backfilled with helium and the peak temperature dropped to $138^{\circ} \mathrm{C}$.

Figure 4-3 shows the transient performance of the cask/canister system during DSC loading, drying, and backfilling operations. The measurement locations of the five 


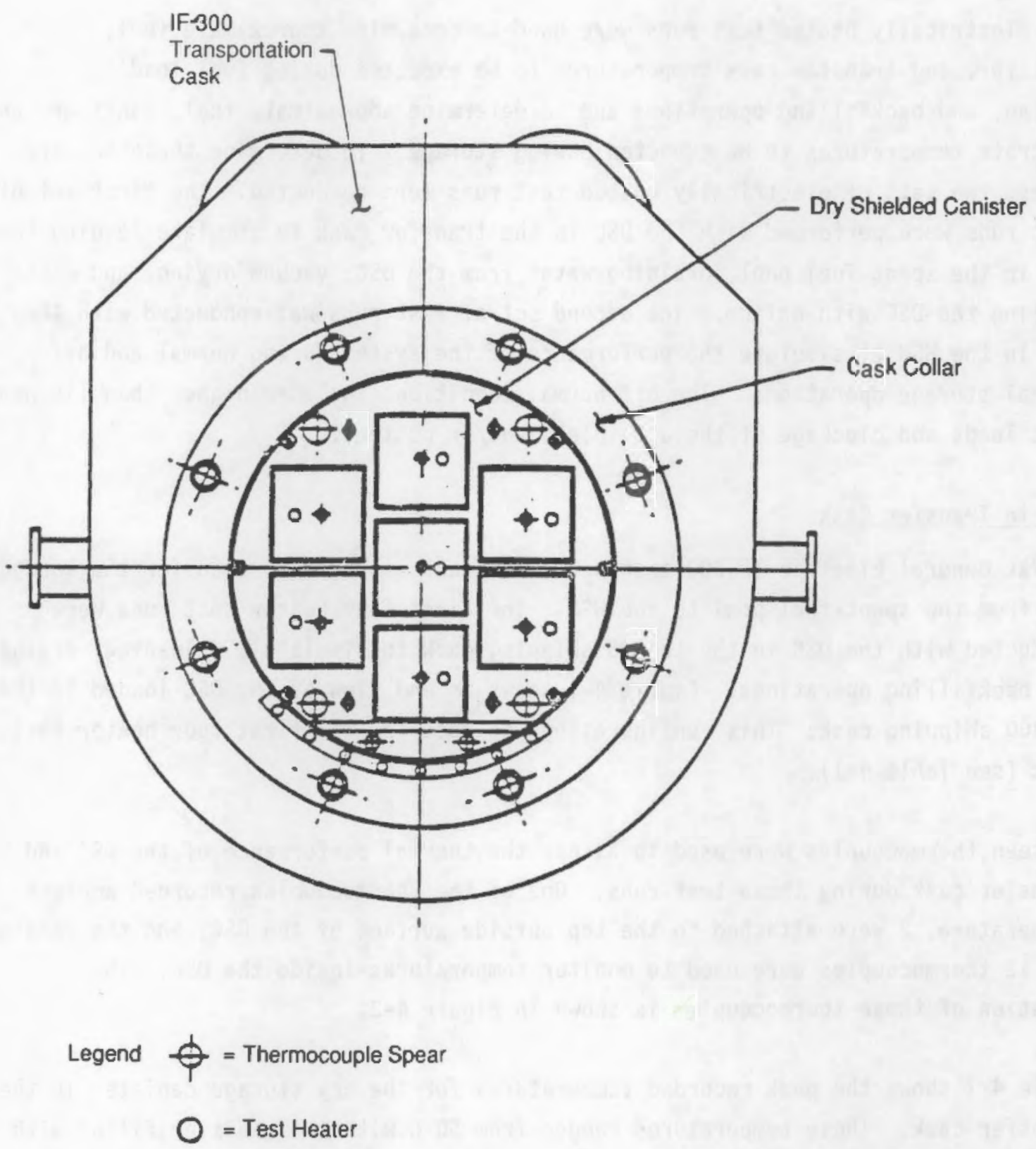

Figure 4-1. Dry Storage Canister and Heater Locations Associated with the First Four Heater Test Runs 


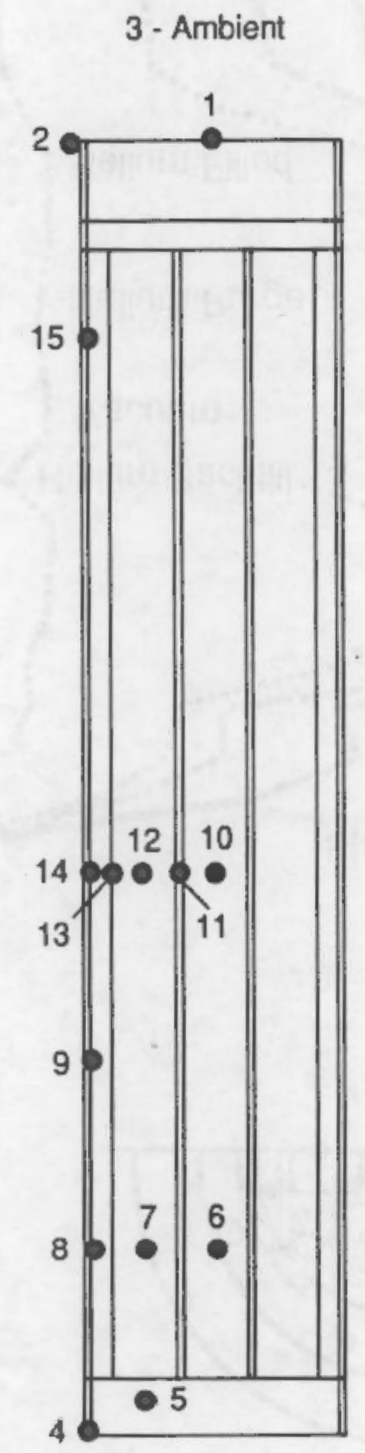

Figure 4-2. Location of DSC Thermocouples Used in the Electrically Heated Test Runs in the Transfer Cask 


\section{Mid Elevation}

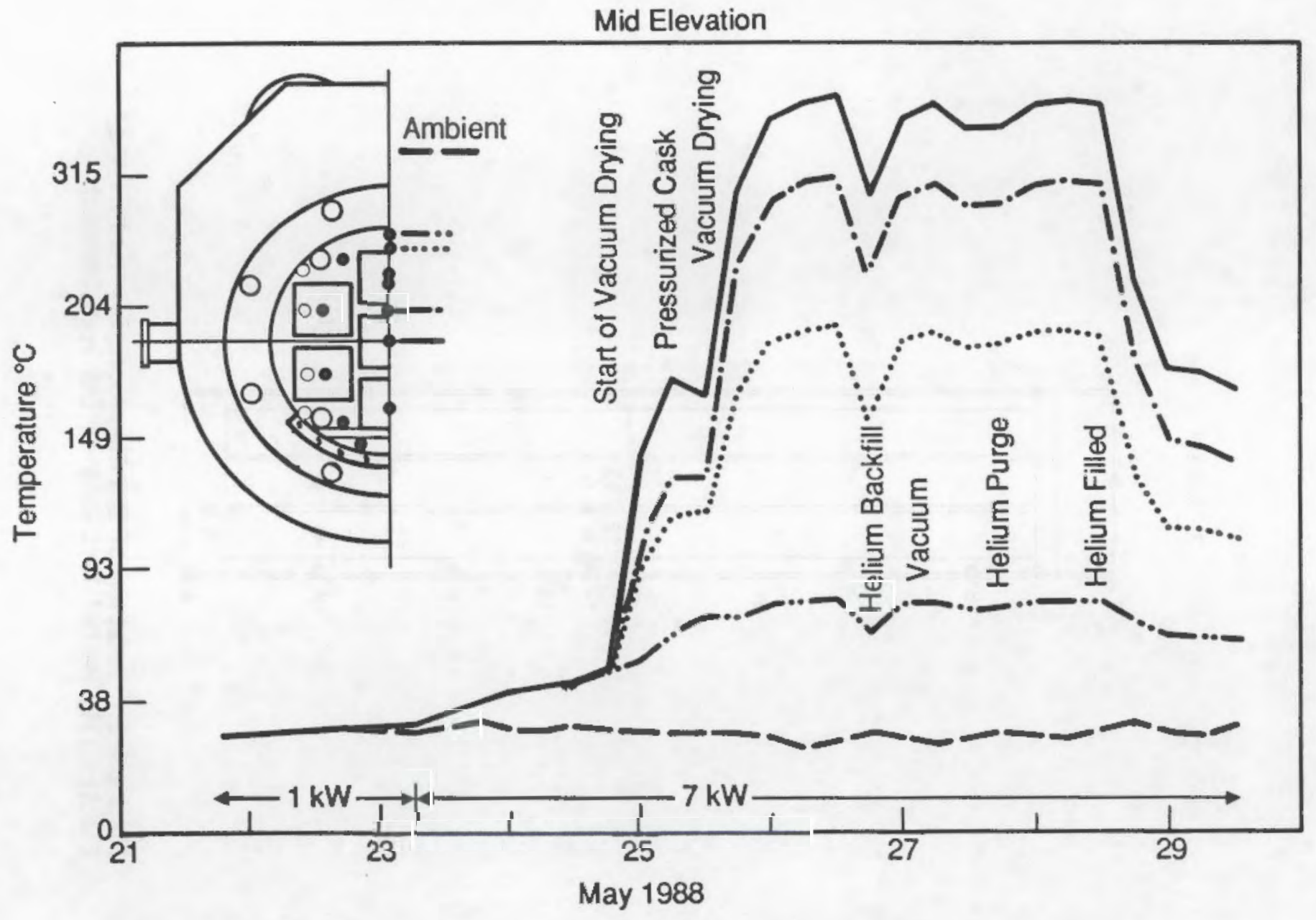

Figure 4-3. Dry Storage Canister Temperatures During Simulated Fuel Loading 
internal DSC thermocouples used to produce the data are identified in Figure 4-2. They were located near the axial midplane of the cask, about $78 \mathrm{in}$. from the bottom of the DSC.

At the start of the transient period, the cask was full of water and the cask, DSC, and water were at ambient temperature. The curves show that the temperatures at the indicated locations were close to the ambient temperature until the heater power was increased to $7 \mathrm{~kW}$. At $7 \mathrm{~kW}$, the temperatures increased slowly until the water was drained from the cask. At the start of vacuum drying, the temperatures increased rapidly until steady-state temperatures were reached. Two anomalies were observed, temperature plateaus on May 25 and temperature dips on May 26 . These temperature anomalies were caused by a short-duration backfilling of the cask with helium. Rapid decreases in temperatures occurred on May 28 when the cask was again backfilled with helium.

\section{DSC in Horizontal Storage Module}

After the DSC was backfilled with helium, it was transferred to the HSM where additional heater test runs were conducted to simulate the NUHOMS system performance with spent fuel (see Table 4-1).

Seventy-six thermocouples were used to assess the thermal performance of the DSC and HSM during these tests. Three thermocouples recorded the ambient temperature, 12 recorded the outlet air temperature, 25 were used to monitor DSC temperatures, and 36 monitored the HSM heat shield and concrete temperatures.

Test run HT-5 simulated the normal operation of the NUHOMS system. Test run HT-6 shows the effect of plugging the air inlets. In test run HT-7, the outlet vents were plugged along with the inlet vents. At the end of test run HT-7, the inlet and outlet vents were unplugged. In test run HT-8, the heater power was increased to about $13 \mathrm{~kW}$ and then decreased to $2.2 \mathrm{~kW}$.

Table 4-1 shows the peak recorded temperatures for the DSC in the HSM. During normal operation (test run HT-5), peak basket, heat shield, and concrete temperatures reached $201{ }^{\circ} \mathrm{C}, 79^{\circ} \mathrm{C}$, and $58^{\circ} \mathrm{C}$, respectively. Blockage of the air inlet vents (test run HT-6) increased basket, heat shield, and concrete temperatures by about $15^{\circ} \mathrm{C}$. However, the temperature difference between the canister and the heat shield did not change appreciably, indicating that the heat shield was still being cooled by convection. It should also be observed that the difference between the peak 
concrete temperature and the ambient temperature increased when the air inlets were blocked indicating a small corresponding decrease in cooling. It appears that blocking the inlet vent did not significantly affect the heat dissipation capability of the module.

When both inlet and outlet air vents were blocked (test run HT-7), the heat shield temperature increased more than the concrete and DSC temperatures (see Table 4-1). The canister and DSC temperatures increased by about the same amount and the difference between the concrete and ambient temperatures increased. The reason the heat shield temperatures increased more than the concrete and DSC temperatures was because connective heat loss from the heat shield was decreased because of total airflow blockage. The variable power level test runs show that the tests performed as expected.

Table 4-1 shows a substantial increase in basket temperatures for an increase of heater power from 7 to $13 \mathrm{~kW}$ (test run HT-8); this increase was accompanied by an increase in heat shield and concrete temperatures. However, the concrete temperatures were not much different from those for a partial blockage. When the power was cut back to $2.2 \mathrm{~kW}$, basket, heat shield, and concrete temperatures decreased as expected.

The transient performance of the DSC and HSM is shown in Figure 4-4. The temperature measurement locations chosen in Figure 4-4 were selected to show the response of the canister skin, HSM heat shield, and concrete to changes in canister heater output and airflow.

As the heaters were turned on at the beginning of test run HT-5, the temperature of the storage sleeves ( $\mathrm{C5}$ and $\mathrm{C8}$ ), canister shell (C1), and heat shield (HS40) increased rapidly. The inner concrete temperature ( $\mathrm{HB}$ ) also increased, but at a slower rate and the outer concrete temperature (H15) paralleled the ambient temperature. The reason for the difference between the outer concrete temperature and the ambient temperature may be because of solar heating. Similar differences in ambient temperature and inlet air temperatures were observed.

Steady-state temperatures were approached by the end of test run HT-5 as can be seen by the leveling out of the temperatures and by the temperatures on 0ctober 3 . The temperatures on October 3 represent conditions similar to those on 


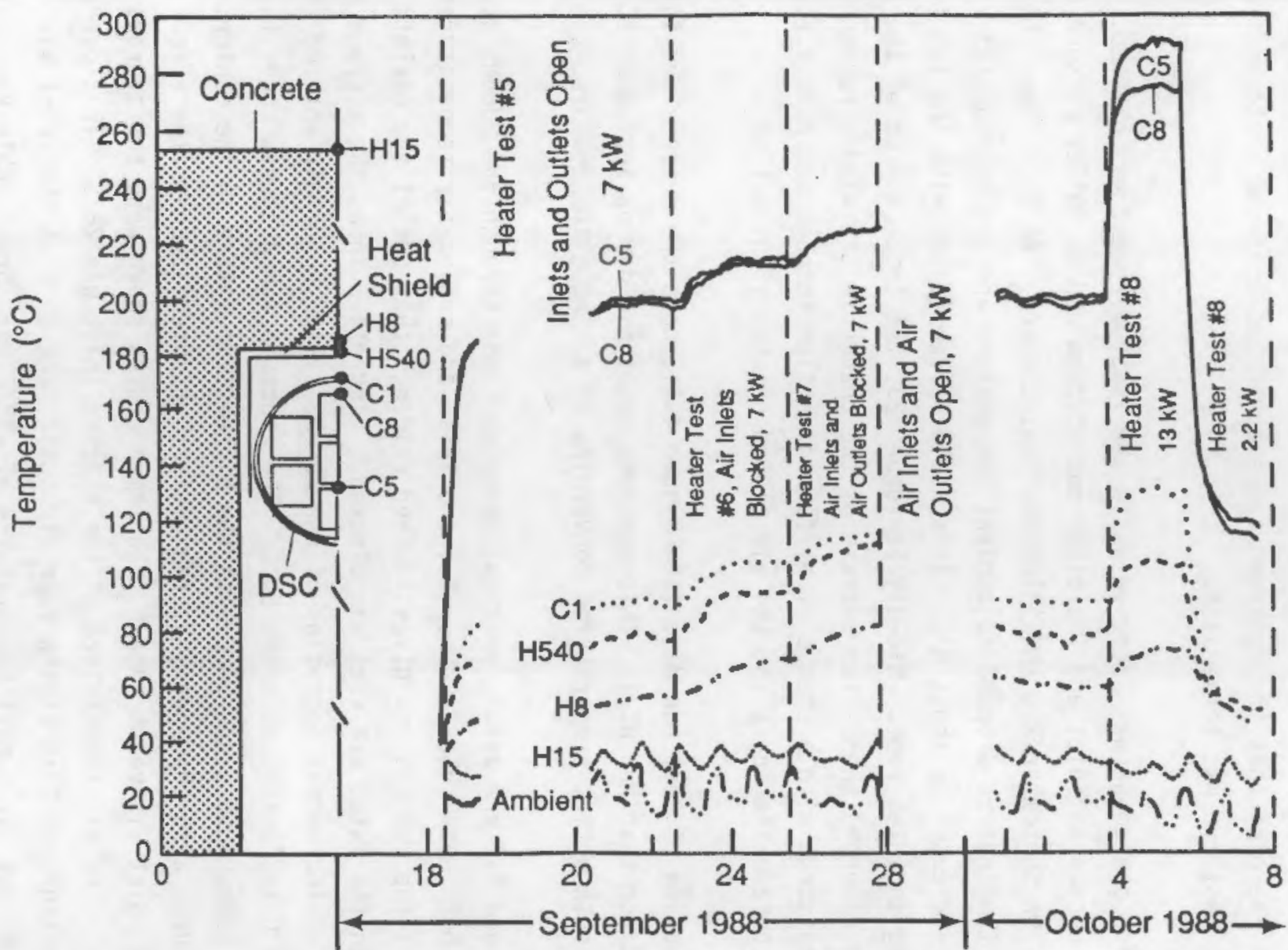

Figure 4-4. Temperature Performance of the NUHOMS System During the Electricaliy Heated Tests 
September 20. The temperatures on September 20 were reached by heating the NUHOMS system from a lower temperature and those on October 3 were reached by cooling the system from a higher temperature. Both had a heat input of $7 \mathrm{~kW}$.

In test run HT-6, the air inlet vents were blocked, resulting in a small increase in the canister, heat shield, and internal concrete temperatures. It is not evident from the plot that the concrete temperature had achieved a steady state by the time the test run was terminated.

An interesting phenomena was observed while the inlet air vent was blocked. One of the outlets became an inlet and the other outlet remained an outlet as seen in Figure 4-5. On September 22, the inlet vent was blocked. At this time, the front outlet vent temperature dropped to ambient temperature and the rear outlet vent temperature increased by about $5^{\circ} \mathrm{C}$. This would be consistent with the front outlet vent becoming an inlet vent. Mid-day September 23, the temperatures of the two outlet vents reversed themselves because of the change in the wind direction, this would be consistent with a change of airflow direction through the HSM; i.e., the rear outlet became the inlet and the air flowed out the front outlet.

At the conclusion of test run HT-6 (see Figure 4-4), both the outlets and inlets were blocked for test run HT-7. This occurred about mid-day on September 26 and resulted in both outlet temperatures converging to a single temperature.

Figures 4-6 and 4-7 are axial, vertical cross sections through the NUHOMS system showing the DSC, heat shield, concrete, and inlet and outlet air temperatures. Comparison of the two figures gives further evidence that one of the outlets became an inlet when the inlet air vent was blocked. Figure 4-6 shows the average module temperature during normal operation of the NUHOMS system. The air entered the system at $23^{\circ} \mathrm{C}$ and exited at about $50^{\circ} \mathrm{C}$. The concrete temperatures above the heat shield were between $55^{\circ} \mathrm{C}$ and $58^{\circ} \mathrm{C}$ with the higher temperature in the center. The DSC temperatures also show peaks at the center. Figure 4-7 shows the effect of blocking the inlet air vent. Again, the temperatures shown were the average temperatures. The air temperature at the blocked inlet was $28^{\circ} \mathrm{C}$. This corresponds with a temperature of $27^{\circ} \mathrm{C}$ at the rear air outlet and $65^{\circ} \mathrm{C}$ at the front air outlet, compared with peak air outlet temperatures of $\sim 50^{\circ} \mathrm{C}$ for normal unblocked operation. The concrete surface temperature near the cooler outlet $\left(37^{\circ} \mathrm{C}\right)$ was the same as the center concrete surface temperature. Finally, the concrete temperature next to the 


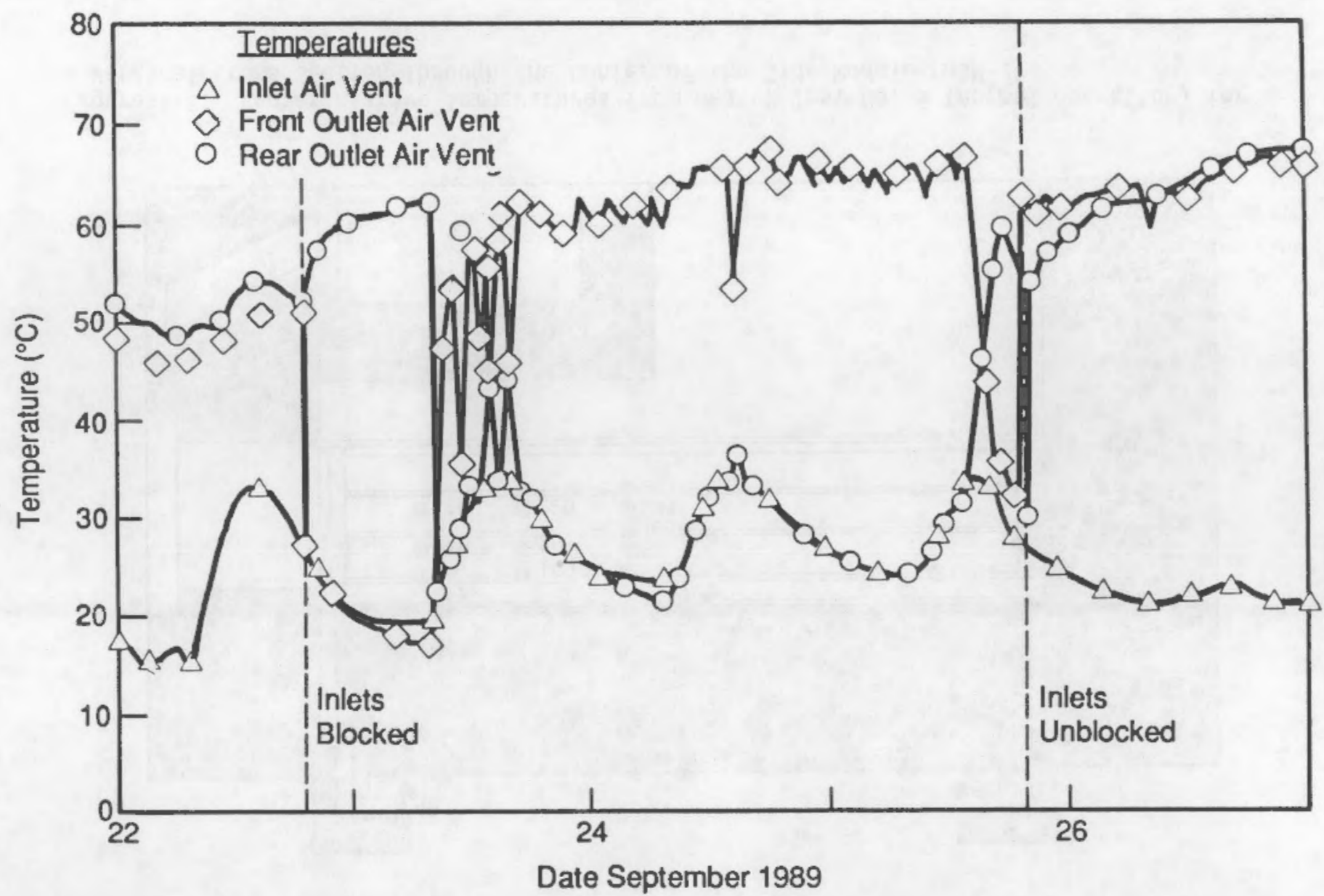

Figure 4-5. Effect of Blocking the Inlet Air Vents 


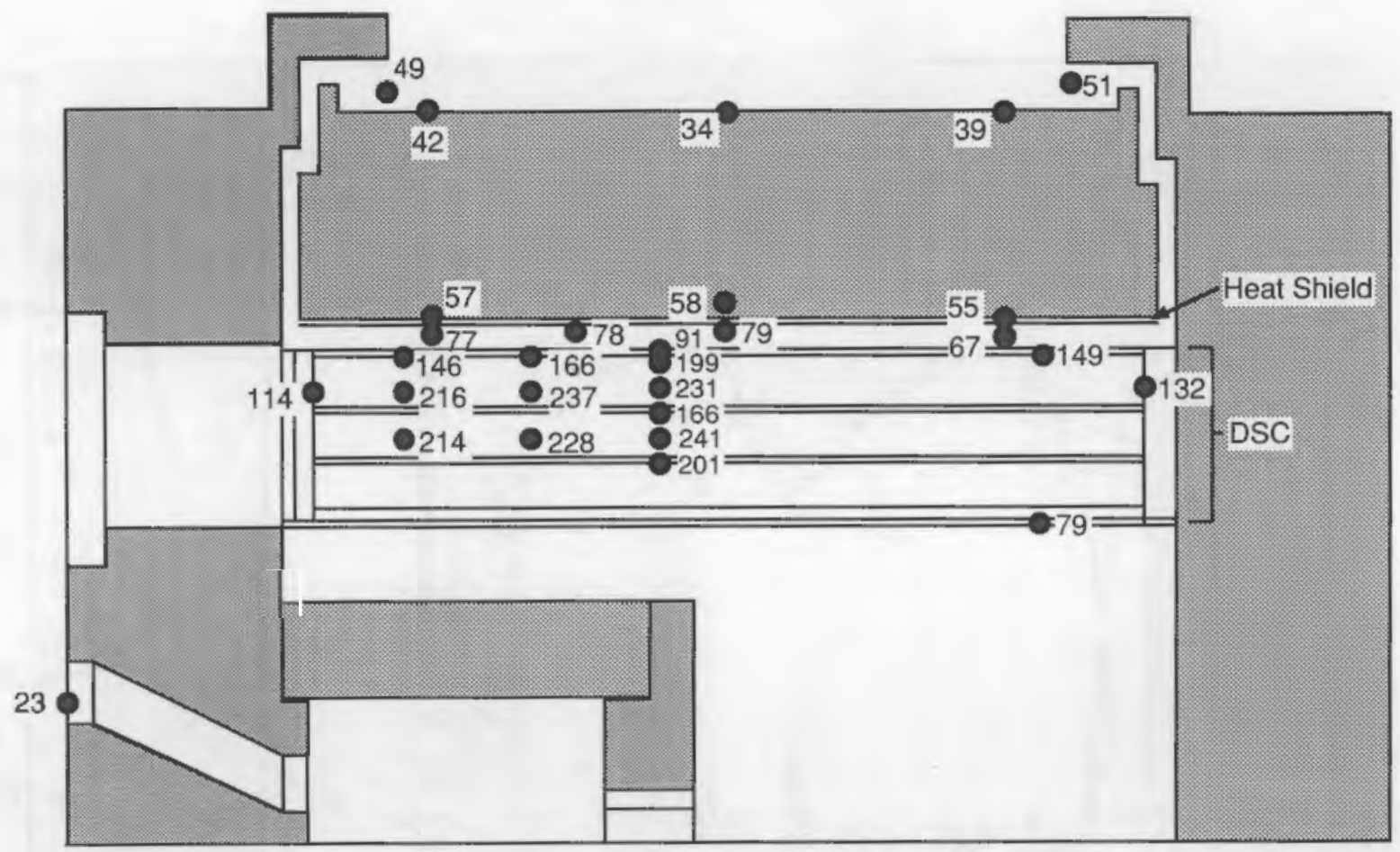

Figure 4-6. Representative Temperatures from Heater Test No. 5 (normal operation) for a Vertical Cross Section Through the Center of the Side Module (HSM-3) 


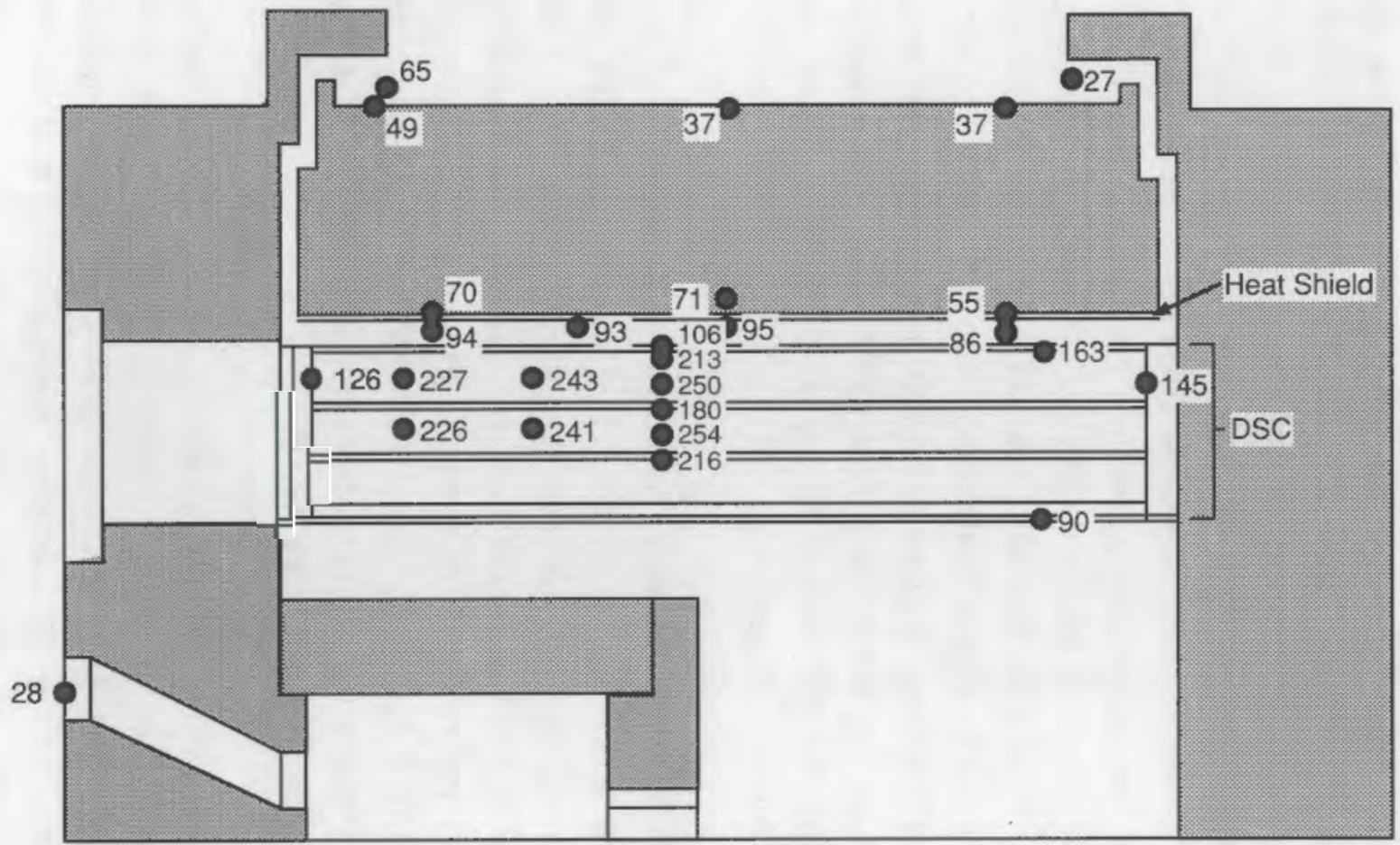

Figure 4-7. Representative Temperatures from Heater Test No. 6 (7 kW, inlets blocked) for a Vertical Cross Section Through the Center of the Side Module (HSM-3) 
heat shield at the rear of the module was the same for the inlet, blocked as it was for normal operation. The other internal concrete and heat shield temperatures increased during inlet air blockage. Therefore, one of the outlets acted as an inlet when the inlet vents were blocked.

Figure 4-4 shows evidence of a lack of airflow in the HSM with all vents blocked (test run $\mathrm{HT}^{-7}$ ). Without convective cooling, the temperature of the heat shield approached that of the DSC and the temperature of the concrete continued to increase. The temperatures of the canister and the concrete would be expected to increase until the temperature gradient through the concrete was sufficient to conduct the heat to the outside air. However, the rate of temperature increase of the concrete, DSC, and heat shield indicate that a steady state was not achieved during the complete air blockage heater test run. The rate of inside concrete temperature increased at the time the test run was terminated on the order of $4^{\circ} \mathrm{C} /$ day; this was not a particularly rapid temperature increase indicating that the system was close to equilibrium. Figure 4-8 shows the temperatures of a vertical slice through the cask during the total air blockage case. The temperatures were obtained near the end of the test run on September 27, 1989, and are consistent with the temperatures found in Figure 4-4.

When the inlet and outlet air vents were unblocked to start test run HT-8, the temperature returned to normal as can be seen in Figure 4-4. During the early part of test run $\mathrm{HT}-8$, the heat input to the canister was increased from $7 \mathrm{~kW}$ to $13 \mathrm{~kW}$. This was accompanied with a rapid increase in the canister, heat shield, and inside concrete temperatures. The temperature plots in Figure 4-4 indicate that a steady state was achieved within 2 days. At this time, the heat input was decreased from $13 \mathrm{~kW}$ to $2.2 \mathrm{~kW}$. The temperature rapidly decreased and was beginning to approach steady state when test run HT-8 was terminated.

Figure 4-9 shows the temperature through an axial, vertical cross section of the NUHOMS system with a heat load of $13 \mathrm{~kW}$. Comparison of this figure with Figure 4-6 shows that increasing the heat load from 7 to $13 \mathrm{~kW}$ significantly increased $\left(100^{\circ} \mathrm{C}\right)$ the internal temperatures in the DSC canister, increased the heat shield temperature $\left(27^{\circ} \mathrm{C}\right)$, and had 1 ittle effect on the concrete $\left(17^{\circ} \mathrm{C}\right.$ increase) and the outlet air temperatures $\left(11^{\circ} \mathrm{C}\right.$ increase). 


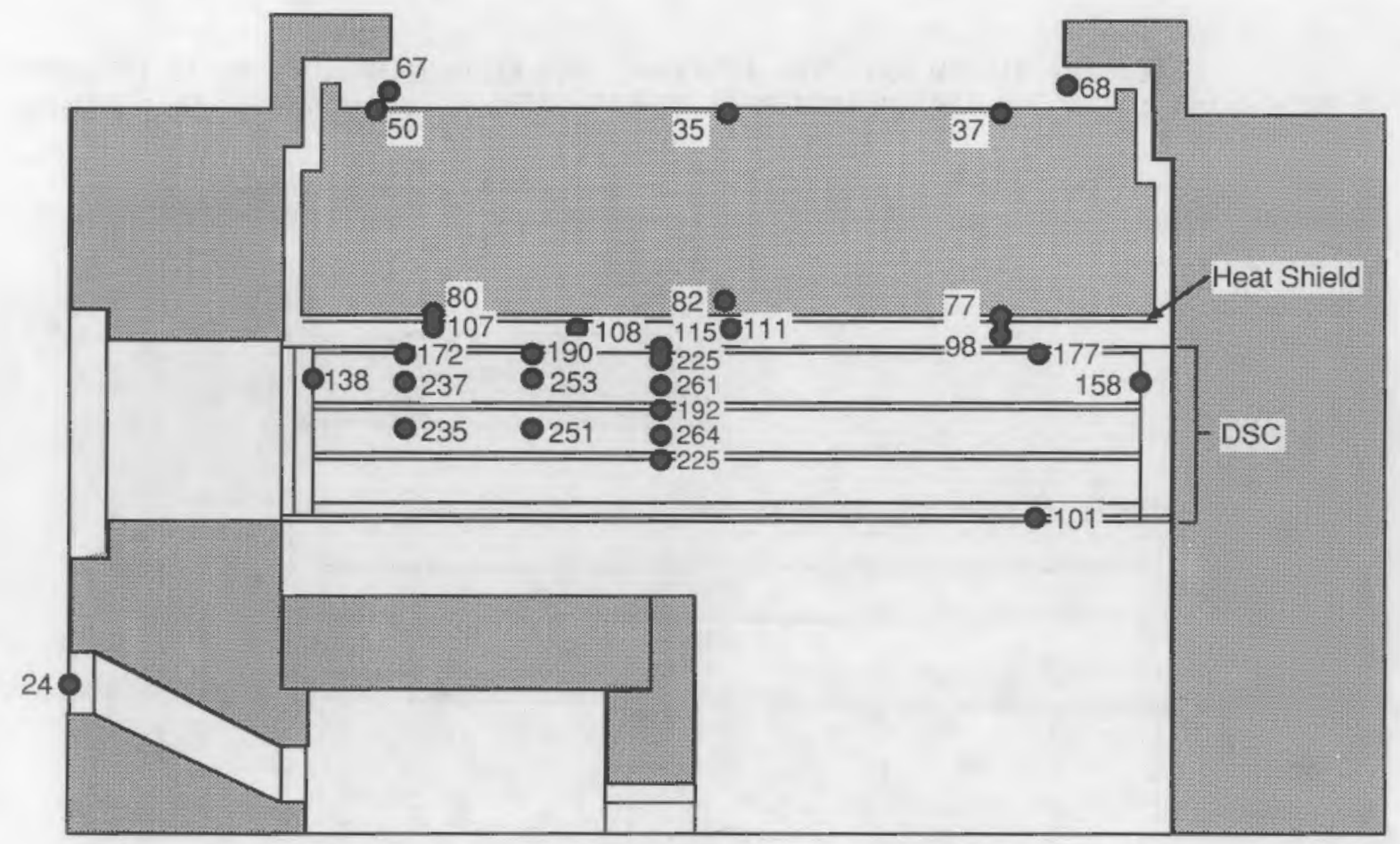

Figure 4-8. Representative Temperatures from Heater Test No. 7 (7 kW, Inlets and Outlets Blocked) for a Vertical Cross Section Through the Center of the Side Module (HSM-3) 


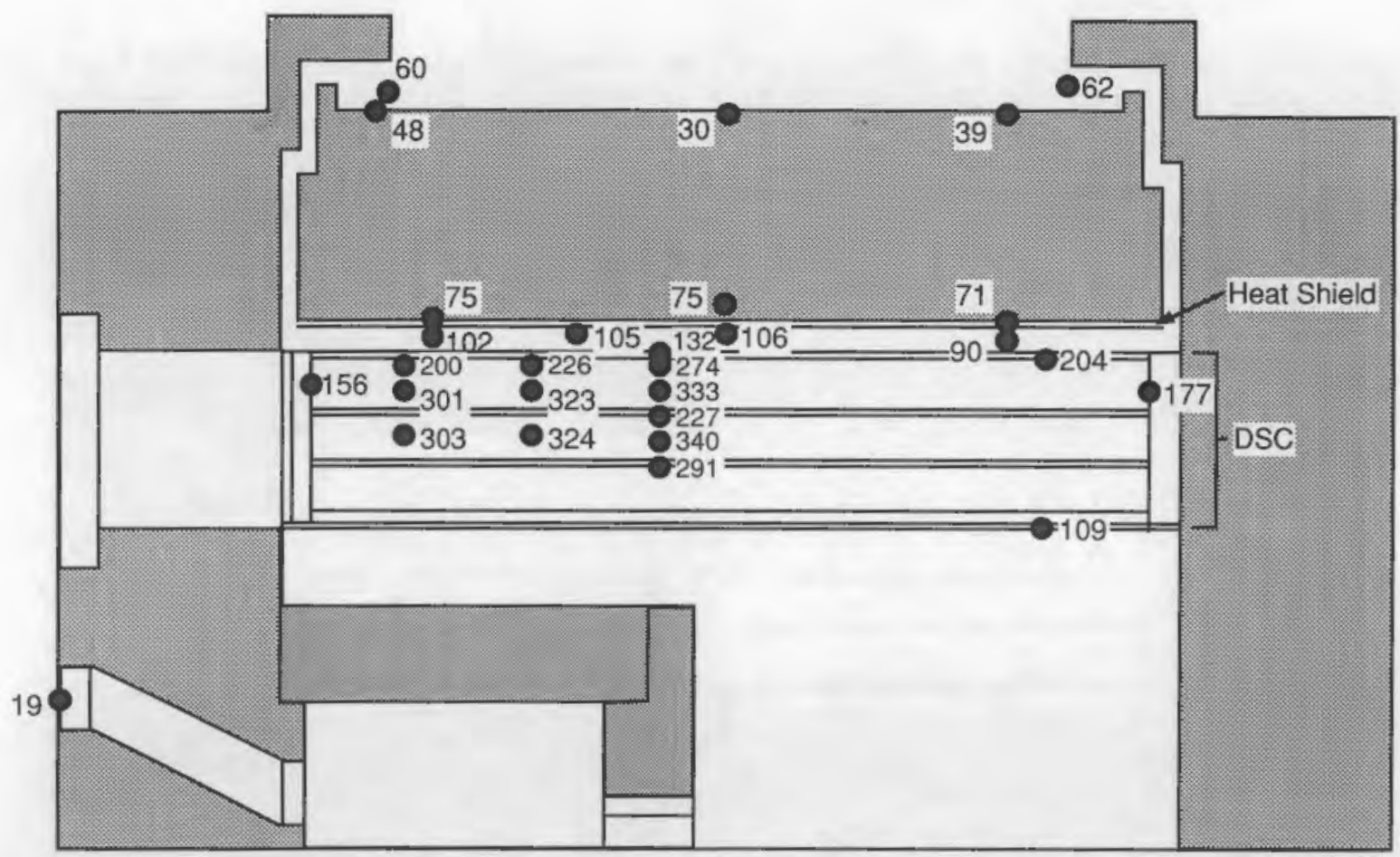

Figure 4-9. Representative Temperatures from Heater Test No. 8 (13 kW) for an Axial Vertical Cross Section Through the Center of the Side Module (HSM-3) 


\section{Spent-Fuel Storage Demonstration}

The NUHOMS system was loaded with spent fuel from March through JuTy 1989 . The first canister of fuel was loaded into HSM-1 on March 16, 1989. The next canister of fuel was loaded into the center module (HSM-2) on June 28, 1989. The final canister of fuel was loaded into HSM-3 on July 3, 1989. The HSM-2, HSM-3, and their respective canisters were instrumented with thermocouples.

Table 4-1 shows the peak temperatures measured in the fuel, basket, heat shield, and concrete for the spent fuel storage demonstration. The limited fuel temperature data were obtained from one thermocouple spear that survived the handling test, heater test, and fuel loading. The peak measured fuel temperature was $181^{\circ} \mathrm{C}$. This temperature corresponded to peak basket, heat shield, concrete, and ambient temperatures of $146,59,49$, and $29^{\circ} \mathrm{C}$, respectively. It is interesting to note that the peak fuel temperature did not change significantly with two or three modules loaded in the three-module HSM system. The fully loaded modules (three HSMs loaded) had slightly higher heat shield and concrete temperatures.

Data collection was started shortly after the canister of spent fuel was placed in HSM-2 and continued through September 1989. Part of the transient temperature history for this module is shown in Figure 4-10. The measurement locations selected for this plot are near the axial center of the module. The legend on the figure indicates their respective cross-sectional locations. Additional temperature measurements were taken to determine the temperature of the ambient, inlet, and outlet air. These temperatures are also shown on the plot.

The ambient-air and inlet-air temperatures should have been the same. The difference noted on the figure is probably due to location differences. It should be noted that these temperatures paralleled each other with near constant offset. The outlet-air temperatures did not show the characteristic temperature cycles of the ambient air. Apparently, the night/day ambient air cyclic temperatures were damped out by the thermal mass and heat transfer from the concrete and DSC. Only the outside surface of the concrete (H17) and the bottom surface of the DSC (C3) showed much daily temperature cycling (see Figure 4-10). The magnitude of these temperature cycles was reduced from those of the ambient air. The outlet air showed more variation from a mean or steady-state value than the other temperature traces. Since the spikes on these temperatures were predominately in the downward direction, they were attributed to wind gusts that would cool the outlet thermocouples 


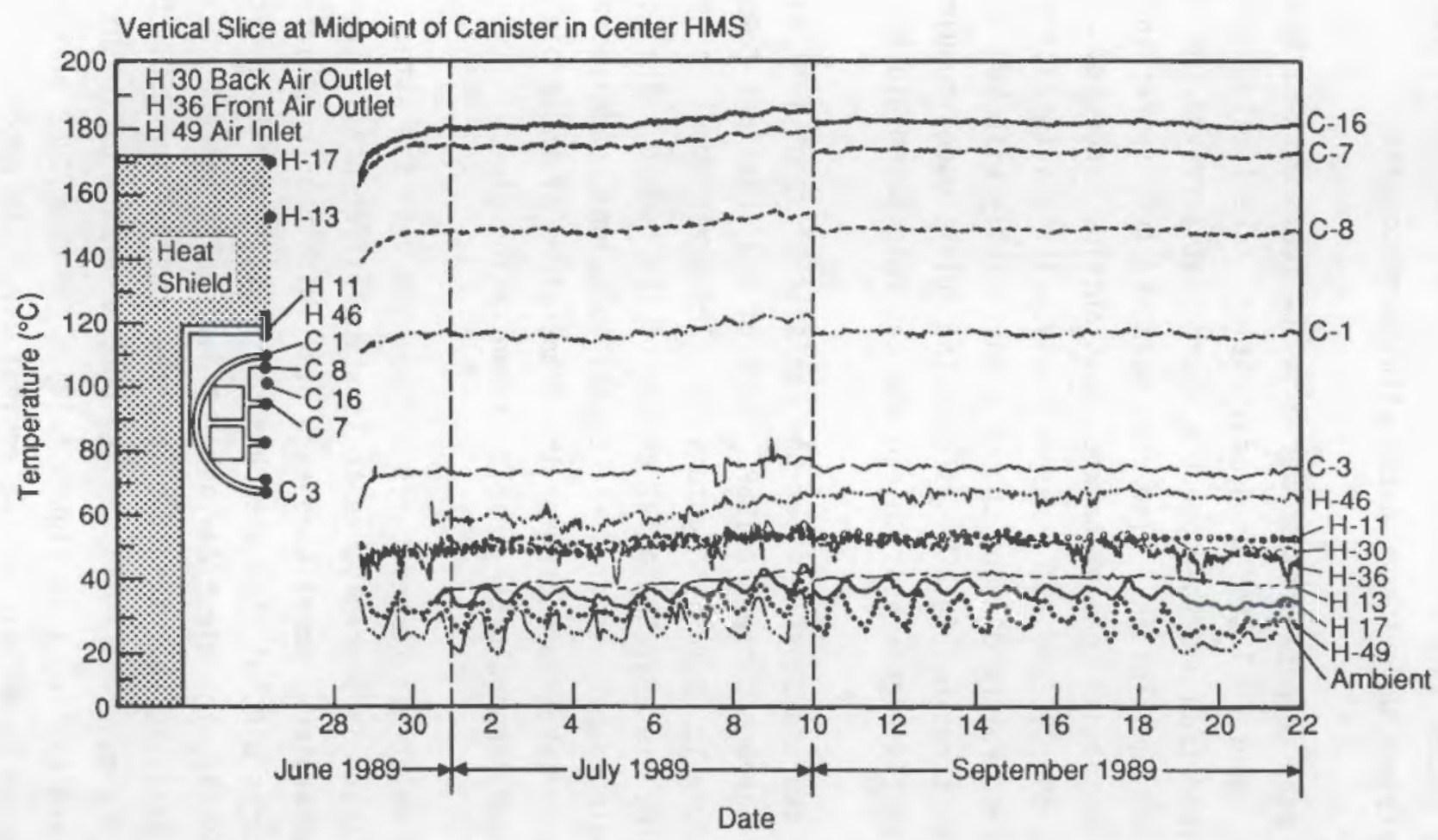

Figure 4-10. Temperature History from the Center DSC/HSM (HSM-2) Loaded with Spent Fuel. A vertical section through the axial midpoint of the canister can be seen. 
and hence lower their temperatures. The heat shield (H46) also showed some of the sporadic responses of the outlet temperature. This was also attributed to the effect of wind on the airflow in the HSM.

It should be noted that the temperature of the upper DSC skin (C1) was significantly hotter than the temperature of the lower skin (C3). This was caused by the airflow path and its localized temperature and flow rate. Position C3 was cooled with unheated air with potentially higher flow rates than those at $\mathrm{Cl}$. This can better be seen from an axial, vertical cross section through the module along the axis of the module as shown in Figure 4-11. Figure 4-11 al so shows the temperatures at all functional measurement locations and identifies the temperature measurement locations used in Figure 4-10. This section through the module shows that the skin temperatures of the DSC were higher at the top than at the bottom. The DSC internal temperatures peaked in the axial center as would be expected.

Figure 4-12 shows a cross section through the center of the modules at the measurement locations used in Figure 4-10. This axial location was about $9 \mathrm{ft} 10 \mathrm{in}$. from the front face of the module. This figure shows that the DSC skin temperature increased from $73^{\circ} \mathrm{C}$ at the bottom to $85^{\circ} \mathrm{C}$ at the side to $116^{\circ} \mathrm{C}$ at the top. Temperatures of the empty sided HSM-3 were cooler than the loaded center HSM side as would be expected.

The third canister of fuel was loaded into the HSM on July 3, 1989. This canister of fuel was placed in HSM-3 and completed the loading of the three-module NUHOMS system. The presence of this canister had little effect on the temperatures of the center module/canister as can been seen from additional examination of Figure 4-10. As the figure shows, very little heating of the center canister, fuel, or concrete occurred after the final module was loaded. What little heating did occur paralleled the increase in average ambient temperature. Therefore, it was concluded that the operation of one module has little impact on the operation of adjacent modules.

The temperatures of axial and vertical cross sections through the modules are shown in Figures 4-13 through 4-15. Figures 4-13 and 4-14 show axial and vertical cross sections through the axis of the center and side instrumented modules. The temperatures of corresponding locations were about the same as would be expected because the heat generation rates in the two modules were about the same. However, the outlet air temperature from the side module was slightly less than the 


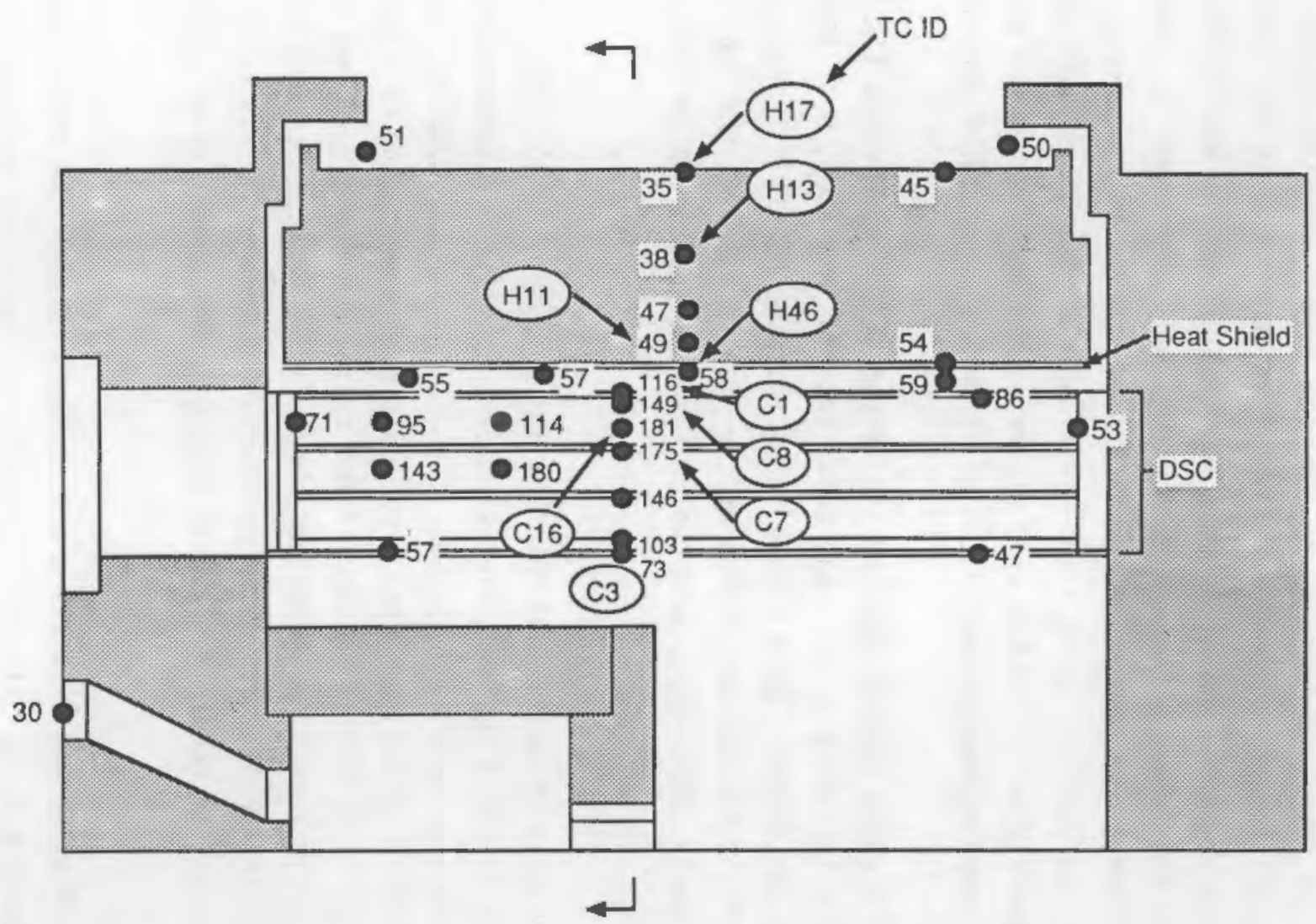

Figure 4-11. Representative Temperatures from the Center DSC/HSM Loaded with Spent Fuel on July 3, 1989, Prior to Loading the Side Module (HSM-3). This is a vertical-section view through the center of HSM-2. 


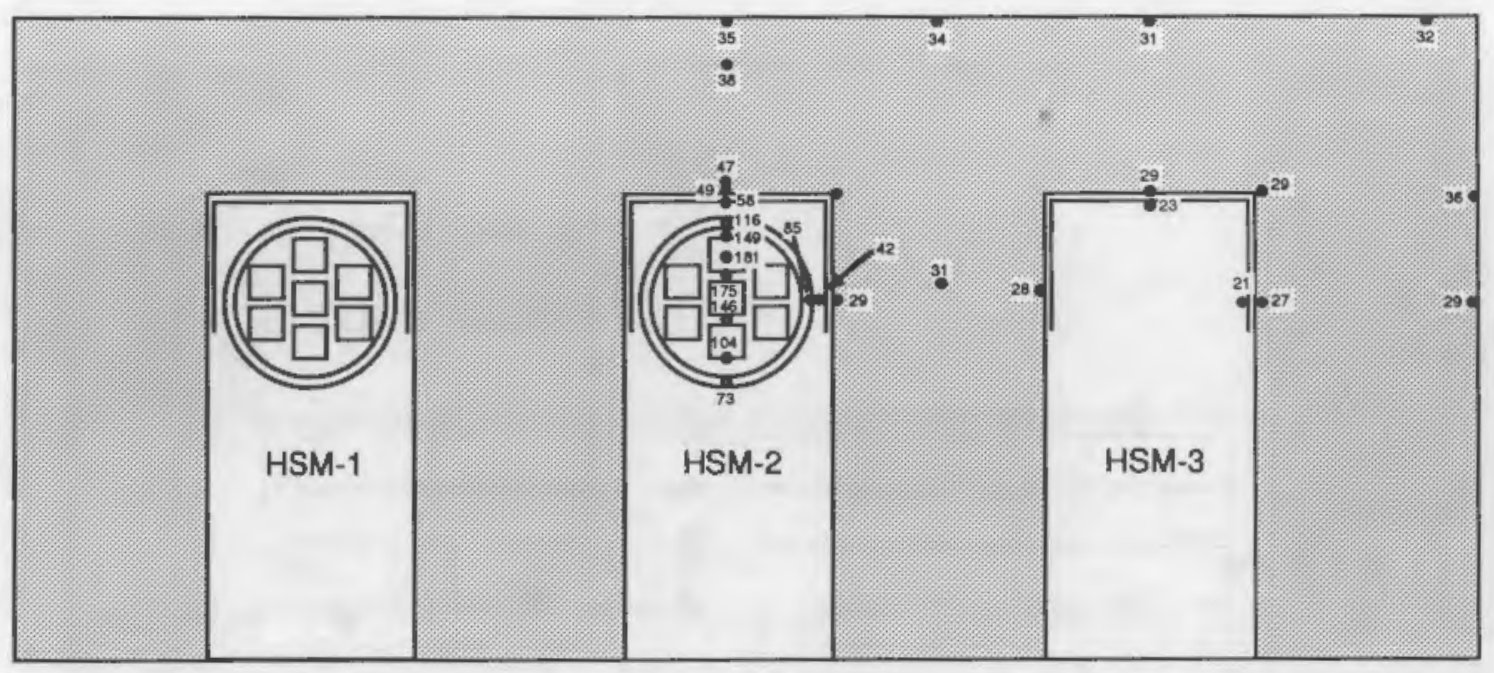

Figure 4-12. Temperatures in the NUHOMS System on July 3, 1989, Prior to Loading Spent Fue1 in the Last Module (HSM-3). A vertical section through the axial midpoint of the canisters can be seen. 


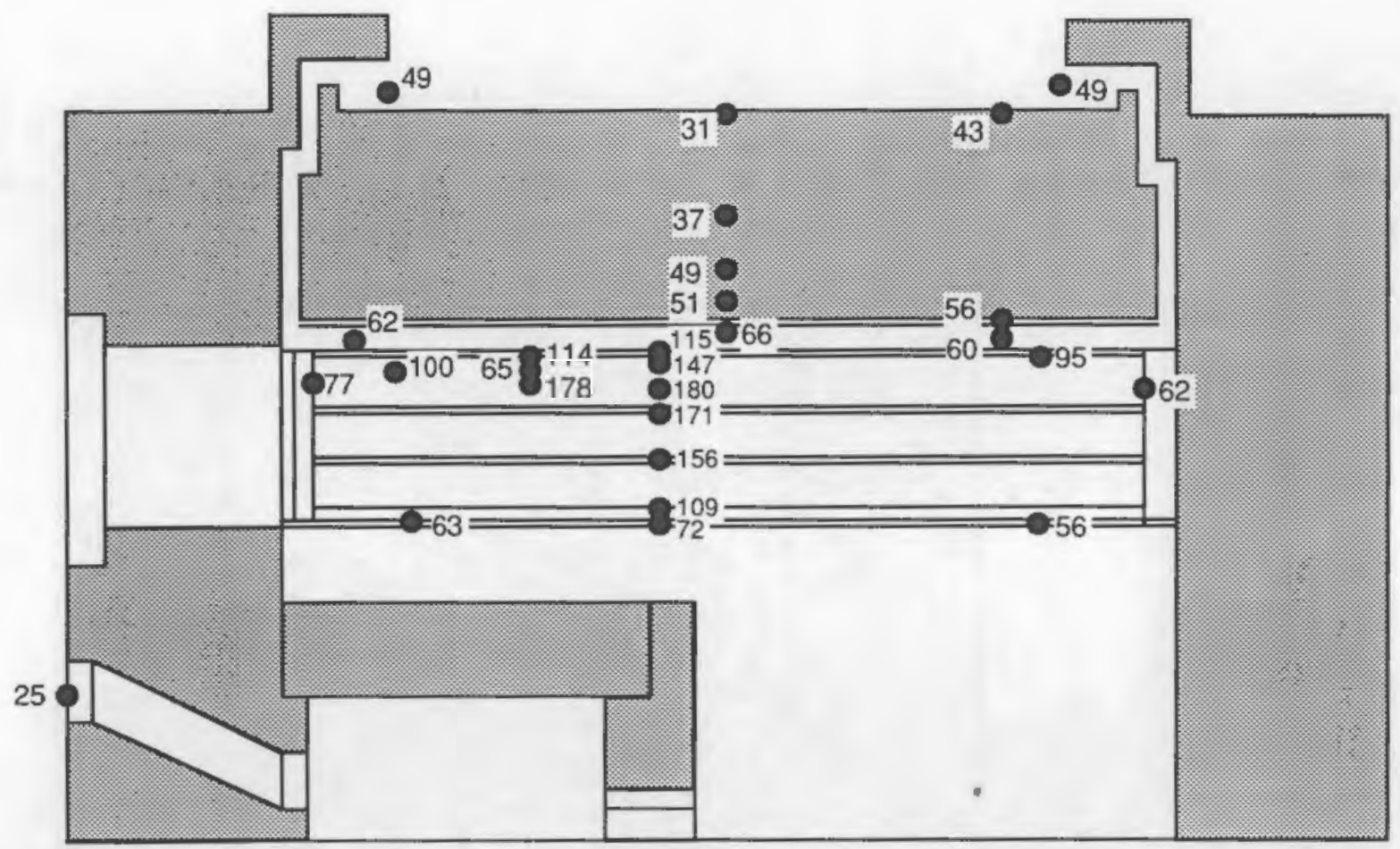

Figure 4-13. Temperatures in the NUHOMS System on September 21, 1989, with all Modules Loaded with Spent Fuel. A vertical section along the axis of the center module (HSM-2) can be seen. 


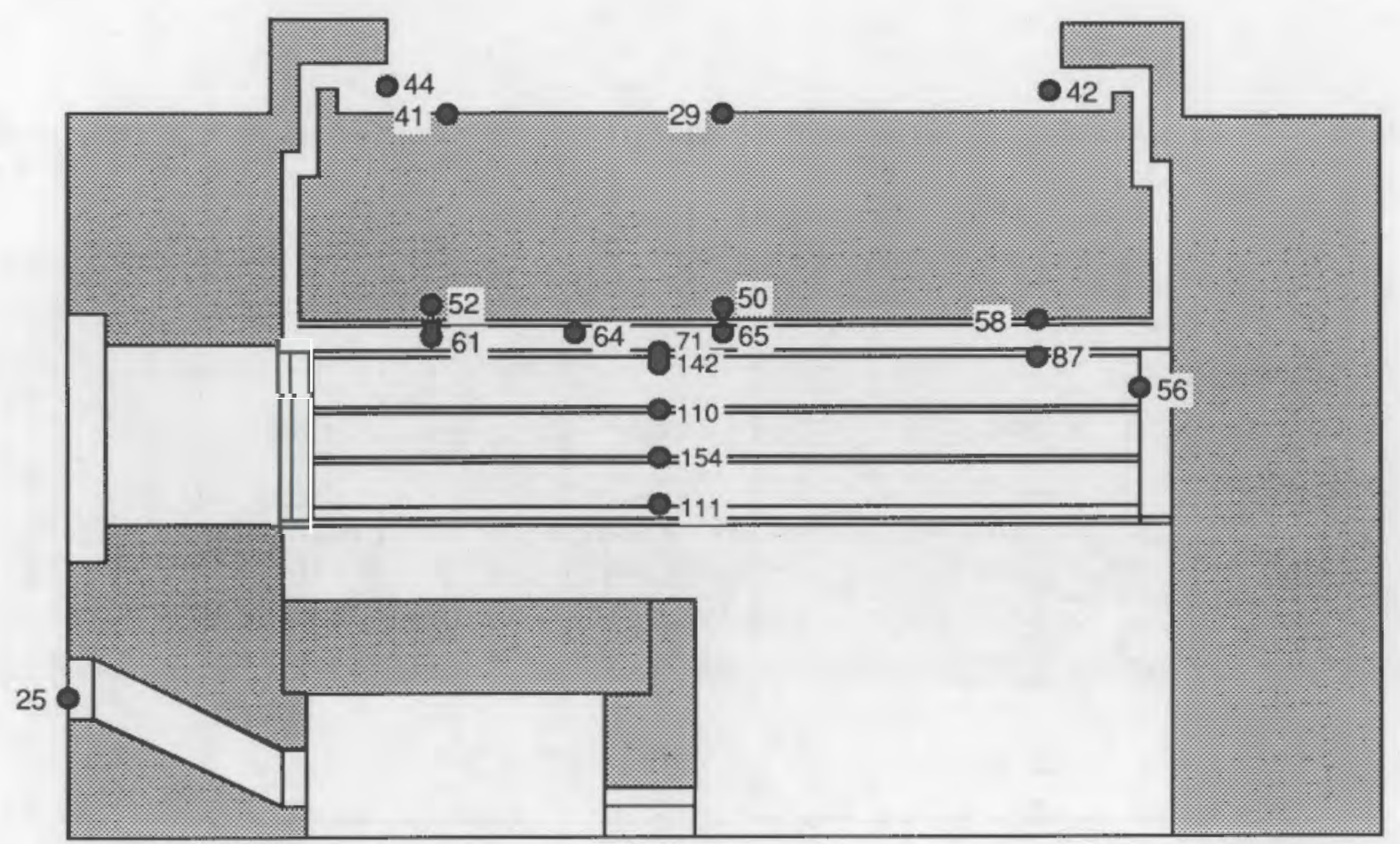

Figure 4-14. Temperatures in the NUHOMS System on September 21, 1989, with all Modules Loaded with Spent Fuel. A vertical section along the axis of the side module (HSM-3) can be seen. 


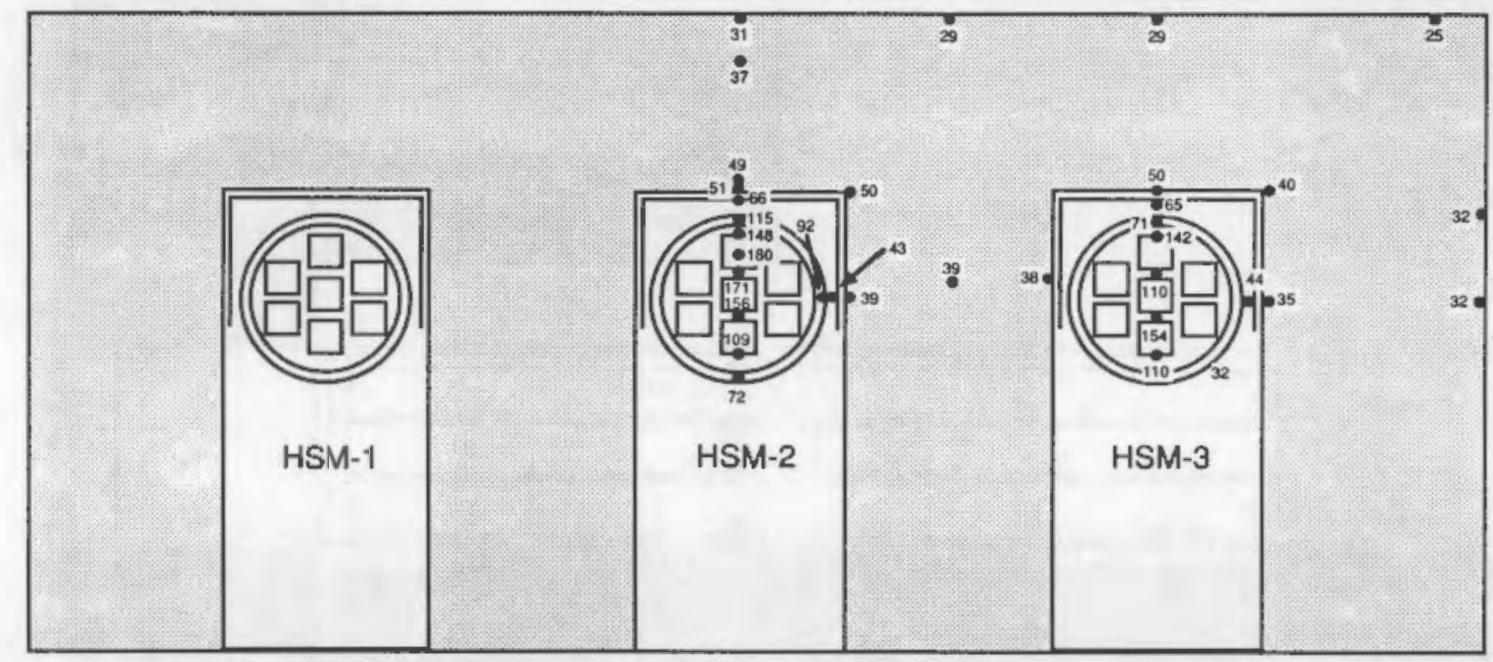

Figure 4-15. Temperatures in the NUHOMS System on September 21, 1989, with all Modules Loaded with Spent Fuel. A vertical cross section through the midpoint of the canisters can be seen. 
temperature from the center module. This may have been caused by heat loss through the exterior surface of the side module. The center module did not lose significant amounts of heat through transverse conduction due to the insulating effect of the two adjacent side modules. Figure 4-15 supports this hypothesis. This figure shows that the side module exterior wall temperature was $32^{\circ} \mathrm{C}$ and the inside concrete wall temperature was as $10 \mathrm{w}$ as $35^{\circ} \mathrm{C}$. At a similar location in the center module, the concrete temperatures from the center module to the side module only decreased by $1^{\circ} \mathrm{C}\left(39\right.$ to $\left.38^{\circ} \mathrm{C}\right)$.

\section{SHIELDING}

Dose rates were measured at selected locations on the surface of the modules and $3 \mathrm{ft}$ from the modules. The results of these measurements are shown in Figure 4-16. As can be seen from the figure, the major part of the total surface dose rates was a result of gamma radiation but the dose rates were relatively low. All neutron dose rates were low. At a distance of $3 \mathrm{ft}$, the doses due to gamma sources were also very low.

It is interesting to note that the gamma dose rate around the front outlet air vent was much greater than at the rear outlet air vent. This could be caused by the alignment of the DSC in the HSM module. The fuel assemblies lower end fittings (sources of high gamma dose rates resulting from cobalt-60) were more nearly aligned with the front outlet air vent than were the upper end fittings with respect to the rear outlet air vent. This may have resulted in some radiation streaming through the front outlet air vent. Other dose rates higher than $0.5 \mathrm{mrem} / \mathrm{hr}$ neutron and $2 \mathrm{mr} / \mathrm{hr}$ gamma are associated with penetrations through the HSM. 


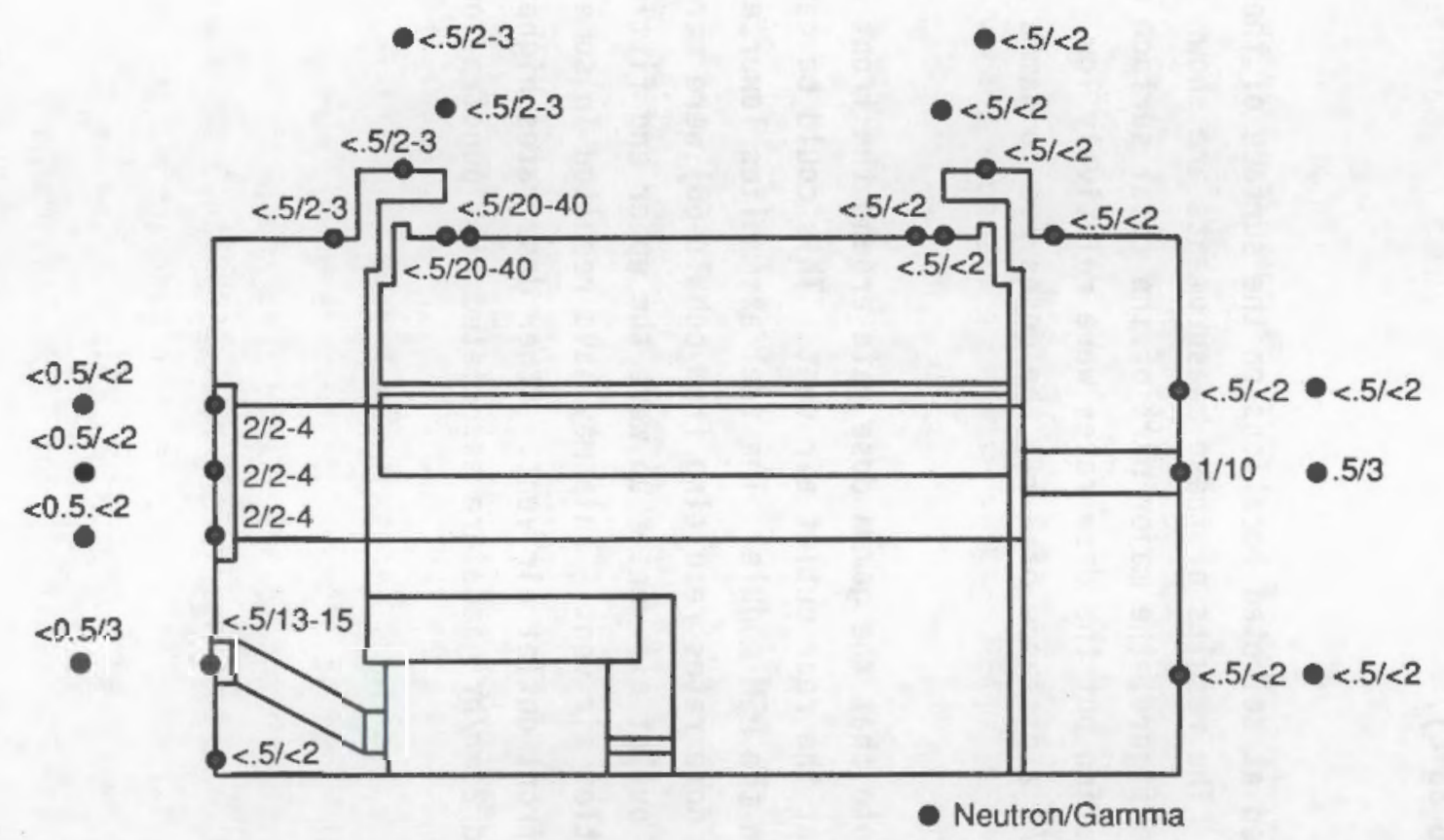

Figure 4-16. Radiation Dose Rates at the Surface of the Modules and at $3 \mathrm{ft}$ from the Surface (mrem/hr) 


\section{Section 5 \\ REFERENCES}

1. NUTECH Engineers, Inc. "Topical Report for the NUTECH Horizontal Modular Storage System for Irradiated Nuclear Fuel," NUH-001, Rev. 1A, NUTECH Engineers, Inc., San Jose, CA (1984).

2. Carolina Power and Light Company. "Independent Spent Fuel Storage Installation Safety Analysis Report H. B. Robinson Steam Electric Plant," Carol ina Power and Light Co., Raleigh, NC (1985).

3. "General Description: IF-300 Irradiated Fuel Transportation System," NEDO-10864C, General Electric Co., San Jose, CA, July 1983.

4. U.S. Department of Energy. "Spent Fuel Storage Requirements 1989-2020," DOE/RL-89-30, U.S. Department of Energy, October 1989.

5. U.S. Department of Energy. "Solicitation for Cooperative Agreement Proposal," DE-SC06-83RL10421, U.S. Department of Energy, 1983. 

Appendix A

SPENT FUEL DATA

Table A-1

FUEL ASSEMBLY DATA

Horizontal Storage Module HSM-1 (side) Loaded 3/16/89

$\begin{array}{lrrrrrrr}\text { Fuel assembly ID no. } & \text { K05 } & \text { K25 } & \text { K06 } & \text { K20 } & \text { K12 } & \text { K42 } & \text { K35 } \\ \text { Initial enrichment } & 2.90 & 2.90 & 2.90 & 2.90 & 2.90 & 2.90 & 2.90 \\ \text { Active fuel length, in. } & 144 & 144 & 144 & 144 & 144 & 144 & 144 \\ \text { Burnup, MWd/MTU } & 32344 & 31894 & 33556 & 32374 & 33691 & 33686 & 33761 \\ \text { Decay heat, W (3/16/89) } & 776 & 765 & 834 & 775 & 818 & 823 & 818 \\ \text { Cooling time, days } & & & & & & & \\ \quad \text { (1/26/89) } & 1825 & 1825 & 1825 & 1825 & 1825 & 1825 & 1825 \\ \text { Cycles irradiated } & \text { R2C7 } & \text { R2C8 } & \text { R2C8 } & \text { R2C8 } & \text { R2C8 } & \text { R2C8 } & \text { R2C8 } \\ & \text { R2C8 } & \text { R2C7 } & \text { R2C7 } & \text { R2C7 } & \text { R2C9 } & \text { R2C9 } & \text { R2C9 } \\ & \text { R2C9 } & \text { R2C9 } & \text { R2C9 } & \text { R2C9 } & \text { R2C7 } & \text { R2C7 } & \text { R2C7 }\end{array}$

Horizontal Storage Module HSM-2 (Instrumented) Loaded $6 / 28 / 89$

Fuel assembly ID no.

Initial enrichment

K32

K08 K07

$\mathrm{K} 07$
2.90

$\mathrm{K} 47$
2.90

K40

2.90

$\mathrm{K} 17$

K33

Active fuel length, in.

144

2.90

Burnup, MWd/MTU

Decay heat, $W(6 / 28 / 89)$

32875

762

32792

760

33468

798

144

144

32831

30746

705

2.90

2.90

Cooling time, days

$(1 / 26 / 89)$

1825

1825

1825

773

33290

144

Cycles irradiated

R2C8

R2C7

$\mathrm{R} 2 \mathrm{C8}$

R2C8

R2C7

1825

R2C8

1825

R2C8

$\mathrm{R} 2 \mathrm{C} 7$

R2C9

$\mathrm{R} 2 \mathrm{C} 7$

766

$\mathrm{R} 2 \mathrm{C} 7$

R2C9

R2C9

R2C9

1825

R2C 8

$\mathrm{R} 2 \mathrm{C} 9$

R2C7

1825

$\mathrm{R} 2 \mathrm{C} 8$

R2C 9

$\mathrm{R} 2 \mathrm{C} 7$

Horizontal Storage Module HSM-3 (Side-Instrumented) Loaded $7 / 3 / 89$

Fuel assembly ID No.

Initial enrichment

Active fuel length, in.

Burnup, MWd/MTU

Decay heat, $W(7 / 3 / 89)$

Cooling time, days

$(1 / 26 / 89)$

Cycles irradiated

$\begin{array}{rr}\text { K41 } & \text { K45 } \\ 2.90 & 2.90 \\ 144 & 144 \\ 33250 & 32176 \\ 692 & 737 \\ & \\ 1825 & 1825 \\ \text { R2C8 } & \text { R2C7 } \\ \text { R2C9 } & \text { R2C8 } \\ \text { R2C7 } & \text { R2C9 }\end{array}$

$K 43$
2.90
144
30820
703

K46

2.90

144

33149

776

1825

R2C8

R2C9

$\mathrm{R} 2 \mathrm{C} 7$

\section{5}

R2C8

R2C9

$\mathrm{R} 2 \mathrm{C} 7$
K36

2.90

144

33811

789

1825

R2C8

R2C9

$\mathrm{R} 2 \mathrm{C} 7$
K48

2.90

144

32215

744

K14

2.90

30977

713

A-1 

Appendix B

MEASUREMENT UNCERTAINTIES

\section{TEMPERATURE}

Temperature measurement uncertainty was produced by the thermocouples, extension wires, and data acquisition system (DAS). Each component in the temperature measurement chain added to the overall uncertainty. The measurement chain for the dry shielded canister (DSC) and horizontal storage module (HSM) are shown below.

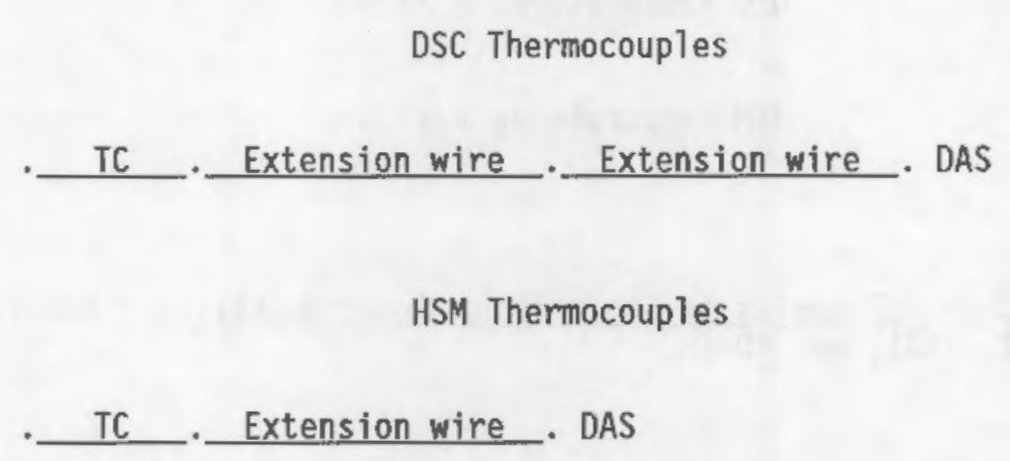

Following the derivation of Schenck ( 1 ), the overall uncertainty was equal to the square root of the sum of the squares of the individual temperature measurement uncertainties. The individual uncertainties were from different sources.

\section{THERMOCOUPLES}

The thermocouples used in the DSC were designed by Omega Engineering, Incorporated, model No. $77-\mathrm{J}-20$. These thermocouples had accuracies of $\pm 2.2^{\circ} \mathrm{C}$ or $0.75 \%$ of the reading, whichever was greater.

The thermocouples used in the HSM were fabricated during construction from Type $J$ thermocouple wire. The accuracy of the fabricated thermocouples was not tested, but is assumed to be similar to the accuracy of the DSC thermocouples, $\pm 2.2^{\circ} \mathrm{C}$ or $0.75 \%$ of the reading, whichever is greater.

Because the maximum temperature recorded by any thermocouple was less than $300^{\circ} \mathrm{C}$, the thermocouple uncertainty equals $\pm 2.2^{\circ} \mathrm{C}$. 


\title{
EXTENSION WIRE
}

The extension wire used was Type " $\mathrm{J}$ " thermocouple wire. Since the extension wires were near ambient temperature, the uncertainty was $\pm 2.2^{\circ} \mathrm{C}$ for each extension.

DATA ACQUISITION SYSTEM

The uncertainty for the data acquisition system was judged to be less than $\pm 1^{\circ} \mathrm{C}$.

OVERALL UNCERTAINTY

Taking the square root of the sum of the squares of the uncertainties of the individual components led to the following estimate of the overall uncertainty of the temperature measurements:

\author{
DSC temperatures $= \pm 3.9^{\circ} \mathrm{C}$ \\ HSM temperatures $= \pm 3.3^{\circ} \mathrm{C}$
}

\section{REFERENCE}

1. H. Schenck, Jr. Theories of Engineering Experimentation. New York: McGraw-Hi11, 1961, pp. 40-48. 


\section{Appendix C}

HEAT TRANSFER DATA

The measured temperature data are given in Table $\mathrm{C}-1$ and $\mathrm{C}-2$. The temperature measurement locations for the information in Table $\mathrm{C}-1$ are shown in Figure $\mathrm{C}-1$. The temperature locations for the data in Tables $\mathrm{C}-2$ and $\mathrm{C}-3$ are shown in Figures $\mathrm{C}-2$ through $\mathrm{C}-7$.

\section{Table C-1}

TEMPERATURE MEASUREMENTS FOR THE ELECTRICALLY HEATED DRY STORAGE CANISTER LOADED IN THE IF-300 TRANSFER CASK

Dry Storage Canister Condition

Day/Time 1988

Power (kW)

\section{Thermocouple Location}

TC 1 Top Center

TC 2 Top Edge

TC 3 Ambient

TC 4 TC well terminals

TC 5 TC No. 23, bottom plate

TC 6 TC No. 17, center fuel - 26 in.

TC 7 TC No. 14, top fuel - 26 in.

TC 8 TC No. 10, ID top can - 26 in.

TC 9 TC No. 9, ID top can - 52 in.

TC 10 TC No. 19, center fuel - 78 in.

TC 11 TC No. 7 , top of center sleeve

$$
\text { - } 78 \text { in. }
$$

TC 12 TC No. 16, center top fuel

$$
\text { - } 78 \text { in. }
$$

TC 13 TC No. 8, top of top sleeve

$$
-78 \text { in. }
$$

\begin{tabular}{|c|c|c|c|}
\hline $\begin{array}{r}\text { Water } \\
\text { Filled } \\
22 / 0001 \\
0.7 \\
\end{array}$ & $\begin{array}{r}\text { Water } \\
\text { Filled } \\
24 / 1800 \\
7.0 \\
\end{array}$ & $\begin{array}{r}\text { Vacuum } \\
\text { Orying } \\
28 / 1200 \\
7.0 \\
\end{array}$ & $\begin{array}{r}\text { Helium } \\
\text { Filled } \\
28 / 1200 \\
7.0 \\
\end{array}$ \\
\hline \multicolumn{4}{|c|}{ Temperature $\left({ }^{\circ} \mathrm{C}\right)$} \\
\hline $\begin{array}{l}28.8 \\
28.8 \\
23.8 \\
25.0 \\
21.1 \\
21.6 \\
21.6 \\
22.2 \\
22.7 \\
23.8\end{array}$ & $\begin{array}{l}50.0 \\
48.8 \\
25.0 \\
44.4 \\
38.3 \\
46.1 \\
45.0 \\
45.0 \\
47.2 \\
52.7\end{array}$ & $\begin{array}{r}61.1 \\
59.4 \\
25.5 \\
45.5 \\
90 \\
247.2 \\
220.0 \\
66.6 \\
72.7 \\
288.3\end{array}$ & $\begin{array}{r}70.5 \\
71.6 \\
27.7 \\
48.3 \\
42.7 \\
108.3 \\
102.2 \\
48.8 \\
58.3 \\
168.3\end{array}$ \\
\hline 23.8 & 50.5 & 255.5 & 138.3 \\
\hline 23.8 & 52.2 & 251.1 & 146.1 \\
\hline $\begin{array}{l}23.3 \\
23.8 \\
26.1\end{array}$ & $\begin{array}{l}50.5 \\
50.0 \\
51.6\end{array}$ & $\begin{array}{r}191.6 \\
80.0 \\
97.2\end{array}$ & $\begin{array}{r}106.1 \\
63.3 \\
85\end{array}$ \\
\hline
\end{tabular}

TC 14 TC No. 1, ID top can - 78 in.

TC 15 TC No. 12, ID top Can - 153 in. 
Table C-2

TEMPERATURE MEASUREMENTS FDR THE ELECTRICALLY HEATED DRY STORAGE CANISTER LOADED IN THE HORIZONTAL STORAGE MDDULE

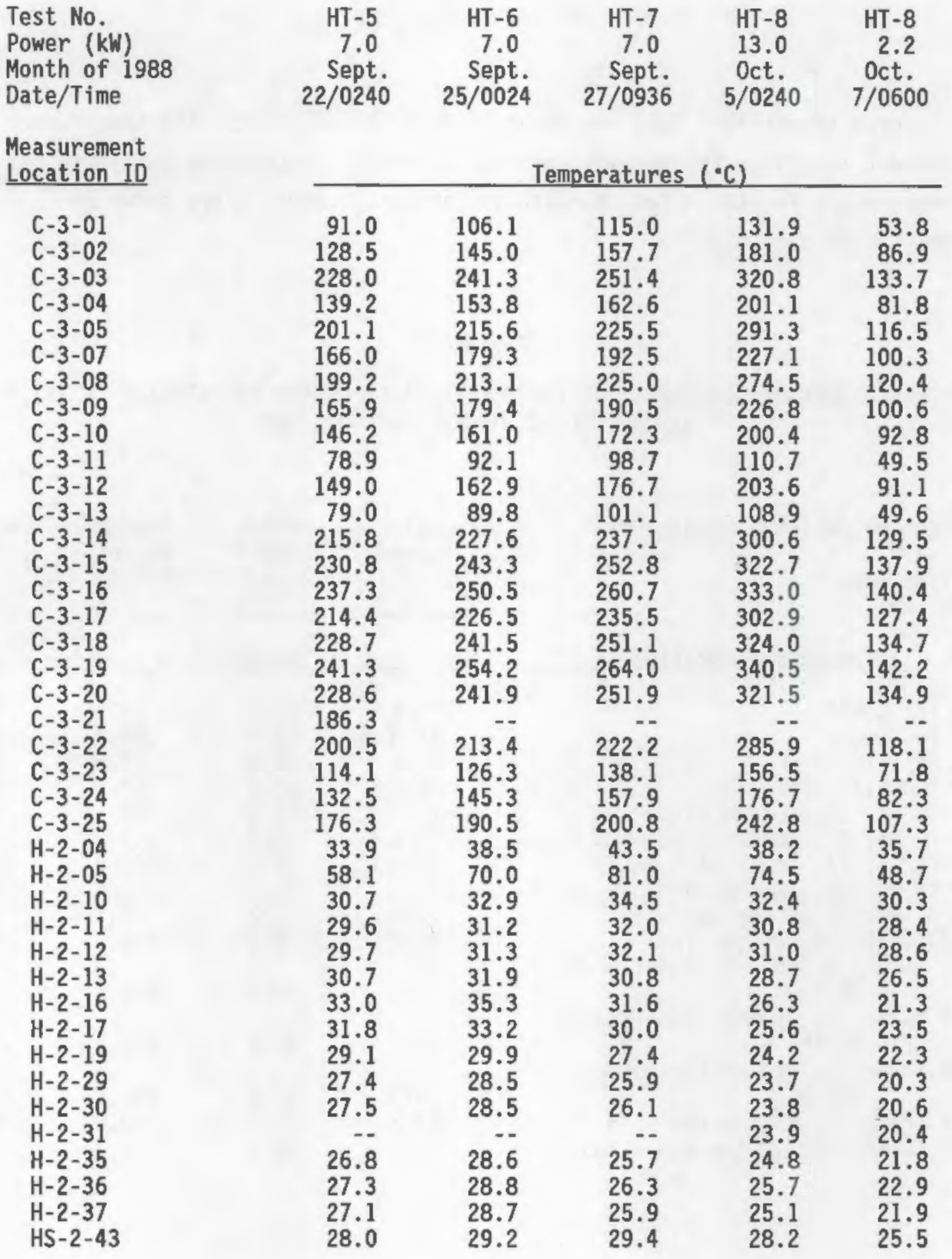


Table C-2 (Contd)

TEMPERATURE MEASUREMENTS FOR THE ELECTRICALLY HEATED DRY STORAGE CANISTER LOADED IN THE HORIZONTAL STORAGE MODULE

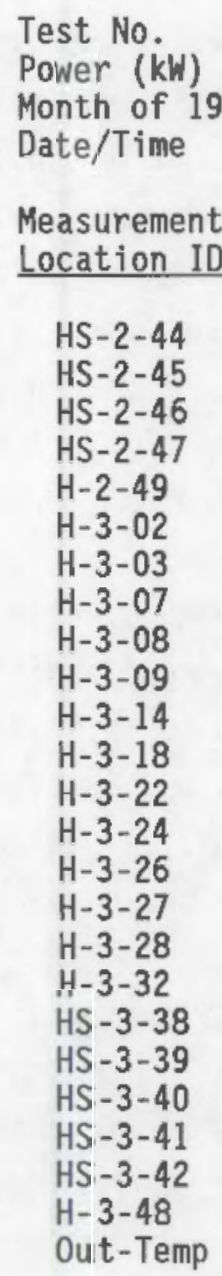

$\begin{array}{rrrrr}\text { HT-5 } & \text { HT-6 } & \text { HT-7 } & \text { HT-8 } & \text { HT-8 } \\ 7.0 & 7.0 & 7.0 & 13.0 & 2.2 \\ \text { Sept. } & \text { Sept. } & \text { Sept. } & \text { Oct. } & \text { Oct. } \\ 22 / 0240 & 25 / 0024 & 27 / 0936 & 5 / 0240 & 7 / 0600\end{array}$

Temperatures $\left({ }^{\circ} \mathrm{C}\right)$

$\begin{array}{rrrrr}26.4 & 28.0 & 26.9 & 25.4 & 21 \\ 28.0 & 29.2 & 29.6 & 28.6 & 25.9 \\ 27.7 & 29.1 & 29.3 & 28.4 & 25.8 \\ 27.2 & 28.6 & 28.7 & 27.4 & 25.0 \\ 23.7 & 27.1 & 23.2 & 20.8 & 16.1 \\ 36.4 & 49.1 & 60.3 & 41.1 & 32.2 \\ 37.9 & 49.9 & 61.2 & 43.2 & 34.2 \\ 44.7 & 54.8 & 63.5 & 53.9 & 40.0 \\ 57.9 & 70.6 & 82.2 & 75.0 & 47.4 \\ 38.1 & 49.9 & 60.8 & 43.5 & 34.6 \\ 31.4 & 33.6 & 29.2 & 24.9 & 19.0 \\ 39.4 & 36.6 & 36.9 & 39.0 & 32.4 \\ 41.7 & 48.7 & 50.5 & 48.1 & 37.8 \\ 57.1 & 69.5 & 80.4 & 75.2 & 48.2 \\ 49.7 & 26.5 & 63.9 & 59.0 & 33.1 \\ 51.7 & 26.5 & 68.4 & 62.3 & 34.3 \\ 51.2 & 28.3 & 69.8 & 60.7 & 34.0 \\ 49.2 & 64.7 & 67.0 & 59.5 & 33.8 \\ 48.4 & 70.2 & 89.2 & 58.9 & 34.3 \\ 67.3 & 85.9 & 98.1 & 89.5 & 45.8 \\ 78.8 & 95.5 & 111.3 & 106.4 & 52.6 \\ 77.9 & 93.3 & 107.9 & 104.6 & 52.6 \\ 77.3 & 93.5 & 106.7 & 102.5 & 51.5 \\ 23.2 & 28.1 & 23.8 & 19.3 & 15.2 \\ 21.2 & 24.1 & 19.7 & 15.0 & 10.3\end{array}$


Table C-3

TEMPERATURE MEASUREMENTS FOR FUEL IN THE DRY STORAGE CANISTER LOADED IN THE HORIZONTAL STORAGE MODULE

\begin{tabular}{|c|c|c|c|}
\hline & & $\begin{array}{l}\text { Partial } \\
\text { Load } \\
\end{array}$ & $\begin{array}{l}\text { Ful1 } \\
\text { Load }\end{array}$ \\
\hline $\begin{array}{l}\text { Month of } 1989 \\
\text { Date/Time }\end{array}$ & & $\begin{array}{l}\text { July } \\
2 / 1920\end{array}$ & $\begin{array}{l}\text { Sept. } \\
20 / 1680\end{array}$ \\
\hline $\begin{array}{l}\text { Measurement } \\
\text { Location ID }\end{array}$ & $\begin{array}{c}\mathrm{TC} \\
\text { Resistance }\end{array}$ & \multicolumn{2}{|c|}{ Temperatures $\left({ }^{\circ} \mathrm{C}\right)$} \\
\hline$C-2-01$ & 40 & 115.9 & 1155 \\
\hline$c-2-02$ & 40 & 85.4 & 910 \\
\hline$C-2-03$ & 38 & 73.3 & 72.5 \\
\hline$C-2-04$ & 39 & 103.8 & 109.1 \\
\hline$C-2-05$ & 60 & 145.8 & 155.8 \\
\hline$C-2-07$ & 40 & 174.6 & 171.5 \\
\hline$C-2-08$ & 40 & 148.8 & 147.6 \\
\hline$C-2-09$ & 37 & 114.3 & 114.4 \\
\hline$C-2-10$ & 35 & 94.7 & 100.3 \\
\hline$C-2-11$ & 35 & 57.3 & 63.2 \\
\hline$C-2-12$ & 45 & 86.0 & 95.4 \\
\hline$C-2-13$ & 45 & 47.3 & 56.1 \\
\hline$C-2-15$ & 36 & 180.2 & 178.6 \\
\hline$C-2-16$ & 40 & 180.9 & 180.4 \\
\hline$C-2-23$ & 35 & 70.6 & 76.8 \\
\hline$C-2-24$ & 45 & 52.5 & 61.8 \\
\hline$C-2-25$ & 40 & 122.0 & 127.7 \\
\hline$C-3-01$ & 40 & -- & 70.8 \\
\hline$C-3-04$ & 35 & -- & 110.7 \\
\hline$c-3-05$ & 40 & -. & 153.5 \\
\hline$C-3-07$ & 40 & -- & 110.3 \\
\hline$C-3-08$ & 37 & -- & 142.3 \\
\hline$c-3-12$ & 49 & $\cdots$ & 87.1 \\
\hline$C-3-24$ & 45 & -- & 55.7 \\
\hline$C-3-25$ & 37 & -- & 102.2 \\
\hline $\mathrm{H}-2-04$ & 35 & 30.5 & 39.5 \\
\hline $\mathrm{H}-2-05$ & 32 & 29.4 & 49.7 \\
\hline H-2-10 & 33 & 28.4 & 38.7 \\
\hline $\mathrm{H}-2-11$ & 33 & 48.8 & 51.4 \\
\hline $\mathrm{H}-2-12$ & 33 & 47.1 & 49.5 \\
\hline $\mathrm{H}-2-13$ & 32 & 37.8 & 37.4 \\
\hline$H-2-16$ & 33 & 34.0 & 28.6 \\
\hline $\mathrm{H}-2-17$ & 32 & 35.2 & 31.5 \\
\hline $\mathrm{H}-2-19$ & 34 & 45.0 & 42.6 \\
\hline $\mathrm{H}-2-2 \mathrm{I}$ & 35 & 53.7 & 55.7 \\
\hline $\mathrm{H}-2-23$ & 32 & -- & 42.8 \\
\hline
\end{tabular}


Table C-3 (Contd)

TEMPERATURE MEASUREMENTS FOR FUEL IN THE DRY STORAGE CANISTER LOADED IN THE HORIZONTAL STORAGE MODULE

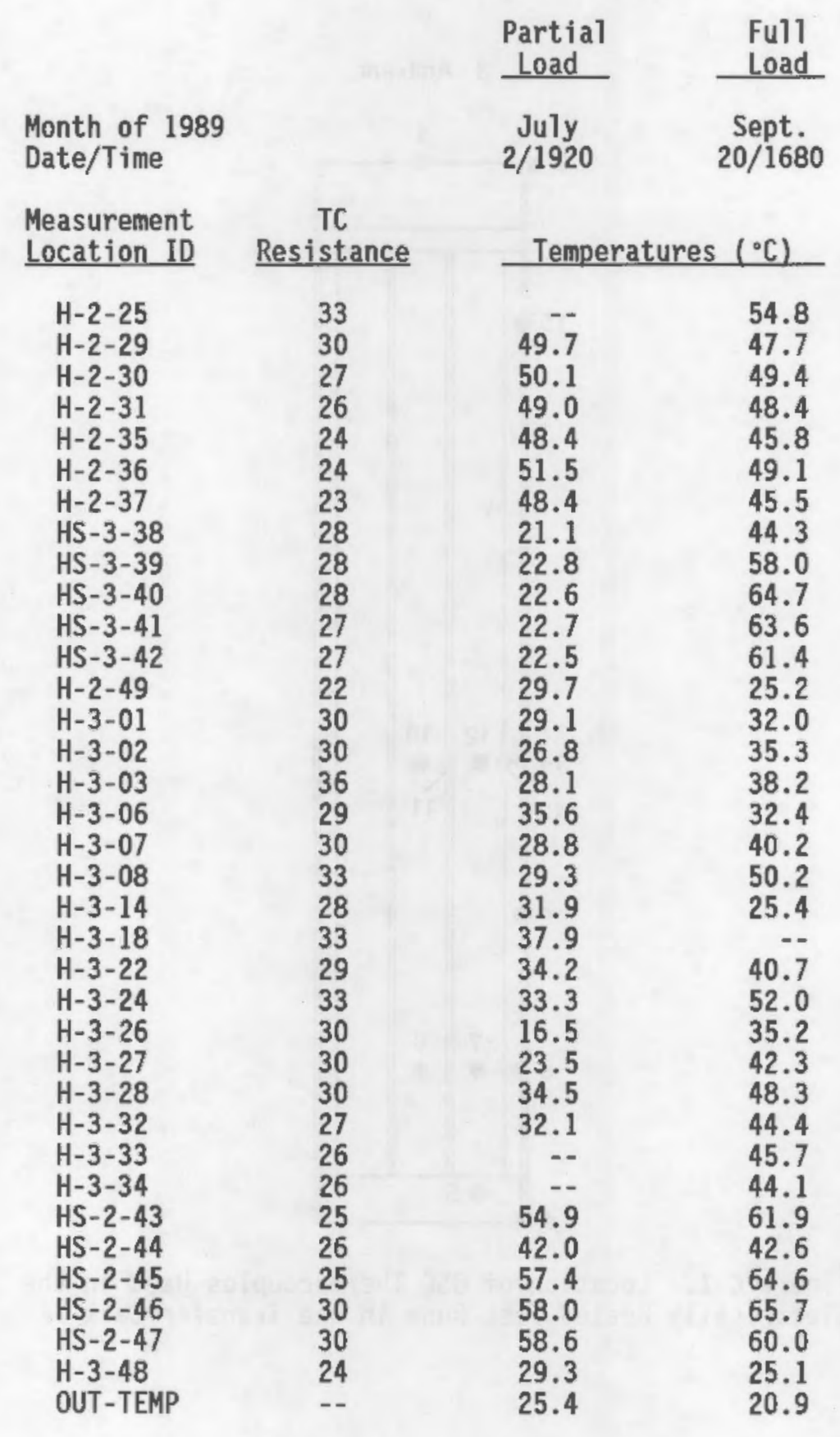




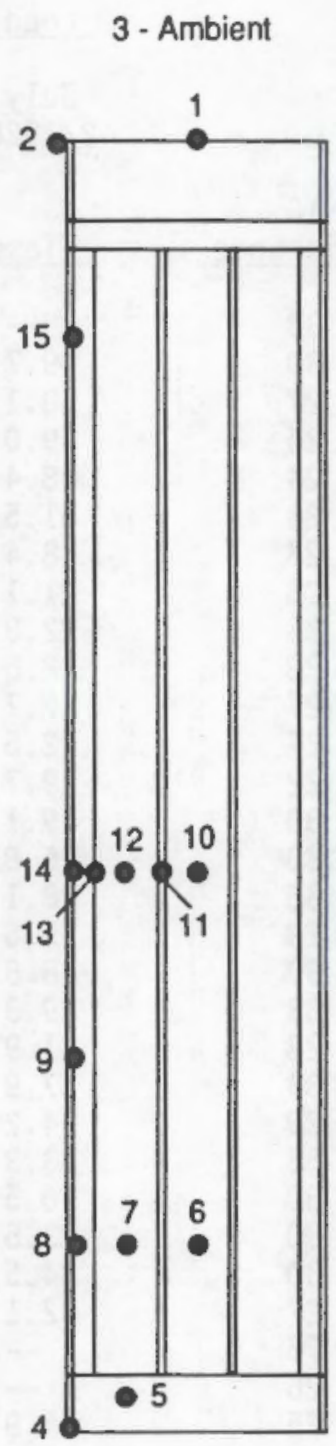

Figure C-1. Location of DSC Thermocouples Used in the Electrically Heated Test Runs in the Transfer Cask 


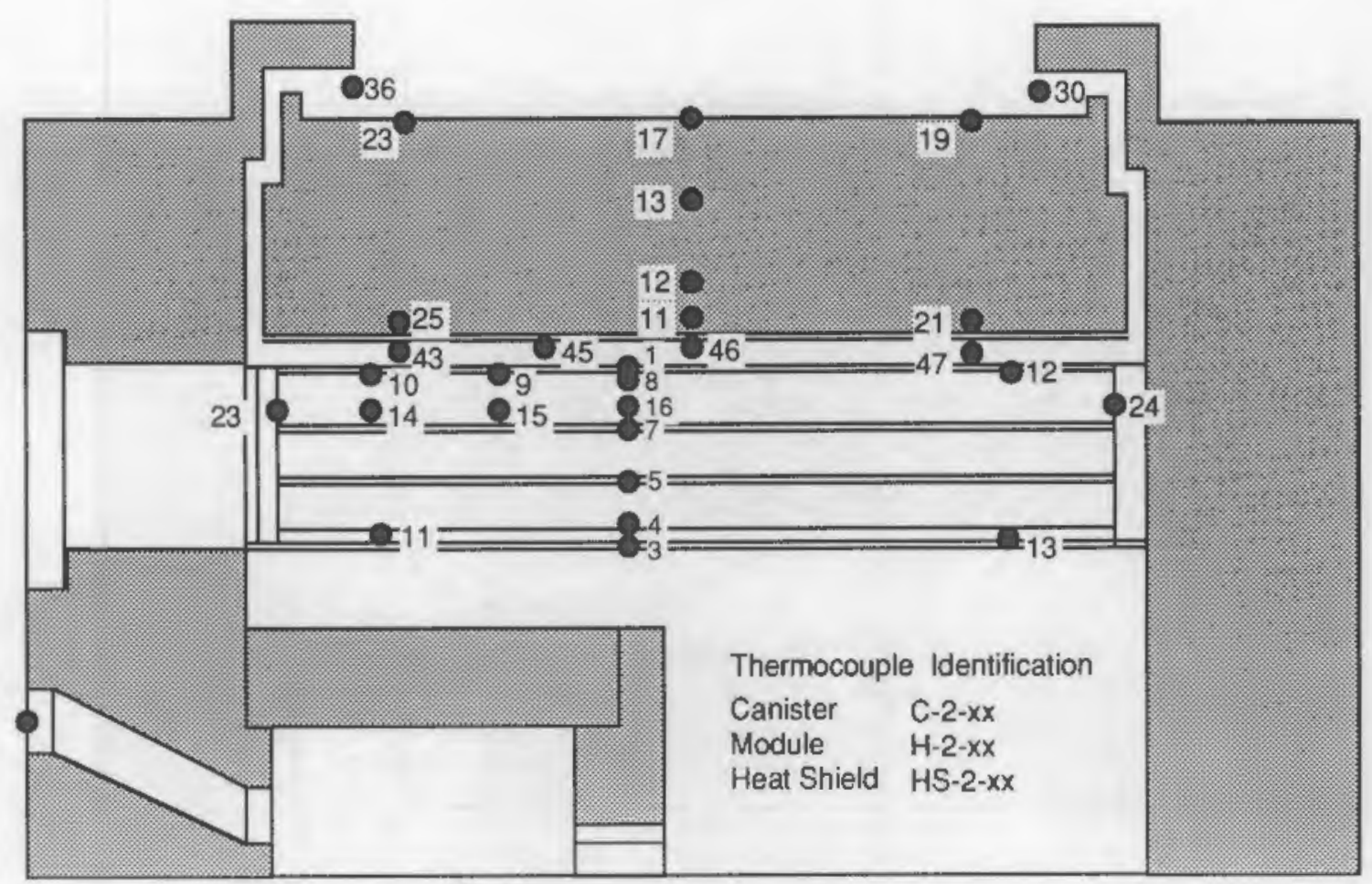

Figure C-2, Thermocouple Locations in Center Module (HSM-2)

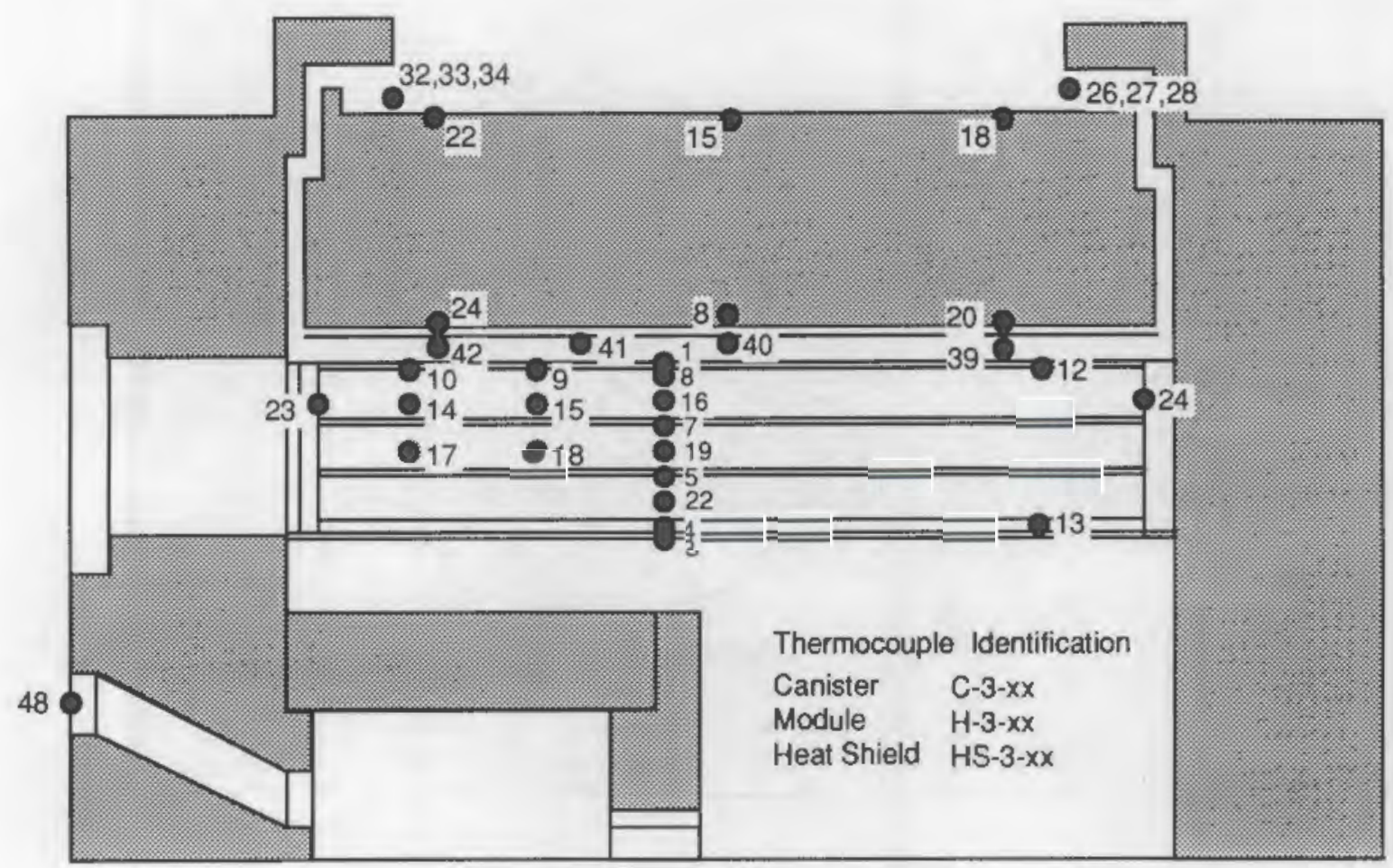

Figure C-3. Thermocouple Locations in Side Module (HSM-3) 


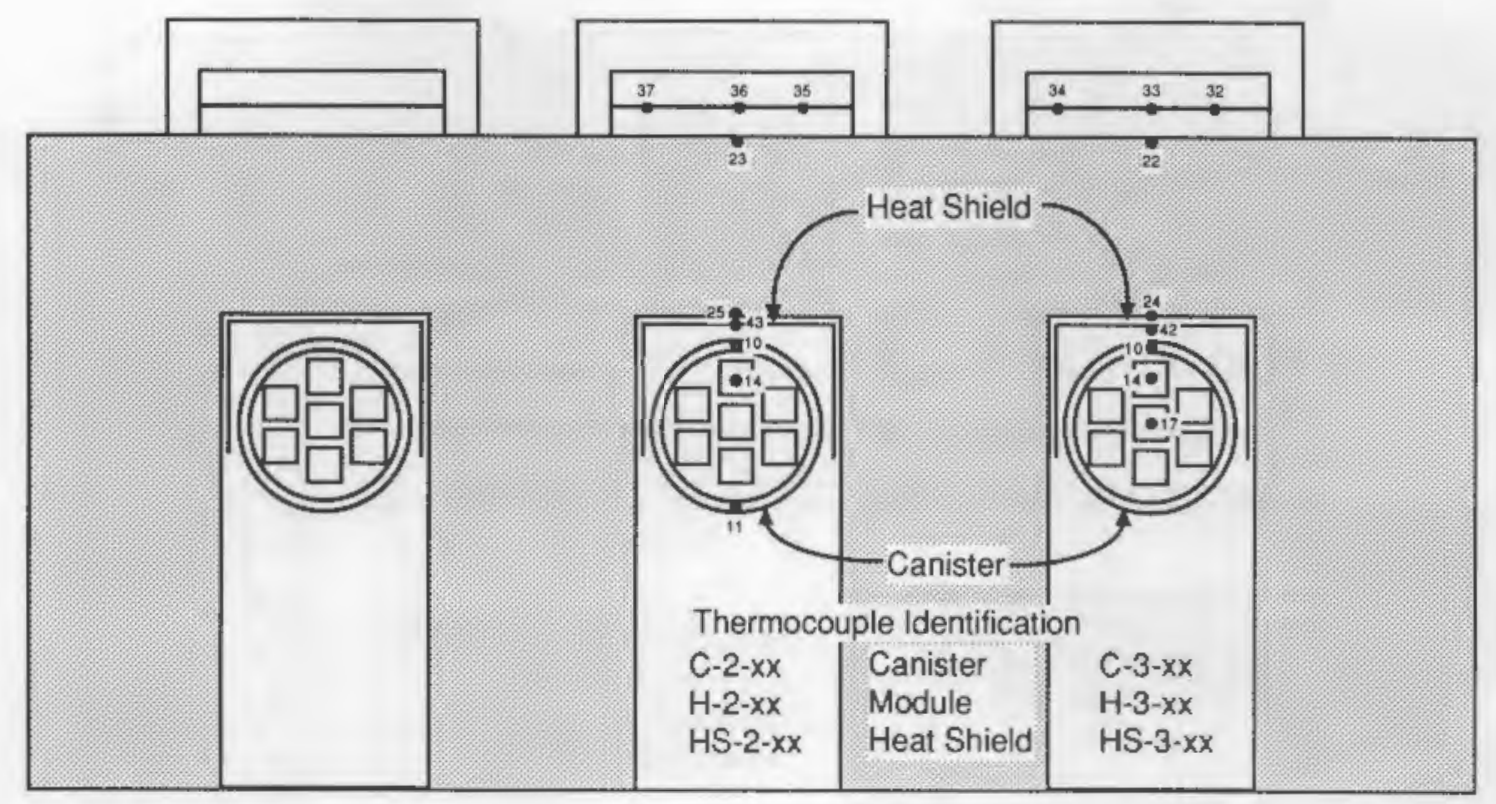

Figure $\mathrm{C}-4$. Thermocouple Locations $5 \mathrm{ft} 2$ in. from the Front of the Module

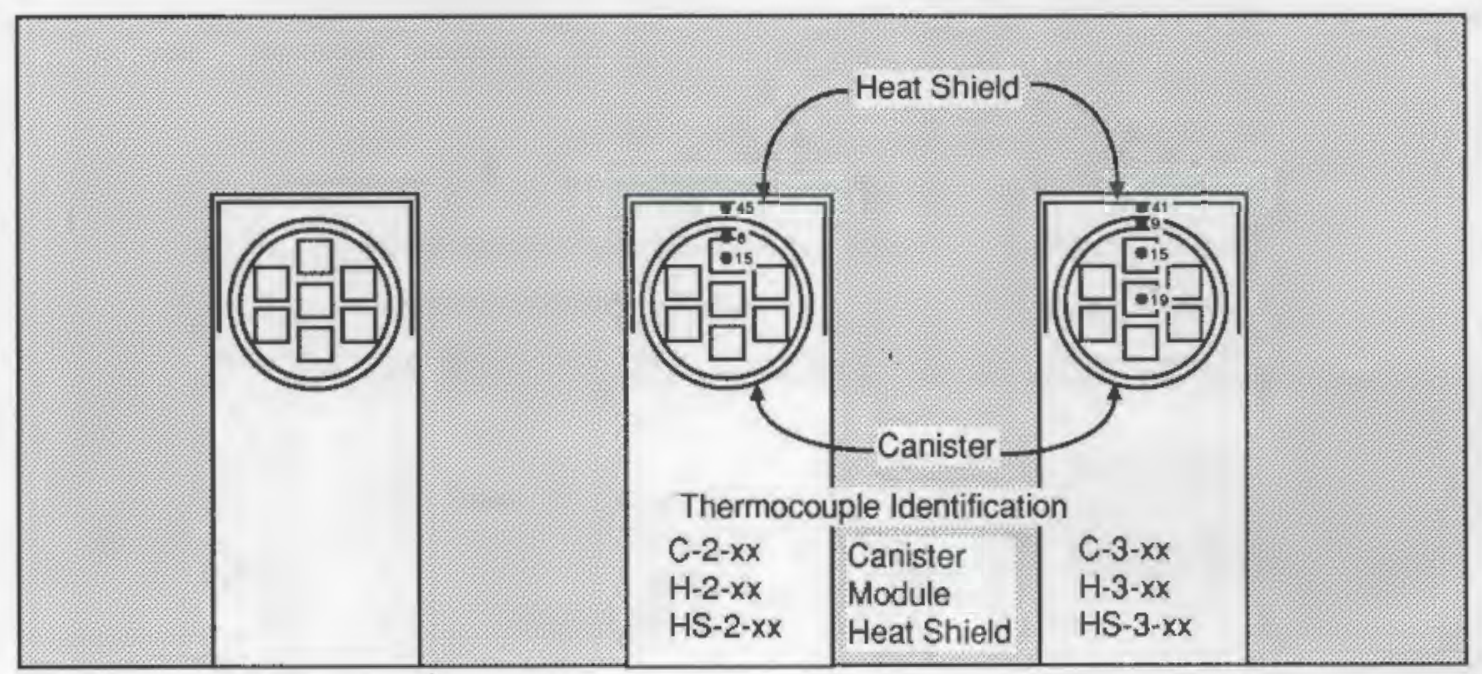

Figure C-5. Thermocouple Locations $7 \mathrm{ft} 2 \mathrm{in.}$ from the Front of the Module 


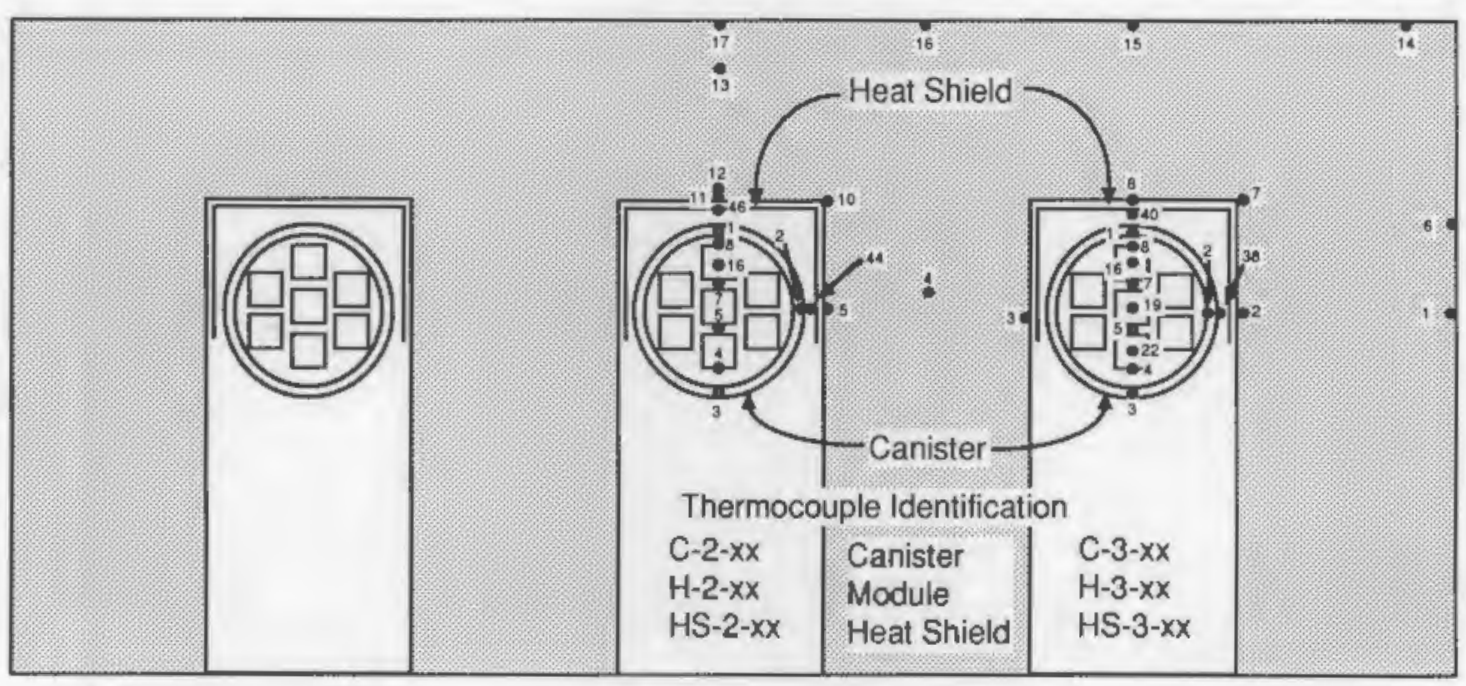

Figure $\mathrm{C}-6$. Thermocouple Locations $9 \mathrm{ft} 3 \mathrm{in}$. from the Front of the Module (axial center)

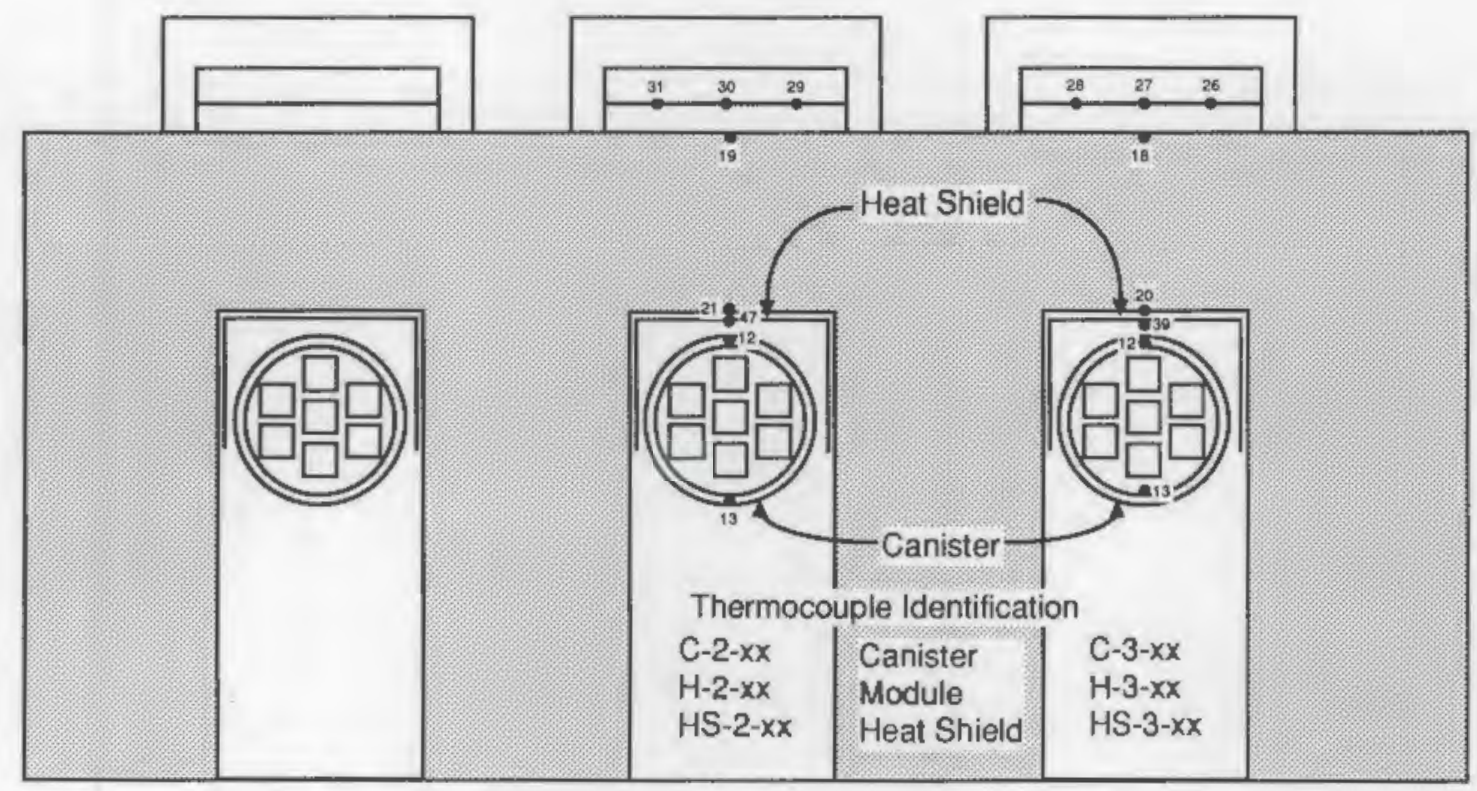

Figure C-7. Thermocouple Locations $15 \mathrm{ft} 6 \mathrm{in}$. from the Front of the Module 

Appendix D

DOSE RATE DATA

RADIATION SURVEY MEASUREMENTS FOR THE NUHOMS SPENT FUEL PERFORMANCE TEST

Radiation Dose Rate Measurements at the surface of the module prior to fuel loading.

Date

Location

$01 / 18 / 89$

HSM-1

Neutron Gamma

$(\mathrm{mrem} / \mathrm{h})(\mathrm{mr} / \mathrm{h})$
$01 / 18 / 89$

HSM-2

Neutron Gamma Neutron Gamma

$(\mathrm{mrem} / \mathrm{h})(\mathrm{mr} / \mathrm{h})$ (mrem/h) $(\mathrm{mr} / \mathrm{h})$

Center of cover plate

Left air inlet vent

Right air inlet vent

Left drain

Right drain

Ram Penetration

Front air outlet vent

Rear air outlet vent

$\begin{array}{ll}0 & <2 \\ 0 & <2 \\ 0 & <2 \\ 0 & <2 \\ 0 & <2 \\ 0 & <2 \\ 0 & <2 \\ 0 & <2\end{array}$

$\begin{array}{llll}0 & <2 & 0 & <2 \\ 0 & <2 & 0 & <2 \\ 0 & <2 & 0 & <2 \\ 0 & <2 & 0 & <2 \\ 0 & <2 & 0 & <2 \\ 0 & <2 & 0 & <2 \\ 0 & <2 & 0 & <2 \\ 0 & <2 & 0 & <2\end{array}$

Radiation Dose Rate Measurements at the surface of the module after fuel loading.

Date

Location

$04 / 20 / 89$

HSM-1

Neutron Gamma $(\mathrm{mrem} / \mathrm{h})(\mathrm{mr} / \mathrm{h})$

\section{$06 / 28 / 89$}

HSM-2

Neutron Gamma Neutron Gamma $(\mathrm{mrem} / \mathrm{h})(\mathrm{mr} / \mathrm{h})(\mathrm{mrem} / \mathrm{h})(\mathrm{mr} / \mathrm{h})$

$07 / 03 / 89$

HSM-3
Center of cover plate

Left air inlet vent

Right air inlet vent

Left drain

Right drain

Ram Penetration

Front air outlet vent

Rear air outlet vent
1.0

2.5

2.0

0.5

0.5

0.5

2.5

1.0
3.0

25.0

23.0

0.1

0.5

0.5

50.0

0.7
2.0

$<0.5$

$<0.5$

$<0.5$

$<0.5$

$<0.5$

$<0.5$

$<0.5$

2.0
15.0
15.0
$<2.0$
$<5.0$
$<2.0$
35.0
$<2.0$

$\begin{array}{rr}1.0 & 2.0 \\ 0.5 & 15.0 \\ 0.5 & 14.0 \\ 0.5 & 5.0 \\ 0.5 & 5.0 \\ 0.5 & 2.0 \\ 0.5 & 15.0 \\ 0.5 & 2.0\end{array}$


Dose Rate Measurements at the surface of the west side of the modules. (a)

Distance from
Front to Rear
of HSM (ft)

1

3

5

7

9

11

13

15

17

19

21

\begin{tabular}{cc}
$2^{\prime}$ & $3^{\prime \prime}$ \\
\hline $\begin{array}{c}\text { Neutron Gamma } \\
\text { mrem/h }\end{array}$ & mrem/h/h \\
\hline
\end{tabular}

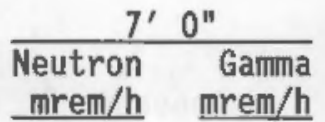

\begin{tabular}{cc}
$9^{\prime}$ & $0^{\prime \prime}$ \\
$\begin{array}{c}\text { Neutron } \\
\text { mrem/h }\end{array}$ & Gamma \\
\hline
\end{tabular}

$<0.5$

$<0.5$

$<0.5$

$<0.5$

$<0.5$

$<0.5$

$<0.5$

$<0.5$

$<0.5$

$<0.5$

$<0.5$

2
2
2
2
2
2
2
2
2
2
2

$<0.5$

$<0.5$

$<0.5$

$<0.5$

$<0.5$

$<0.5$

$<0.5$

$<0.5$

$<0.5$

$<0.5$

$<0.5$

2
2
2
2
2
2
2
2
2
2
2

$<0.5$

$<0.5$

$<0.5$

$<0.5$

$<0.5$

$<0.5$

$<0.5$

$<0.5$

$<0.5$

$<0.5$

$<0.5$

2
2
2
2
2
2
2
2
2
2
2

Dose Rate Measurements at 3 feet from the west side of the modules. (a)

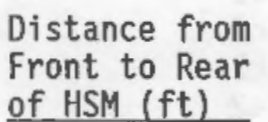

of HSM (ft)

1
3
5
7
9
11
13
15
17
19
21

\begin{tabular}{|c|c|}
\hline 2 & \\
\hline $\begin{array}{l}\text { Neutron } \\
\text { mrem/h/h }\end{array}$ & $\begin{array}{r}\text { Gamma } \\
\text { mrem/h/h }\end{array}$ \\
\hline
\end{tabular}

\begin{tabular}{l} 
Neutro \\
mrem/ \\
\hline$<0.5$ \\
$<0.5$ \\
$<0.5$ \\
$<0.5$ \\
$<0.5$ \\
$<0.5$ \\
$<0.5$ \\
$<0.5$ \\
$<0.5$ \\
$<0.5$ \\
$<0.5$
\end{tabular}

$7^{\prime} 0^{\prime \prime}$

$<0.5$

$<0.5$

$<0.5$

$<0.5$

$<0.5$

$<0.5$

$<0.5$

$<0.5$

$<0.5$

$<0.5$

$<0.5$

$$
\begin{aligned}
& 2 \\
& 2 \\
& 2 \\
& 2 \\
& 2 \\
& 2 \\
& 2 \\
& 2 \\
& 2 \\
& 2 \\
& 2
\end{aligned}
$$

0.5

$<0.5$

$<0.5$

$<0.5$

0.5

$<0.5$

$<0.5$

0.5

0.5

$<0.5$

\begin{tabular}{c} 
Gam \\
mrem \\
\hline \\
2 \\
2 \\
2 \\
2 \\
2 \\
2 \\
2 \\
2 \\
2 \\
2 \\
2
\end{tabular}

\begin{tabular}{cc}
$9^{\prime}$ & $0^{\prime \prime}$ \\
$\begin{array}{c}\text { Neutron } \\
\text { mrem/h }\end{array}$ & $\begin{array}{c}\text { Gamma } \\
\text { mrem/h }\end{array}$ \\
\hline
\end{tabular}

$<0.5$

$<0.5$

$<0.5$

$<0.5$

$<0.5$

$<0.5$

$<0.5$

$<0.5$

$<0.5$

$<0.5$

$<0.5$

2
2
2
2
2
2
2
2
2
2
2

(a) Readings represent threshold level of detection of the instruments. 
Dose rate measurements on the HSM roof, $5 \mathrm{ft} 3 \mathrm{in}$. from the west edge.

\begin{tabular}{c} 
Distance from \\
Front to Rear \\
of HSM \\
(ft in.) \\
\hline $0^{\prime \prime}$ \\
$1^{\prime} 6^{\prime \prime}$ \\
$5^{\prime} 4^{\prime \prime}$ \\
$7^{\prime}$ \\
$9^{\prime}$ \\
$11^{\prime}$ \\
$13^{\prime}$ \\
$15^{\prime}$ \\
$16^{\prime} 8^{\prime \prime}$ \\
$20^{\prime} 6^{\prime \prime}$ \\
$22^{\prime}$
\end{tabular}

\begin{tabular}{|c|c|c|c|}
\hline \multicolumn{4}{|c|}{ Elevation Above HSM Roof } \\
\hline \multicolumn{2}{|c|}{ Contact } & \multicolumn{2}{|c|}{$3 \mathrm{ft}$} \\
\hline $\begin{array}{l}\text { Neutron } \\
\text { (mrem/h) }\end{array}$ & $\begin{array}{c}\text { Gamma } \\
\text { (mrem/h) }\end{array}$ & $\begin{array}{l}\text { Neutron } \\
\text { (mrem/h) }\end{array}$ & $\begin{array}{c}\text { Gamma } \\
\text { (mrem/h) }\end{array}$ \\
\hline$<0.5$ & 2 & $<0.5$ & 2 \\
\hline$<0.5$ & 2 & $<0.5$ & 2 \\
\hline$<0.5$ & 20 & $<0.5$ & 5 \\
\hline$<0.5$ & 6 & $<0.5$ & 3 \\
\hline$<0.5$ & 2 & $<0.5$ & 2 \\
\hline$<0.5$ & 2 & $<0.5$ & 2 \\
\hline$<0.5$ & 2 & $<0.5$ & 2 \\
\hline$<0.5$ & 2 & $<0.5$ & 2 \\
\hline$<0.5$ & 2 & $<0.5$ & 2 \\
\hline$<0.5$ & 2 & $<0.5$ & 2 \\
\hline$<0.5$ & 2 & $<0.5$ & 2 \\
\hline
\end{tabular}


